\title{
VIII. Das Ende des Kontrollrats 1947/48
}

\section{Die Moskauer Außenministerkonferenz 1947}

Bereits anläßlich der Pariser Außenministerkonferenz im Sommer 1946 hatten Beobachter den Eindruck gewonnen, „daß der Kontrollrat nicht in der Lage sein werde, sich auf irgendwelche wichtigen Entscheidungen in Deutschland zu einigen "1. Gewisse Erfolge, die er im wirtschafts- und finanzpolitischen Bereich aufzuweisen hatte, waren nur auf den ersten Blick erheblich; die "Einheitlichkeit" der Maßnahmen in den Zonen, die auch nur punktuell praktiziert wurde, war kein Schritt auf dem Wege zur Einheit, sondern Zeichen der Vertagung angesichts der Unvereinbarkeit der deutschland-, transformations- und sicherheitspolitischen Positionen. Der Kontrollrat verwaltete Deutschland lediglich, da er die in Potsdam vertagten politischen Konflikte nicht zu lösen vermochte. Mehrfach hatten die vier Kontrollratsgruppen den vorgesehenen Weg beschritten, strittige Fragen an ihre Regierungen zurückzuverweisen, doch war das in aller Regel wenig hilfreich gewesen. Nach einem Jahr der Ersatzlösungen „,im Rahmen des Kontrollrats“ erschien es angebracht, eine Bilanz der bisherigen Tätigkeit zu ziehen und es dem Rat der Außenminister zu überlassen, durch Grundsatzentscheidungen dem Kontrollrat neue Perspektiven zu eröffnen.

Ein Bericht schon für die New Yorker Außenministerkonferenz im Dezember 1946, wie es die USA erhofft hatten, kam nicht zustande. Einmal waren die Verhandlungen über die Friedensverträge mit den osteuropäischen Ländern und Italien noch nicht abgeschlossen; zum anderen wollte die Sowjetunion aus Prestigegründen den Friedensvertrag mit Deutschland auf der nachfolgenden Konferenz in Moskau Anfang 1947 verhandeln ${ }^{2}$. Bevin kam die Verzögerung ebenfalls gelegen, weil bis dahin mit der Bizone weitere vollendete Tatsachen für eine Westlösung geschaffen werden konnten ${ }^{3}$. Und erst recht war Frankreich nicht an einer Beratung in New York interessiert. Da Bidault entschlossen war, Fortschritte in der Deutschlandfrage zu vereiteln, stand der Mißerfolg dieser Konferenz bereits vorher fest. Unter Hinweis auf die Novemberwahlen und die Regierungsneubildung in Frankreich ließ er sich durch Couve de Murville vertreten. Dieser wurde angewiesen, im Falle einer Beratung deutschlandpolitischer Grundsatzfragen höchstens als „Beobachter" teilzunehmen und Grundsatzbeschlüsse, etwa über die „Verfassung eines Deutschen Reiches“, durch Verlassen des Raumes zu verhindern. Da die Franzosen überzeugt waren, im Vorfeld nicht durch einen amerikanisch-sowjetischen Ausgleich in der Reparationsfrage überrascht zu werden, da sie gleichzeitig wußten, daß die Briten den amerikanischen Plänen für eine

1 TL, Oral History Collection, Riddleberger (1972), S. 84. NA, RG 59, 740.00119 Control(Germany)/ 7-1646 (Cramer an Hilldring). FRUS, 1947/II, S. 856.

${ }^{2}$ FRUS, 1946/II, S. 1464 f., 1474, 1476, 1481 ff. NA, RG 43/WWII\&PWConf, box 94, folder: Germany II (Committee on German Questions, CFM-Subcommittee New York, 10. 12. 1946).

${ }^{3}$ Deighton, Impossible Peace, S. 116. 
deutsche Regierung ebenso kritisch gegenüberstanden wie umgekehrt die USA den britischen Sozialisierungsabsichten an der Ruhr, schien die Chance gegeben, ,im einen wie im anderen Falle die nach unserer Auffassung günstigsten Tendenzen auszunutzen“4.

Das allgemeine Bestreben, die Deutschlandfrage bis zur Moskauer Konferenz zu vertagen, bedeutete keineswegs, daß die Mächte zu einer Einigung nicht mehr bereit waren. Zweifellos hatte die Sowjetunion ein Interesse am Erfolg dieser Konferenz und damit der Kontrollratsarbeit ${ }^{5}$. Auf amerikanischer Seite hegte Marshall die Überzeugung, ein Arrangement mit der Sowjetunion werde möglich sein, weil diese es sich nicht leisten könne, „daß die Konferenz in einer Sackgasse endet, und daher könnten sie einen taktischen Rückzug einleiten, wenn eine Formel gefunden wird, die ihr Gesicht wahrt" ${ }^{\text {"6 }}$. Zurückhaltender waren die Briten, deren Konferenzplanung unter dem Stichwort „Neues Potsdam“ stand. Endlich schien die seit langem angestrebte Revision des Potsdamer Abkommens möglich, da die Sowjetunion es nicht riskieren werde, ein Scheitern der Konferenz zu provozieren. Daher lief Bevins Verhandlungsstrategie in Moskau, für die er die Zustimmung des Kabinetts erhielt, auf ein erneutes Ultimatum an die Sowjetunion hinaus, das diese voraussichtlich nicht akzeptieren würde: „Wenn die Russen uns nicht vollständig entgegenkommen, und das werden sie auf dieser Konferenz nicht tun“, werde es keine Einigung geben. Und eine Teileinigung um ihrer selbst willen war Bevin nicht bereit zu akzeptieren: Im Friedensvertrag mit Deutschland dürfe es nicht noch einmal zu dehnbaren Formelkompromissen und zur Ausklammerung zentraler Sachfragen bzw. Streitpunkte kommen. Andernfalls müsse die faktische Teilung Deutschlands als vorübergehende $Z$ wischenlösung in Kauf genommen werden; nur so seien die Sowjets in eine Gesamtlösung nach westlichen Vorstellungen zurückzuzwingen: „Im Falle des Scheiterns sind die Russen viel zu besorgt, die Zweiteilung Deutschlands und die Einbeziehung der Ressourcen der Ruhr in einen westlichen Block zu verhindern, als daß sie das Scheitern einer Einigung mit dem Aufkündigen des Prinzips der Vier-Mächte-Kontrolle beantworten würden. Sie würden lieber im Rahmen der gegenwärtigen unsicheren Regelungen weitermachen." Die größere Handlungsfreiheit der Westmächte in ihren Zonen werde deren Rekonstruktion beschleunigen; ,in dem Maße, in dem diese wirtschaftliche Erholung voranschreitet, werden wir uns gegenüber den Russen in einer stärkeren Verhandlungsposition befinden, deren eigene Zone sich vermutlich mit der Zeit aus einem

4 AMAE, Y 289, Bl. 45 ff., 66 ff., 130 ff., $200 \mathrm{f}$. Die französische Vertagungsabsicht wurde in der Presse bekannt. Mit dem Argument, bis zu den Neuwahlen im November 1946 deutschlandpolitisch nicht handlungsfähig zu sein, hatte Frankreich bereits im September auf Zeit gespielt. NA, RG 43/WWII\&PWConf, box 94, folder: Germany II (Caffery, 18. 9. 1946; Acheson an Marshall, 14. 11. 1946).

5 Die Tägliche Rundschau (13.12. 1946) erklärte, trotz aller Schwierigkeiten sei die Konferenz nicht zum Scheitern verurteilt, der Ost-West-Gegensatz nicht unüberwindlich.

6 TL, Oral History Collection, Kindleberger (1973), S. 71; ebenda, Hickerson, S. 29 (Marshall und andere im State Department, sogar Harriman; Bohlen und Durbrow nicht mehr); ebenda, Harriman (1971), S. 18 (Marshall und Eisenhower, also nicht zufällig die Militärs, verwiesen darauf, daß Stalin im Weltkrieg stets Wort gehalten habe). NA, RG 59/Bohlen, box 4, folder: Conversations (Acheson/ Matthews, 23. 12. 1946); RG 43/WWII\&PWConf, box 191, folder: Moscow Misc. (19. 3. 1947). Mit Sorge registrierten die Briten, daß Marshall bereit schien, „einen Preis für die Einheit Europas zu bezahlen“, daß auch seine Berater sich nicht über eine einheitliche Politik gegenüber Deutschland wie gegenüber der Sowjetunion einig waren. PRO, FO 371/64423/C53 (Bevin, 28. 12. 1946); PREM 8/ 702 (Bevin, 23. 3. 1947). 
Aktivposten in einen Kostenfaktor verwandeln wird.“ In der Überzeugung, daß die Sowjetunion bzw. die SBZ vom Westen abhängiger sei als umgekehrt, hatten es die Briten nicht eilig. Wenn es nicht möglich war, „unseren Willen in den Hauptfragen“ durchzusetzen, dann konnten sie bis zur nächsten Session der Außenministerkonferenz warten und die Vertagung nutzen, ihre Position der Stärke in der Bizone ,in enger Zusammenarbeit mit den Amerikanern und, soweit als möglich, mit den Franzosen“ weiter ausbauen. Aber solange noch Aussichten auf eine Generalbereinigung zwischen den Alliierten bestanden, das wußte er, konnte Bevin diesen Kurs weder in der Öffentlichkeit noch innerhalb der eigenen Regierung durchsetzen. Das eigentliche Kunststück würde insofern sein, dafür zu sorgen, daß „die Verantwortung für das Scheitern [...] auf die Schultern der Russen gelegt wird, die voll für den gegenwärtigen Stand der Dinge verantwortlich sind“" .

Frankreich sah die Moskauer Konferenz als Chance, erstmals direkt und umfassend Einfluß auf eine Generalregelung der deutschen Frage nehmen zu können, nachdem es in Yalta und Potsdam ausgeschlossen worden war. Bidault wollte das notfalls durch eine Schaukelpolitik zwischen Ost und West erreichen. Er hatte weniger Angst vor Deutschland selbst als vor einem „wiederbelebten Deutschland unter sowjetischer Schirmherrschaft“, er war aber gleichwohl bereit, „mit dem Kreml dahingehend handelseinig zu werden, die russische Politik in Ostdeutschland und z. B. die Reparationen zu unterstützen [...], wenn die Russen ihm hinsichtlich der internationalen Kontrolle der Ruhr, der Wirtschaftsunion des Saarlandes mit Frankreich u.ä.m. folgen, trotz der bekannten Tatsache, daß die russischen Pläne, in direktem Gegensatz zu den französischen Plänen, eine starke Zentralregierung in Deutschland fordern“. Bidault kündigte den USA Anfang Februar 1947 an, sie würden mit den französischen Vorschlägen in Moskau nicht sehr zufrieden sein: „Ich weiß nur zu genau, daß Frankreich ein besiegtes Land ist und daß unsere Träume, seine Macht und seine ,gloire" wiederherzustellen, zu diesem Zeitpunkt völlig unrealistisch erscheinen. Während ich das privat Ihnen gegenüber zugeben kann, kann ich es gegenüber dem französischen Volk oder gegenüber der gesamten Welt nicht eingestehen. “8

Damit zeichnete sich bereits in New York bzw. im Vorfeld der Moskauer Konferenz ab, welche Punkte zwischen den Alliierten kontrovers waren, welche taktischen Zweckbündnisse in Einzelfragen möglich schienen, welche Forderungen sich unversöhnlich gegenüberstanden, welche Positionen zwischen welchen Mächten kompromißfähig waren: Reparationen, besonders aus laufender Produktion; Kontrolle des Ruhrgebiets durch Sozialisierung oder Internationalisierung; politische Dezentralisierung und/oder Wirtschaftseinheit; pragmatische Zwischenlösungen im Kontrollrat oder Friedensvertrag mit Deutschland. Entsprechend vorsichtig war der Auftrag der New Yorker Außenministerkonferenz an den Kontrollrat formuliert, für die Moskauer

7 PRO, PREM 8/791 (C.P.(47)68, 20. 2. 1947; Hervorhebung im Original). Appendix ,A' des Papiers war eine ausformulierte Überarbeitung der relevanten Teile des Potsdamer Abkommens. FO 944/ 761 (Draft Revision of the Potsdam Agreement); FO 371/64244 (Objectives for Moscow). Mit seiner Taktik des Alles oder Nichts wußte Bevin in Moskau eine Einigung über Zentralverwaltungen zu verhindern. Deighton, Impossible Peace, S. $144 \mathrm{ff}$.

8 NA, RG 59, 740.00119 Control(Germany)/2-747 (Caffery an Marshall). Zu entsprechenden Vorstößen in Moskau vgl. AMAE, Y 291, Bl. 92 ff. (13. 1. 1947). Bidault wurde auf der Moskauer Außenministerkonferenz rasch ernüchtert, was die Möglichkeiten sowjetischer Rückendeckung betraf. Er selbst betrieb eine undurchsichtige, auf kurzfristige Vorteile bedachte Politik, die nach beiden Seiten Forderungen stellte, ohne eigene Offerten zu machen. NA, RG 59, 740.00119 Council/3-2447. 
Session einen Zustandsbericht zu erarbeiten. Dessen potentieller Wert war jedoch durch Bevins Forderung begrenzt, der Kontrollrat dürfe selbst keine Lösungsmöglichkeiten für die strittigen Fragen unterbreiten. Das deutete darauf hin, daß man der Einigungsbereitschaft der Militärgouverneure mißtraute, es entsprach aber vor allem Bevins Ansatz, keine Einzelkompromisse, sondern nur eine politische Paketlösung zu suchen. Die sowjetische Weigerung, dem Kontrollrat detailliertes Zahlenmaterial über ihre Zone vorzulegen, reduzierte dessen Möglichkeiten weiter, einen „einvernehmlichen Bericht“ zu erarbeiten. Dieser mußte sich auf allgemeine Feststellungen beschränken, aus Mißtrauen angesichts des wechselseitigen Versteckspiels taktische Verhandlungspositionen aufbauen, um in Moskau für die zu erwartende Aufrechnung von „Schuld“ und „Verantwortlichkeiten“ für die Stagnation in Deutschland gewappnet zu sein.

\section{a. Der Kontrollratsbericht}

Bei den Beratungen der Außenminister in New York über die Tagesordnung der nächsten Session in Moskau schlugen die USA am 6. Dezember 1946 neben der Einsetzung eines besonderen Komitees von „Stellvertretern“ zur Beratung des Deutschlandproblems einen Bericht des Kontrollrats vor über „(a) die Gestalt und Aufgaben einer provisorischen deutschen Regierung und (b) die Errichtung von Zentralverwaltungen und andere Probleme, die mit der wirtschaftlichen und politischen Zukunft Deutschlands unter der Vier-Mächte-Herrschaft verbunden sind“. In ihrem Entwurf einer Tagesordnung fügten sie zum einen den Byrnes-Plan zur Entmilitarisierung Deutschlands, zum anderen die Begrenzung der Besatzungstruppen in Europa hinzu. Die Sowjets griffen die Anregung auf, erweiterten ihren Tagesordnungs-Vorschlag aber um drei Punkte, nämlich die Auflösung Preußens, den Bericht der Kohleexperten und die Ausdehnung des Kontrollratsberichts auf Fragen der „Anwendung der Beschlüsse der Berliner [Potsdamer] Konferenz zu Entmilitarisierung, Demokratisierung, wirtschaftlichen Fragen und Reparationen“. Der französische Vermittlungsvorschlag vom 7. Dezember sah, mehr im sowjetischen Sinn, eine Tagesordnung mit zehn Themen vor, in der nicht nur die amerikanischen und sowjetischen Punkte, sondern auch die französischen Sonderwünsche enthalten waren, nämlich das zukünftige Schicksal von Rhein und Ruhr, in Verbindung mit der endgültigen Grenzziehung und der Gewährleistung dauerhafter wirtschaftlicher und militärischer Kontrollmaßnahmen?. Danach waren insgesamt drei Berichte des Kontrollrats vorgesehen: ein allgemeiner über die Zustände in Deutschland unter der Vier-Mächte-Kontrolle, ein zweiter über die Auflösung Preußens und als dritter der der Kohleexperten ${ }^{10}$. In dem nun folgenden Feilschen um Tagesordnung und Kontrollratsbericht versuchten alle Delegationen, ihre speziellen Wünsche einzubringen: Die Sowjets beharrten auf einem Bericht, der sich vor allem auf die Umsetzung der Potsdamer Beschlüsse konzentrieren sollte; die Amerikaner hatten ein Resümee der bisherigen Arbeit und aus diesen Erfahrungen resultierende Empfehlungen für die Zukunft im Auge; die Franzosen wollten alles ausklammern, was nach einer impliziten Billigung von Zentralverwaltungen oder gar einer möglichen Regierung aussah, insofern einen reinen Rechenschaftsbe-

9 FRUS, 1946/II, S. 1464 f., 1469, 1476-78.

10 Letzterer Bericht lag seit September 1946 vor. Vgl. oben S. $182 \mathrm{f}$. 
richt; die Briten legten besonderen Wert auf einen „Sachbericht“, der neben „allen territorialen, wirtschaftlichen, politischen und finanziellen Fakten" auch exakte Angaben über entnommene Reparationen, Kriegsgefangene, Auslandsguthaben usw. enthalten sollte.

Nachdem die Stellvertreter mit dem Entwurf einer Tagesordnung überfordert waren, brauchten die Außenminister eine weitere Sitzung, bis sie sich auf die Tagesordnung und die Anweisung an den Kontrollrat einigten. Die Tagesordnung zur Deutschlandfrage wurde fünfgeteilt: zunächst der Bericht des Kontrollrats über seine Tätigkeit „seit seiner Entstehung“ in den Bereichen „Demilitarisierung, Entnazifizierung, Demokratisierung, wirtschaftliche Prinzipien, Reparationen“, sodann die Frage der Zentralverwaltungen und „andere Probleme“ der allgemeinen „Situation“ (auf französisches Verlangen statt „Zukunft“) Deutschlands unter der Vier-Mächte-Verwaltung, abschließend die Auflösung Preußens. Getrennt davon, und damit ohne einen entsprechenden Kontrollratsbericht, blieben die „Form und Reichweite der provisorischen politischen Organisation Deutschlands“. Auch hier hatte Frankreich erreicht, daß das Wort „Regierung“ nicht aufgenommen wurde. Weiterhin stand ein Bericht der Deutschland-Stellvertreter an, der sich mit Aspekten des Friedensschlusses, inkl. der Grenzfragen, befassen sollte. Es folgten schließlich der Byrnes-Plan zur Entmilitarisierung Deutschlands und der Bericht der Kohleexperten ${ }^{11}$.

Infolge der Trennung von Bestandsaufnahme durch den Kontrollrat und Zukunftsplanung durch die Stellvertreter war die Frage der Friedensregelung auch institutionell von den Differenzen über die bisherige Besatzungspolitik abgekoppelt worden, vor allem da der Kontrollratsbericht nicht - wie die USA wünschten - Grundlage von Vorschlägen der Stellvertreter sein durfte, sondern beide parallel und unabhängig voneinander erarbeitet werden mußten. Zudem vermochte die Sowjetunion ihre seit Potsdam vertretene Auffassung zu verankern, daß der Kontrollrat in der Reparationsfrage keine Zuständigkeiten in der SBZ besitze, sondern nur für die Lieferungen der Westzonen bzw. die sowjetischen Gegenlieferungen zuständig sei. Bevins Forderung nach präzisen Angaben für die SBZ wehrte Molotow mit dem Argument ab, „der Kontroll-

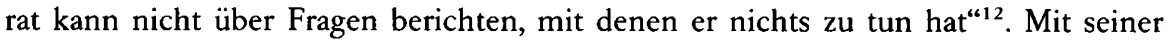
Zusage, Zahlen über die Reparationsentnahmen aus der SBZ auf der Moskauer Konferenz ergänzend zum Kontrollratsbericht vorzulegen ${ }^{13}$, setzte sich der sowjetische Außenminister zwar hinsichtlich der Offenlegung der Maßnahmen in der SBZ selbst unter Zugzwang, behauptete aber die prinzipielle Rechtsauffassung seiner Regierung. Hauptgewinner war jedoch Frankreich. Nachdem es bereits im Vorfeld seinen Widerstand gegen rasche Entscheidungen angekündigt hatte, waren praktisch alle seine Forderungen berücksichtigt worden: Dem Kontrollrat war verwehrt, Schlußfolgerungen aus seiner bisherigen Arbeit zu ziehen und Lösungsvorschläge zu unterbreiten. Alle Zukunftsfragen waren auf das unverbindliche Niveau von „Überlegungen“ und „Vorbereitungen“ heruntergeschraubt, konnten so durch die Separierung von den besatzungspraktischen Zwängen politisch im eigenen Sinne gelöst oder ohne unmittelbare Rückwirkung auf die Zonenpolitik vertagt werden.

1 FRUS, 1946/II, S. $1521 \mathrm{ff} ., 1531 \mathrm{f}$.

12 FRUS, 1946/II, S. $1523 \mathrm{f}$.

13 Nach französischen Informationen forderte Moskau entsprechende Angaben bei der SMAD ein, die Entnahmen in Höhe von \$3 Mrd. meldete. Kessel, Westeuropa, S. 173. 
In Berlin befaßte sich das Koordinationskomitee am 21. Dezember erstmals mit dem Bericht. Obwohl es in dieser Sitzung nur um die Formulierung von Richtlinien und die Verteilung der Themen auf die Direktorate ging, reproduzierten sich sofort die Debatten der Außenminister. Frankreich wollte lediglich einen Bericht über die bisherigen Verhandlungen akzeptieren; die Sowjetunion schlug eine Teilung in Tätigkeitsbericht der Direktorate und Empfehlungen für die Überwindung des Stillstands seitens des Koordinationskomitees vor. Als die sowjetische Delegation Clays Drohung mit einem Minderheitenbericht dahingehend erweiterte, im Bericht sollten generell „unterschiedliche Auffassungen“" erscheinen, reagierte dieser heftig: In dem Fall sei es angebrachter, wenn jede Delegation ihren eigenen Bericht vorlegte, auch wenn dies das Eingeständnis des „vollständigen Versagens“ des Kontrollrats beinhalte. Kurotschkin mahnte daraufhin seine Kollegen, ,alle möglichen Mittel“ für eine Einigung einzusetzen und "größere Geduld“ zu zeigen; Clays Beharren auf Empfehlungen des Kontrollrats „zur Korrektur vergangener Fehler“ ging in der Vertagung der Debatte unter.

Die Direktorate nahmen ihre Beschäftigung mit dem Bericht an die Außenminister noch im Dezember auf, verteilten die Arbeit auf die Komitees, Unterkomitees und Arbeitsgruppen, setzten sich mit benachbarten Direktoraten bei Überschneidungen und Ergänzungen in Verbindung, legten erste Richtlinien für Inhalt und Reichweite der angeforderten Berichtsentwürfe fest. Die Ausarbeitungen der Unterorgane waren nach einem einheitlichen Schema aufgebaut: Zunächst wurde ein Überblick über die Beratungen und (gegebenenfalls) Entscheidungen des Kontrollrats in ihrem Zuständigkeitsbereich gegeben, dem sich „Entwicklungsberichte“ der Zonen anschlossen, gelegentlich auch „Sachberichte“ mit entsprechenden Statistiken; den Abschluß bildete ein „Zustandsbericht“. Nur in einem einzigen Fall, nämlich bei den Reparationen, waren "Schlußfolgerungen und Empfehlungen" vorgesehen. Nachdem alle Unterorgane ihre Berichte termingerecht vorgelegt hatten, konnte das Koordinationskomitee vom 10. bis 24. Februar in sieben Sitzungen die Endfassung erarbeiten. Den ersten Teil, der aus weniger umstrittenen Abschnitten bestand, billigte der Kontrollrat aus Zeitmangel blind, nachdem die Vorlage erst Stunden vor Sitzungsbeginn fertiggestellt worden war; über den Gesamtbericht stimmte der Kontrollrat am 25. Februar, mit kleinen stilistischen Modifikationen, praktisch ohne Debatte ab.

Relativ unproblematisch waren nur die eng miteinander verknüpften Sektionen VIII (Territoriale Neuordnung) und IX (Auflösung Preußens), nachdem sich der Kontrollrat am 25. Februar 1947 auf das Gesetz Nr. 46 zur Auflösung Preußens geeinigt hatte. Differenzen gab es im Bereich der Sektion VII (Bevölkerungstransfer), die sich weniger auf die Umsiedlung der Deutschen als auf die Rückführung der Displaced Persons und alliierten Kriegsgefangenen bezogen. Während die Sowjetunion die zwangsweise Überweisung ihrer (ehemaligen) Staatsangehörigen forderte, sahen die Westmächte diese als Staatenlose an, denen zumindest die Freiheit verblieb, nicht in ihre Heimatländer zurückzukehren. Kontrovers waren die übrigen sechs Sektionen, von denen der Sowjetunion besonders die Abschnitte I (Entmilitarisierung), II (Entnazifizierung) und III (Demokratisierung) am Herzen lagen, während die Westmächte ihre Aufmerksamkeit auf die Sektionen IV (Wirtschaft) und V (Reparationen) lenkten. Eine besondere Situation lag bei der Sektion VI (Zentralverwaltungen) vor, da allein hier die Konstellation nicht Ost gegen West hieß; angesichts der unverän- 
derten Grundsatzpositionen verzichtete der Kontrollrat auf eine neuerliche Generaldebatte.

Die Konflikte im Koordinationskomitee spitzten sich von Beginn an auf die Berichtspflicht der Sowjetunion zu. Die verweigerte, gedeckt durch den von Molotow in New York erfolgreich behaupteten Rechtsstandpunkt, alle Angaben über die Zahl der Kriegsgefangenen, die Demontagen, die laufenden Reparationen („nicht-kommerzielle Exporte"), die Besatzungskosten und den Transfer deutschen Eigentums in Deutschland an ausländische Eigentümer (also die Sowjet AGs). Diesen Standpunkt lehnten die Vertreter der Westmächte als indiskutabel ab, sondern forderten die Gleichbehandlung aller Zonen, zumal sie gehofft hatten, mit Hilfe des Berichts Einblick in die SBZ zu gewinnen: sei es durch Inspektionsteams, sei es durch Offenlegung entsprechender Daten. Zwar mußte Clay, dem das Einvernehmen zwischen Bevin und Molotow in New York unbekannt geblieben war, schließlich zurückstecken, nachdem er aus Washington korrigiert worden war. Das hinderte ihn jedoch nicht daran, kurzerhand für sich das gleiche Recht in Anspruch zu nehmen, da er nicht akzeptieren wollte, daß der Kontrollratsbericht sich in seinen Wirtschafts- und Reparationsabschnitten nur auf die Westzonen bezog. Schützenhilfe erhielt er von Robertson, der - gestützt auf einen nachträglichen Re-Interpretationsversuch Bevins - die Version einbrachte, Molotow habe in New York den Einschluß der Zahlen in den Kontrollratsbericht nicht prinzipiell abgelehnt, sondern diese nur in einer eigenen Rubrik aufgeführt wissen wollen. Die Franzosen reihten sich zögernd in die westliche Front ein: Machten Briten und Amerikaner Angaben, würde ihre Delegation Gleiches tun, die Zahlen aber offiziell wieder zurückziehen, sollten die Sowjets bei ihrer Weigerung bleiben ${ }^{14}$. Als die SMAD auf ihrem Standpunkt beharrte, stellten die Briten am 13. Januar ihre Mitarbeit in den entsprechenden Direktoraten ein. Sie lenkten schließlich ein, da die Sowjets durch das offizielle Protokoll der New Yorker Konferenz gedeckt waren und Bevin sich korrigieren mußte. Da die triumphierenden Sowjets mit Ausnahme globaler Angaben über die Produktionskapazität in einigen Industriebranchen weiterhin keine Zahlen vorlegten, ging Clay auf Blockadekurs; er werde nur die Informationen geben, die alle anderen Mächte ebenfalls beisteuerten ${ }^{15}$. Daraufhin stellten die Sowjets vorübergehend in mehreren Unterorganen die Mitarbeit ein. Die Verhandlungen drohten zu scheitern, zumal die verärgerten Clay und Robertson wiederholt in Einzelfragen (z. B. den Gegenlieferungen) versuchten, sich zu revanchieren und den Sowjets ähnliche Niederlagen zu bereiten. Als diese sich unbeeindruckt zeigten, steuerten die beiden offenkundig auf eine prinzipielle Polarisierung in Gestalt zweier getrennter Berichte zu: einen der Westmächte und einen der Sowjetunion. Die USA drohten, die Abschnitte IV (Wirtschaftsfragen) und V (Reparationen) im Bericht ganz auszusparen, obwohl diese sich angesichts der eng miteinander verwobenen Probleme von Wirtschaftseinheit, Industrieniveau, Import-Export und Reparationen im wesentlichen auf eine Darstellung der bisherigen Verhandlungen und der grundsätzlichen Differenzen beschränkten.

14 BA, Z 45 F/OMGUS, 2/118-3/2-9 (CORC/M(47)1-5, 7.-27. 1. 1947). CP, S. 297, 301 f., 304 f. AO, Berlin/3276/1/2007 (ECOFIN, 15. 1. 1947). Die „complete reciprocity“ hatte Bevin auf der Pariser Konferenz im Mai 1946 als Waffe eingeführt, um sowjetischen Forderungen entgegentreten zu können, selbst wenn sie berechtigt waren. Deighton, Impossible Peace, S. 88 f.

15 BA, Z 45 F/OMGUS, 2/102-3/5 (CORC/P(47)1/3, Tab: US-Brief, 27. 1. 1947). 
Das gab Sokolowski willkommenen Anlaß, Briten und Amerikanern vorzuwerfen, sie suchten lediglich einen „Vorwand“, um einen gemeinsamen Bericht scheitern zu lassen. Obwohl Bevin offiziell seine Position habe zurücknehmen müssen, verweigerten die Westmächte weiterhin die Auskünfte über ihre Zonen, um über das „Begraben“ der Wirtschafts- und Reparationsabschnitte ihr Ziel indirekt doch noch zu erreichen. Er unterstellte ihnen die Absicht, sie nähmen, um die Arbeitsunfähigkeit des Kontrollrats zu demonstrieren, willentlich dessen „Zerbrechen“ in Kauf. Sein abschließender Appell, am Kontrollrat festzuhalten, „selbst wenn er in einigen Aspekten seiner Tätigkeit mit Schwierigkeiten konfrontiert ist“, war sicherlich nicht nur für die Galerie bestimmt. Auch in inoffiziellen Gesprächen gewannen westliche Vertreter den Eindruck, daß die Sowjetunion an einer Einigung interessiert $\operatorname{sei}^{16}$. Aber gerade das bestärkte sie in ihrer Auffassung, durch eine harte Verhandlungslinie die Sowjetunion zu Zugeständnissen zwingen zu können. Doch war mit diesen Auseinandersetzungen eine scharfe Note in den Ton der Verhandlungen eingezogen, obwohl die Direktorate und das Koordinationskomitee bis zum 10. Januar 1947 Konsens über die Grundlinien von sechs der neun Sektionen des Berichts erzielt hatten. Der Kontrollrat konnte die Differenzen nicht ausräumen. Es kam im Gegenteil zu einer weiteren Verschärfung, als Sokolowski den sowjetischen Standpunkt hinsichtlich der begrenzten Kompetenz des Kontrollrats in der SBZ bzw. jenseits der Grenzen Deutschlands bekräftigte (z. B. Kriegsgefangene) und zugleich den Westmächten - zumindest nach deren Eindruck - die Schuld an einem möglichen Scheitern bereits im Vorfeld zuzuschieben suchte, weil diese pflichtwidrig Informationen über ihre Zonen verweigerten ${ }^{17}$. Nachdem das Statement in den Zeitungen der SBZ wiedergegeben worden war, protestierten die Westmächte Anfang Februar im Koordinationskomitee gegen die von ihnen seit einiger Zeit monierte Pressekampagne der SMAD; sie drohten mit Vergeltung und negativen Auswirkungen für die Moskauer Konferenz. Der Ton der wechselseitigen Vorwürfe war scharf, ohne daß mehr als eine halbherzige Versicherung künftiger Besserung und ein Verweis an einige deutsche Zeitungsredakteure erfolgte.

Im weiteren Verlauf der Verhandlungen war es vor allem Clay, der (bestätigt von seinen westlichen Kollegen) bei jeder Gelegenheit seinen Standpunkt bekräftigte, er werde nur die Informationen beisteuern, die auch die Sowjets zu geben bereit seien. Er machte insgesamt „eine große Show totaler Indifferenz“ und ließ in seinem Verhalten deutlich werden, „daß es ihm egal war, ob es einen einvernehmlichen Bericht gab oder nicht“. Nachdem er aber aus Washington die Anweisung erhalten hatte, der Be-

16 BA, Z 45 F/OMGUS, 2/102-3/5 (CONL/M(47)2, Appendix ,B', 20. 1. 1947; CORC/P(47)1/3, Tab ,A‘: US-Brief, 27. 1. 1947). PRO, PREM 8/791 (C.P.(47)68, 20. 2. 1947, S. 11). Die USA hätten die Sowjets mit „Brutalität“ in die Enge getrieben, so Saint-Hardouin, da sie offenbar meinten, alle Trümpfe in der Hand zu halten. AMAE, Y 185, Bl. 107 f. (1. 3. 1947).

17 Nicht ohne Genuß hielt Sokolowski seinen Kollegen am 20.1. 1947 im Kontrollrat entgegen, die SBZ werde die Angaben zum Stand der Entnazifizierung vorlegen, obwohl sich die Westmächte dazu außerstande erklärten. Gemäß Direktive Nr. 24 vom 12.1. 1946 mußten die vier Mächte halbjährlich dem Kontrollrat über ihre Maßnahmen berichten - erstmals im November 1946, mit dreimonatiger Verspätung. Dabei zeigte sich, daß keine der Mächte sich nach den Vorgaben gerichtet hatte. Welsh (Revolutionärer Wandel, S. $67 \mathrm{ff}$.) setzt die Umsetzung der Direktive in der SBZ für Dezember 1946 an, im Vorfeld der Moskauer Konferenz, als Beweis des Festhaltens an Potsdam wie als Propagandawaffe gegen die Westmächte. Mit Befehl Nr. 201 erließ die SMAD im August 1947 neue Richtlinien zur Anwendung der Direktiven Nr. 24 und 38. Die Verzögerung wurde mit der unbefriedigenden Arbeit der deutschen Behörden begründet. Tägliche Rundschau, 17., 20. und 22. 8. 1947. 
richt sei erwünscht, spornte er seine Kollegen „unbarmherzig“ an und gab sich „so mürrisch und gereizt, wie er es nur konnte“, als es nicht nach seinen Vorstellungen voranging. Die Sowjetunion setzte er unter Druck, indem er ironisch deren frühere Forderung aufgriff, in den Bericht sollten „unterschiedliche Auffassungen“ eingehen. Mit Hilfe von unilateralen Erklärungen suchte er immer wieder zu verankern, die Sowjetunion verhindere eine gemeinsame Verwaltung aller vier Zonen. Er löste damit eine Flut von gleichartigen Statements und Gegenstatements, von offenen und verdeckten Vorwürfen, „Kritik“ und „Polemik“, Schuldzuweisungen, Drohungen und Verfahrensdebatten aus, die den ganzen Bericht zu entwerten drohten. Schließlich wurden die zahllosen Einzelstellungnahmen zugunsten von „Anlagen“ und Grundsatzerklärungen zurückgezogen, nachdem die britische Delegation Amerikaner und Sowjets daran erinnert hatte, daß „der Außenministerrat weder Zeit noch Lust haben werde, einen Bericht vom Umfang eines Telefonbuchs zu lesen“.

Zusätzlich verärgert waren Clay und Robertson, daß Franzosen und Sowjets wenig zum Fortschritt der Beratungen beitrugen, indem sie keine eigenen Entwürfe vorlegten; „die sowjetische Haltung war nicht aktiv destruktiv, aber sie waren in den Details ermüdender als die Franzosen." Da die Sowjetunion weder als einzige Obstruktion betrieb, noch sich die Gelegenheit ergab, sie zur Offenlegung ihrer Karten zu zwingen, hielten sich die Briten bei der Ausarbeitung der Wirtschafts- und Reparationssektionen „für den Augenblick die Tür offen“. Das endlose Feilschen konnte zuletzt nur überwunden werden, indem jeder Delegation das Recht zu einseitigen Zusatzerklärungen eingeräumt werden mußte. Somit lagen, wie es die Franzosen sahen, letztlich doch zwei bzw. drei Berichte vor. Die Angelsachsen vertraten in der Regel identische oder doch sehr ähnliche Positionen, die Sowjets beharrten auf den ihren, während die Franzosen sich „mal nahe bei ihnen [den Angelsachsen] befanden, mal alleine mit unserer Haltung und manchmal im Einklang mit den Russen“. Abgesehen von der Auflösung Preußens konnte angesichts der „absolut divergierenden Prinzipien und widersprüchlichen Bestrebungen“ nirgends wirklich Einigung erzielt werden. Trotz des "Geistes der Verständigung“ auf seiten der Sowjets in den Abschlußberatungen und trotz der gelegentlich durchscheinenden Dissonanzen zwischen den Angelsachsen, die die Hoffnung auf eine begrenzte Lebensdauer der Bizone nährten, warnte Saint-Hardouin vor übertriebenen Erwartungen: Das Klima zwischen Sowjets und Angelsachsen sei zu vergiftet. Er erwartete bei der Beratung des Berichts in Moskau eine „Kampfstimmung“" ${ }^{18}$.

Angesichts dieser Begleitumstände war das wichtigste Ergebnis des Kontrollratsberichts ${ }^{19}$, daß er die unterschiedlichen Interpretationen des Potsdamer Abkommens ebenso verdeutlichte wie die Unvereinbarkeit der Besatzungsinteressen von Angelsachsen und Sowjets. Die divergierenden Maßnahmen hatten zu einer derartigen Auseinanderentwicklung der Zonen geführt, daß auch die kooperationswilligen Kontrollratsmitglieder zur Kenntnis nehmen mußten, daß eine Einigung nicht mehr möglich war. Es zeigte sich in aller Schärfe das doppelte Grunddilemma der Kontrollratskon-

18 PRO, FO 371/64338, 64409, 64410 und 64476. AMAE, Y 185, Bl. 107 f. (Saint-Hardouin, 1. 3. 1947); Y 456, Bl. 88 f. (5. 3. 1947).

19 Ein Exemplar in BA, Z 45 F/OMGUS, 2/108-2/3-7 (CONL/P(47)14); 2/134-2/10-13. Eine Synopse von OMGUS, Summary of Principal Differences, in: 2/134-2/14. Der Bericht der Deputies über ihre Vorberatungen in London in: NA, RG 59, 740.00119 Council/3-1247. 
struktion, daß einerseits die zonale Autonomie in Verbindung mit dem Vetorecht jeder effektiven Arbeit im Wege stand, daß andererseits die Formelkompromisse und unüberbrückbaren Widersprüche des Potsdamer Abkommens für eine solche Politik Möglichkeit und Legitimation boten. Der Kontrollrat war aus eigener Kraft entscheidungs- und handlungsunfähig geworden ${ }^{20}$. Während die USA noch immer glaubten, die Sowjetunion zur Kooperation zwingen zu können, optierten die Briten unter dem Primat der eigenen nationalen Rekonstruktion immer eindeutiger für eine reine Westlösung. Die Bizone war der (letzte) Versuch, Franzosen und Sowjets zur Kooperation zu bewegen; zugleich bezeugte sie die Entschlossenheit, sich von deren Zögern nicht länger unter Druck setzen zu lassen, also notfalls den Alleingang zu wagen. Frankreich sah das mit Sorge, glaubte aber, durch eine Schaukelpolitik zwischen Ost und West ein Maximum an Vorteilen ziehen zu können, weil die Anglo-Amerikaner einen hohen Preis für seine Kooperation bezahlen würden, sollte es zum Bruch mit Moskau kommen. Die Sowjetunion war ihrerseits nicht bereit, zugunsten wirtschaftlicher Vorteile (Reparationen) die politische Kontrolle über ihre Zone zu lockern. Insofern wurde der pragmatischere Ansatz der SMAD letztlich immer wieder aus Moskau korrigiert. Die strategische Unabhängigkeit vom Westen hatte absolute Priorität, auch wenn die Teilung Deutschlands und Europas diesem erst Anlaß und Gelegenheit bot, das deutsche Potential im Rahmen eines „Westblocks“ auszubauen und notfalls gegen die Sowjetunion einzusetzen. Aus diesem Grundwiderspruch ihrer Deutschlandpolitik fand die Sowjetunion nicht heraus, und daran sollte die Moskauer Konferenz scheitern.

Als Clay am 25. Februar 1947 den Kontrollratsbericht unterschrieb, registrierte er enttäuscht: „Ich glaube, das Ergebnis hat sogar Marshall Sokolowski entmutigt.“ Der beurteilte den Bericht sehr zurückhaltend als „wertvoll“, aber „ein wenig lang“. Sholto Douglas gab seiner Enttäuschung Ausdruck, indem er Robertson zur Unterzeichnung entsandte und dort eine Kritik an der Art des Zustandekommens des Berichts verlesen ließ. Den Bericht selbst erachteten die Briten als einen „großen Haufen von oft unwichtigem und gewöhnlich strittigem Material “21 . Clay wäre von dem Bericht, der von taktischen Rücksichten geprägt war, vielleicht etwas weniger entmutigt gewesen, wenn er nicht gleichzeitig hätte erkennen müssen, daß seit der Entlassung von Byrnes sein Einfluß auf die Außenpolitik schwand und der von John Foster Dulles auf den neu ernannten Außenminister Marshall maßgeblicher wurde. In einer Art Kommentar zum Kontrollratsbericht übte der General am 5. März scharfe Kritik an den Planungen des State Department für die Moskauer Konferenz. Diese seien eine Kumulation von Einzelplänen - ohne Gesamtkonzept, ohne Verständnis für den besatzungspraktischen Zusammenhang, ohne Bezug zur Vier-Mächte-Realität in Deutschland ${ }^{22}$. Den Kontrollratsbericht hat er offenkundig zunächst nicht für hilfreich gehalten, obwohl (oder vielleicht gerade weil) er weiter die Hoffnung auf eine Vier-Mächte-Einigung nicht völlig aufgegeben hatte. Im Vorfeld der Konferenz deutete er noch einmal die Möglichkeit an, daß bei „vollständiger Zusammenfassung der deutschen Wirtschaft" Reparationen aus laufender Produktion möglich seien. Er versuchte jedoch, einer Teil-

20 FRUS, 1947/II, S. 856 (John Muccio, stellvertretender Politischer Berater).

21 PRO, FO 371/64410 (24. 2. 1947).

22 FRUS, 1947/II, S. 223-34. 
nahme an der Konferenz auszuweichen, wurde aber von Marshall nach Moskau zitiert, wo seine Tätigkeit auf die Beratung des Kontrollratsberichts reduziert blieb. Nachdem er am Rande der Konferenz vergeblich einen neuen Vorstoß unternommen hatte, über Zugeständnisse in der Reparationsfrage „die russische Einwilligung in die Wirtschaftseinheit Deutschlands zu erkaufen“, bat er um Genehmigung zur frühzeitigen Abreise $^{23}$.

Auch die sowjetische Politik zeigte keinen klaren Kurs. Nach britischem Eindruck befand sich die Sowjetunion „im Status einer gewissen Unsicherheit über ihre eigene zukünftige Politik“. ${ }^{24}$ Hintergrund dieses Schwankens waren offenbar nicht zuletzt die parallel ausgetragenen Konflikte um die Bizone, die am 1. Januar 1947 ins Leben getreten war und einen Umschwung in der Haltung der Sowjets nach sich gezogen hatte. Diese nutzten die französischen Proteste gegen das „dollar-billing“ am 21. Januar zu ersten Attacken auf die Bizone, nachdem sich Sokolowski im Vorfeld mit Noiret kurzgeschlossen hatte, um eine gemeinsame Linie gegen die Angelsachsen zu finden. Diese wiesen die sowjetischen Vorwürfe mit dem Argument zurück, die Zonen seien längst zu „separaten Einheiten“ geworden und die Bizone reduziere deren Zahl lediglich von vier auf drei ${ }^{25}$. Sie suchten (und fanden) einen Kompromiß mit den Franzosen, um die westliche Front im Vorfeld von Moskau nicht auseinanderbrechen zu lassen: Diese behielten im wesentlichen die alten Vorteile, ohne in eine Trizone eintreten zu müssen. Je mehr die Angelsachsen durch Ausbau und Verfestigung der Bizone hofften, die Sowjets zum Einlenken zwingen zu können, desto größer wurden deren Ängste, erpreßt zu werden. Die Niederlage der SED bei den Wahlen in Berlin am 20. Oktober 1946 und die positive Resonanz der Bizonengründung bei Vertretern der Ost-Parteien dürften endgültig die Bereitschaft gedämpft haben, sich mit der SBZ der Bizone anzuschließen, doch wurden entsprechende Erwartungen durch öffentliche Äußerungen Stalins am 30. Oktober 1946 oder Drapers Anfang Januar 1947 weiter genährt $^{26}$.

Immerhin, die Sowjetunion hielt sich die Optionen offen, indem sie keine vollendeten Tatsachen in der SBZ schuf. Der Politische Berater Semjonow konnte sich mit seinen Vorschlägen (die in Übereinstimmung mit der SED standen) nicht durchsetzen,

23 Siehe die gegensätzliche Interpretation bei: Backer, Clay, S. 200 ff. Krieger, Clay, S. 229 ff. Nach Deighton (Impossible Peace, S. 136) wurden Clays Bemühungen um eine Einigung von den Briten verhindert, nach Einschätzung von Kindleberger (Letters, S. 153 f., 160, 184) von Dulles.

24 PRO, FO 371/64476/C1433, C1510; FO 1046/711 (CCG, Political Division, 7. 1. 1947).

25 Vergeblich blieben die britischen Interpretationsversuche Ende November 1946, die Bizone sei eine Art „nucleus“ Zentralverwaltung, die später „by amalgamation“ mit der französischen und sowjetischen Zone vereint werden könne. Die Bizonenverwaltungen, deren Aufgabe „purely executive“ in der ersten Stufe sei, bezögen „their legislative authority directly from the ACC“" und arbeiteten durch die Länderverwaltungen, denen sie Anordnungen gaben und die sie kontrollierten. Aus dieser Konstellation leiteten sie die Forderung ab, eine beratende Körperschaft der deutschen Länder beim Kontrollrat einzurichten. PRO, FO 371/55928/C14617 (28. 11. 1946). Makins wußte, „that these steps will make ultimate four-power agreement much more difficult“. FO 371/65052 (9. 4. 1947); PREM 8/791 (Bevin, C.P.(47)68, 20. 2. 1947).

26 Entsprechende Spekulationen in: AMAE, Y 288, Bl. 391 ff. (30. 10. 1946); Y 378, Bl. 81 ff. (Seydoux an Bidault, 11. 12. 1946), 137 (13.1. 1947), 151 (4. 2. 1947). Die französische Botschaft in Washington meinte Anfang Januar 1947 aus guter Quelle Hinweise zu haben, die Sowjetunion sei „très désireux de maintenir la détente encore fragile qui se marque dans ses relations avec les Etats-Unis et d'arriver avec eux à une entente sur la question allemande“; sie sei bereit „à faire d'importants sacrifices aux exigences américaines en ce qui concerne l'unité économique de l'Allemagne, la forme de son gouvernement, etc.“. Y 371, Bl. 0 [sic] ff. (2. 1. 1947). 
„in der SBZ etwas in der Art einer zonalen deutschen Regierung zu bilden. Deren Funktionen können stufenweise, beginnend bei halbberatenden in der ersten Zeit bis hin zu gesetzgebenden Funktionen in der folgenden Zeit, ausgebaut werden“, um der SED „Macht im Maßstab der ganzen Zone [zu] geben und nicht nur im Maßstab der Provinzen. Dabei muß man im Blick haben, daß früher oder später die Frage der Bildung einer gesamtdeutschen Regierung auftauchen wird, darin müssen Leute eintreten, die Erfahrung in der Leitung eines Staates haben und in ganz Deutschland als Politiker bekannt sind. [...] Es ist notwendig, daß die führenden Kader der SED lernen, einen Staat zu leiten und einen entsprechenden staatlichen Apparat zu schaffen [...], der als Grundstock und Rückhalt bei der Schaffung der gesamtdeutschen Regierungsorgane dienen kann.“ Den Vorwürfen, „daß das der Versuch der Teilung Deutschlands sei, können wir zum einen dadurch entgegentreten, daß ähnliche zonale Organe in den Westzonen schon existieren, und, auf der anderen Seite, daß wir gemäß dem Statut diese Organe nicht vollständig mit allen Rechten einer Regierung ausstatten, sondern im Gegenteil den zeitweiligen Übergangscharakter dieser Organe unterstreichen“. Dazu könne beitragen, „daß in der ersten Zeit, solange er noch nicht auf eigenen Füßen steht, der Rat nur äußerst allgemeine Fragen entscheiden wird. Bis er schließlich auf eigenen Füßen steht, wird noch ziemlich viel Zeit vergehen."27 Am 31. Januar beschied Stalin die Forderung der SED-Spitze nach Schaffung eines Zonenbeirats, daß ein „Zonenorgan“ erst einzurichten sei, „falls die Partner der Bildung einer Zentralregierung oder Zentralverwaltung für Deutschland nicht zustimmten“. Eine Vereinbarung vom 10. Februar 1947, die die Länder und Provinzen durch Errichtung der Deutschen Wirtschaftskommission (DWK) mit den zonalen Zentralverwaltungen verknüpfte, wurde erst am 18. April 1947 in Kraft gesetzt, wäre also noch durch ein positives Ergebnis der Moskauer Außenministerkonferenz korrigierbar gewesen $^{28}$. Aber auch mit der DWK war nichts präjudiziert, sondern die Sowjetunion hatte Strukturen geschaffen, die für den Fall eines Zusammenschlusses denen der Bizone entsprachen, also Startvorteile des Westens ausglichen. Allerdings wäre wohl die Fusion mit der Bizone der einzige Weg gewesen, wie Sokolowskis erregter Protest im Kontrollrat am 25. Februar nahelegte, zu verhindern, daß über die Gründung von bizonalen wirtschaftlichen Zentralbehörden hinaus auch eine solche politischen Charakters erfolgte, der „Keim“ einer westdeutschen Regierung ${ }^{29}$. Das Stuttgarter Bipartite Control Office stelle „neben dem Kontrollrat“ eine konkurrierende alliierte Kontrollinstanz dar und vollziehe „praktisch“ die „Abtrennung“ der Bizone; derart werde die Ruhr der Vier-Mächte-Kontrolle entzogen und der Weg zur Blockbildung eingeschlagen $^{30}$.

27 Zitiert nach: Laufer, Ursprünge, S. $154 \mathrm{f}$.

${ }^{28}$ Bonwetsch/Bordjugov, Stalin und die SBZ, S. 296 (31. 1. 1947). Tjulpanow, Deutschland, S. 146. Endgültig wurde die Bildung der DWK von der SMAD durch Befehl Nr. 138 am 4.6. 1947 angeordnet. Zur Vorgeschichte vgl. Steiner, Länderpartikularismus.

29 Tägliche Rundschau, 21. 2. 1947.

30 Tägliche Rundschau, 6. 11. 1946, S. 1 f. Zwar gab es in der Täglichen Rundschau (8. 12. 1946, S. 1 f.) Angriffe gegen den ",western bloc" als Stärkung der deutschen Reaktion; die Bizone wurde jedoch (noch) nicht angegriffen. Vielmehr wurde das Länderratsgeschäft Nr. 2 im Interzonenhandel als Beleg gefeiert, „daß die Besatzungsmächte bemüht sind, der wirtschaftlichen Einheit Deutschlands den Weg zu ebnen" (ebenda, 24. und 29.12. 1946), ebenso die Mindener Interzonentagung (ebenda, 19. 1., 7. und 11. 2. 1947). Die sowjetische Presse kritisierte Ende 1946/Anfang 1947 die Bizone mit zwei bezeichnenden Vorwürfen: Sie entziehe die Ruhr der Vier-Mächte-Kontrolle und bedeute den 
Aber für eine Fusion der SBZ mit der Bizone bestand weder inhaltlich noch politisch eine reale Geschäftsgrundlage. Ob durch die Vertagung der Deutschlandfrage von der New Yorker auf die Moskauer Außenministerkonferenz tatsächlich die Chance vertan wurde, die Sowjetunion an die Bizone zu binden, wie Clay meinte, das erscheint angesichts der fundamentalen Differenzen wenig wahrscheinlich. Aber noch vermied die Sowjetunion den offenen Bruch. Ihr variabler Verhandlungsstil im Kontrollrat könnte ein Hinweis darauf sein, daß die Sowjetunion zum einen hoffte, in den Verhandlungen zwischen Sokolowski und Clay doch den Durchbruch in der Reparationsfrage zu erzielen, daß sie zum zweiten glaubte, aus einer stärkeren, auf Unterstützung der Deutschen beruhenden Verhandlungsposition heraus den Westen zu entscheidenden Zugeständnissen zwingen zu können, indem sie das Ende der Reparationen in der SBZ und die Rückgabe der sequestrierten Betriebe ankündigte, daß sie zum dritten durch Offerten an Großbritannien und Frankreich eine Spaltung der Westmächte anstrebte ${ }^{31}$. Offenbar aus „Furcht vor einer Isolierung in Moskau“ hatte die sowjetische Regierung seit Ende 1946 Frankreich zu mehr Hartnäckigkeit und Eigenständigkeit bei der Vertretung seiner nationalen Interessen ermuntert und ein Arrangement hinsichtlich der Ruhr und insgesamt der Sicherheit in und vor Deutschland angeboten. Zwar fühlten sich die Franzosen von den USA, zumindest aber von Clay und Draper, unverstanden und im Stich gelassen, doch versäumten es die Sowjets, das französische Angebot eines Kompensationsgeschäfts durch entscheidende Zugeständnisse, z. B. hinsichtlich der Saar ${ }^{32}$, zu honorieren. Jetzt war die Isolation der SBZ kaum mehr reversibel.

Bereits bei der Beratung des ersten Punkts des Kontrollratsberichts auf der Moskauer Außenministerkonferenz zeigte sich die Unversöhnlichkeit der Positionen: Während die Westmächte zunehmend der Erkenntnis Rechnung trugen, die eigene Rekonstruktion nur mit Deutschland verwirklichen zu können, hielt die Sowjetunion an dem Wiederaufbau auf Kosten Deutschlands fest. Molotow erweiterte die Entmilitarisierung um die Fragen der Demontagen und Reparationen, der Demokratisierung, der Landreform usw., zielte also auf eine radikale strukturelle Transformation. Die

Anfang zur Blockbildung im Westen. PRO, FO 371/64422. Bemerkenswert war jedoch die interne Bewertung seitens der SMAD: „Mr Koval stated that although the bizonal agreement [...] was not very pleasant, he considered it valuable as it will provide experience for future action to be taken in unification of German economy." NA, RG 43/WWII\&PWConf, box 187, folder: Misc., Economics (Draper-Kowal, 21. 1. 1947). Drei Tage später sagte Kowal den Präsidenten der SBZ-Zentralverwaltungen: „Es wird ein Wettbewerb der Zonen einsetzen. Wir werden sehen, wer besser arbeitet, welche Form die richtige ist." SAPMO, ZPA, Nl 90/314, Bl. 48.

31 BA, Z 45 F/OMGUS, POLAD-TS/34/1-3 (11.3. 1947). PRO, FO 371/64035/C918 (POLAD, 18. 1. 1947); FO 1047/711 (POLAD, Februar 1947).

32 AMAE, Y 185, Bl. 71 (GFCC, 25. 2. 1947), 107 ff. (Saint-Hardouin, 1. 3. 1947); Y 289, Bl. 79 f.; Y 291, Bl. 194; Y 378, Bl. 140 (18. 1. 1947). AN, 457 (Bidault) AP 61/IV (Saint-Hardouin, 19. 1. 1947). Zwar galt in Moskau das „Saargebiet möglicherweise als Kompromiß“, doch befürchtete man, damit die Frage der Grenzen im Osten neu zu eröffnen und die Glaubwürdigkeit des eigenen Eintretens für die Einheit zu gefährden. Badstübner, Beratungen, S. 106. Botschafter Catroux (Rideau de fer, S. $151 \mathrm{ff}$., $211 \mathrm{ff}$.) beurteilte die sowjetische Reaktion auf die Saarfrage positiver und sah auf der Basis der "réciprocité" von Saargebiet gegen Reparationen bis in den Januar 1947 eine Chance zur Einigung. Unverbindliche Versuche, "that Soviets are ,buttering up“ Bidault as most susceptible of Foreign Ministers and of some possible use in present conference", waren von den Anglo-Amerikanern mit Mißtrauen registriert worden. NA, RG 43/WWII\&PWConf, box 191, folder: Moscow Misc. (19. 3. 1947). Am 17. 3. hatte Molotow offiziell die Abtrennung der Saar als einseitige Maßnahme abgelehnt und in eine Reihe gestellt mit der einseitigen Ruhrkontrolle der Briten und der Gründung der Bizone. Docs. Int. Aff., 1947/48, S. 429. Bidault hat Molotows „abweisende“ Haltung „nicht vergessen“. Seydoux, Erinnerungen, S. 105. 
Westmächte bestanden dagegen auf Wirtschaftseinheit, Einheitlichkeit der politischen Organisation und demokratischen Prinzipien, definierten die ökonomische Sicherung der Lebenshaltung der Deutschen als Grundlage auch der militärischen Sicherheit der Alliierten, zusätzlich garantiert durch eine internationale Kontrolle im Rahmen des Byrnes-Plans ${ }^{33}$. Wechselseitige, detaillierte Vorwürfe, zumeist in Form von vorbereiteten Statements, oft wohl auch als Propaganda für den „heimischen Verbrauch“ gedacht, provozierten Rechnung und Gegenrechnung. Dabei geriet der Kontrollrat zunehmend in die Kritik, besonders seitens der Sowjets. Während auch Murphy diesen intern Anfang Januar 1947 als „im Sterben liegend“ charakterisiert hatte, dessen Zustand - so sein Stellvertreter Muccio - sich seit dem Sommer 1946 permanent „verschlechtert" habe, sah sich Bevin angesichts der Attacken Molotows bemüßigt, dem Kontrollrat für seine Erfolge zu danken ${ }^{34}$.

Die Vorlage des Sonderkomitees für den Kontrollratsbericht reflektierte nicht mehr als die Positionen des Kontrollrats, da ihm mit Clay, Robertson und Sokolowski die Personen angehörten, die bereits in Berlin an der Ausarbeitung des Berichts mitgewirkt hatten. Die Unversöhnlichkeit wurde durch Grundsatzerklärungen der verschiedenen Delegationen eher noch schärfer hervorgehoben ${ }^{35}$. Nachdem Marshall erstmals mit dem Scheitern der Konferenz gedroht hatte, suchten die Minister den Stillstand zu überwinden, indem sie sich die wichtigsten Punkte (Wirtschaftseinheit, industrielle Entwaffnung, Industrieniveauplan, Wiederaufnahme der Reparationen sowie Gestalt und Kompetenzen einer provisorischen Regierung) selbst vorbehielten. Die anderen Fragen verblieben beim Sonderkomitee: Entnazifizierung, Demokratisierung, Displaced Persons und territoriale Reorganisation. Auch beim zweiten Anlauf verlief, abgesehen von dem Konsens in einigen wenigen Punkten, die Debatte so disparat und kontrovers, daß in weiteren Sitzungen erneut nach Kompromissen und Formulierungen gesucht werden mußte ${ }^{36}$. Der Abschlußbericht der Stellvertreter, der von den Au-

33 Die Sowjetunion forderte Ergänzungen, die nach amerikanischer Auffassung nicht nur den Grundcharakter des Byrnes-Plans verändert hätten, sondern ihn verhindern sollten. FRUS, 1947/II, S. 332-36, 351, 388. Docs. Int. Aff., 1947/48, S. 445 ff. Gegenüber Bevin hatte sich Stalin am 24. 3. 1947 positiv geäußert. PRO, FO 800/502/SU/47/24.

34 FRUS, 1947/II, S. 250 f., 309, 846, 856.

35 NA, RG 59, 740.00119 Council/3-2147. FRUS, 1947/II, S. 276, 293, 296 f., 401 ff., 409-25. Die einzigen Punkte, über die das Komitee in seinem ersten Bericht vom 2. 4. 1947 Übereinstimmung erzielte, betrafen die Entnazifizierung, die im Sinne der Kontrollratsdirektiven Nr. 24 und 38 durch die Zonenkommandeure fortgesetzt werden sollte, die auf eine „einheitliche Handhabung“ verpflichtet wurden, und den Abschluß der Landreform in allen Zonen. Über Wahlen, Informationsfreiheit und die Verankerung einer Menschenrechtserklärung in einer gesamtstaatlichen Verfassung oder, auf dem Weg über die Zonenkommandeure, in den Länderverfassungen konnte prinzipielle Einigung erzielt werden; ein Gesamtkonsens scheiterte am französischen Veto gegen gesamtdeutsche Regelungen für Parteien und Gewerkschaften sowie an Meinungsverschiedenheiten über Mehrheits- oder Verhältniswahlrecht. Eine Einigung über Bevölkerungstransfers wurde nicht erzielt, da die alten Differenzen über die Repatriierung der Displaced Persons sich als unüberwindlich erwiesen, zumal die Briten mit der Forderung baldiger Repatriierung der deutschen Kriegsgefangenen antworteten. Erschwerend hinzu trat die französische Forderung, die Aussiedlung der Deutschen aus Osteuropa zu suspendieren, bis auf einer alliierten Konferenz ein organisiertes Auswanderungsprogramm beraten worden sei. FRUS, 1947/II, S. 427-33.

36 Im zweiten Bericht vom 11. 4. 1947 konnte das Sonderkomitee Einigkeit vermelden, die wirtschaftliche Entmilitarisierung zu beschleunigen und deren Durchführung durch eine Vier-Mächte-Kommission zu verifizieren. Der Streitpunkt, ob eine Frist bis zum 31.12. 1947 für die Zerstörung der Rüstungsbetriebe gesetzt werden sollte, wurde von den Außenministern überwunden, indem den Briten zugestanden wurde, notfalls nach Mitteilung an den Kontrollrat diese Frist zu überschreiten. Bei den Betrieben, die als Rüstungspotential eingestuft wurden, plädierten die USA und England für 
ßenministern gebilligt und dem Kontrollrat als „Direktive“ übersandt wurde, enthielt im ersten Teil eine Zusammenfassung der früheren Stellungnahmen, ohne wesentliche Verbesserungen. Im zweiten Teil, der Wirtschaftseinheit und Reparationen behandelte, waren nicht einmal Formelkompromisse erzielt worden. Der Konsens, daß der Kontrollrat nach Durchführung des (suspendierten) Industrieniveauplans Listen über die entfernten Reparationsgüter erstellen sollte, war ebenso bedeutungslos wie die Einigung darüber, daß der Plan einer Revision bedurfte, da mehr als eine isolierte Vereinbarung über die Erhöhung der Stahlproduktion nicht erzielt wurde. Im dritten Teil, der Gestalt und Kompetenzen einer provisorischen deutschen politischen Organisation betraf, bestand Einvernehmen lediglich über Halbsätze, aber nicht über Grundsätze. Einzelne Passagen, deren Wortlaut gebilligt wurde, waren wertlos, da sie an Vorbehalte gebunden oder mit anderen, nicht konsensfähigen Abschnitten verknüpft waren. Während im vierten Teil die Auflösung Preußens wohlwollend zur Kenntnis genommen wurde, war die Erwähnung der Vorbereitungen für einen Friedensvertrag mit Deutschland angesichts der fundamentalen Dissonanzen nicht mehr als eine Pflichtübung, zumal auch die Beratung über eine Vier-Mächte-Kontrolle Deutschlands nach dem Muster des Byrnes-Plans unter wechselseitigen Invektiven begraben wurde. Die Einigung, die Rückführung der deutschen Kriegsgefangenen bis zum Ende des Jahres 1948 abzuschließen, konnte die frostige Stimmung nicht mehr auflockern $^{37}$.

Wie vollständig die Konferenz gescheitert war, zeigte sich an der Weigerung Englands und der USA, angesichts der „fundamentalen“ Differenzen die ungelösten Fragen an die Deutschland-Stellvertreter zu verweisen, d. h. diese auf der politischen Ebene zu halten und nicht dem überforderten Kontrollrat zu überlassen. Marshalls öffentliche Geste, daß „möglicherweise größere Fortschritte auf dem Weg zu einer endgültigen Regelung gemacht wurden, als das wahrgenommen wird“, wurde durch die sehr direkte Schuldzuweisung aufgewogen, die Sowjetunion habe durch ihre falsche Interpretation des Potsdamer Abkommens, durch propagandistische Appelle an „Leidenschaft und Vorurteil“ das Scheitern zu verantworten. Sein Statement (als wäre es auch für den konzilianteren Clay gedacht) kündigte Härte an: „Wir dürfen bei den Grundprinzipien keine Kompromisse eingehen, um Einigung um der Einigung willen zu erzielen. “38 Wenn es das Ziel Molotows gewesen sein sollte, durch endloses Hinauszögern die Westmächte zum offenen Bruch zu provozieren oder unter Druck zu setzen, so war die Taktik vollständig gescheitert. Denn Briten und Amerikaner nahmen die Gelegenheit wahr, in den Konferenzpausen die Weiterentwicklung der Bizone zu verhandeln. Allerdings waren sie darauf bedacht, die Ergebnisse nicht in Moskau, sondern erst nach einer gebührenden Pause von mehreren Wochen bekannt-

eine Koppelung mit der Revision des Industrieniveauplans, die Frankreich im Grundsatz akzeptierte, aber inhaltlich wie zeitlich zu präzisieren wünschte, während die Sowjets kürzere Fristen und die gleichzeitige Zerschlagung von Kartellen und Monopolen verlangten. Diese Differenzpunkte konnten von den Ministern nicht gelöst werden. FRUS, 1947/II, S. $446 \mathrm{ff}$.

37 FRUS, 1947/II, S. 381 ff., 461-71. NA, RG 59, 740.00119 Council/8-1249 (Synoptisches Summary of CFM Agreements and Disagreements on Germany. A Detailed Breakdown of Four Power Positions at the Fourth Session of CFM, Moscow, 1947, prepared by CFM Secretariat, CAD, OMGUS, 1. 7. 1947).

38 Germany 1947-1949, S. 57 ff. Docs. Int. Aff., 1947/48, S. 490-503 (Bevin, 15. 5. 1947). 
zugeben $^{39}$. Bidault, der seine drohende Isolierung mit Sorge beobachtete, konnte sich der Erkenntnis nicht entziehen, daß angesichts des Konferenzverlaufs eine Einigung nicht mehr zu erwarten war und daß damit der Druck auf Frankreich wuchs, sich der Bizone anzuschließen ${ }^{40}$. Demgegenüber zogen die sowjetischen Verantwortlichen eine positive Bilanz. Gegenüber Marshall mahnte Stalin am 15. April zur Geduld. „Es ist möglich, daß kein großer Erfolg auf dieser Session erzielt wird, aber das sollte niemandem Anlaß zur Verzweiflung geben.“ Ähnlich äußerte Tjulpanow, die Konferenz habe „einiges geleistet“, indem sie die Standpunkte präzisiert und Voraussetzungen für einen Kompromiß geschaffen habe ${ }^{41}$. Der Erfolg aus sowjetischer Sicht lag offenkundig darin, wie die SED erklärte, daß die Außenminister den Kontrollrat einvernehmlich angewiesen hatten, die Maßnahmen zur „Demokratisierung“ Deutschlands zu forcieren. „In diesem Beschluß liegt gleichzeitig die Anerkennung für die Richtigkeit der bisher in der Ostzone durchgeführten Politik. “42 In der Rückschau bewerteten auch die USA die Konferenz als einen „taktischen Erfolg“ für die Sowjets, indem sie „der sowjetischen Delegation erheblichen Zeitgewinn verschaffte, Berichte des Kontrollrats über Fragen bereitstellte, bei denen die Westzonen in einer defensiven Position waren, zugleich aber der Sowjetunion vollständige Handlungsfreiheit in den Dingen vorbehalten hat, in denen sie unter Druck stand“43. Das reduzierte die Bereitschaft der Westmächte weiter, bei der Umsetzung der „Direktive“ der Außenminister an den Kontrollrat neue Zugeständnisse zu machen, zumal zwischenzeitlich mit der Bizone, dem Dünkirchen-Pakt und der Truman-Doktrin eine größere Geschlossenheit der westlichen Front hergestellt worden war $^{44}$.

Die „Direktive“ der Außenminister an den Kontrollrat konnte das Scheitern der Konferenz nicht kaschieren. Angesichts seiner politischen Hilflosigkeit waren Ansätze zu einer Lösung von diesem nicht zu erwarten, eher eine weitere Belastung des Klimas zwischen den Alliierten. Das Koordinationskomitee tagte infolge der Berliner Magistratskrise ohnehin in einer „bedrückenden Atmosphäre der Uneinigkeit“ und war seit Wochen nicht mehr in der Lage gewesen, Differenzen in den Direktoraten aufzulösen. Obwohl die offiziellen Dokumente noch nicht übermittelt waren, befaßte es sich am 16. Mai mit den Teilen der Direktive, die enge Terminsetzungen enthielten: der Bestimmung von Obergrenzen für die Besatzungstruppen, der Rückführung der Kriegsgefangenen und der Zerstörung reiner Rüstungsbetriebe. Am 28. Mai wurden die Aufträge der Außenministerkonferenz auf die Direktorate verteilt. Während

39 FRUS, 1947/II, S. 356 ff. Bevin drängte Marshall zu raschen Entscheidungen, die auf Einstellung der Reparationen und Erhöhung des Industrieniveaus hinausliefen, notfalls einseitig in der Bizone. NA, RG 59, 740.00119 Council/4-747.

60 NA, RG 59, 740.00119 Council/3-2447. FRUS, 1947/II, S. 396. AN, 457 (Bidault) AP 13/Moscou 1947 (Observations générales, S. 1-4; Echec de la conférence de Moscou).

1 PRO, FO 800/502/SU/47/38. Die sowjetische Presse zitierte die positiveren Passagen in den Resümees von Bevin und Marshall, auch wenn es verhaltene Kritik gab, die Westmächte suchten Yalta und Potsdam zu revidieren. Tägliche Rundschau, 24.-27. 4. 1947. Erst später wurden in der Nowoje Wremja zu Marshalls Rundfunkrede vom 29. 4. und Bevins Erklärung vor dem Unterhaus am 15. 5. kritischere Töne laut. Tägliche Rundschau, 1. 6. 1947.

42 SAPMO, ZPA, NI 36/753 (21./22. 5. 1947).

43 BA, Z 45 F/OMGUS, 2/102-3/10 (Lt. Colonel H.A. Gerhardt an Assistant Secretaries, Critique on Studies on the London Conference of the Council of Foreign Ministers, Dezember 1947).

44 Erst später erkannte die Sowjetunion, daß erfolgreiche Voraussetzungen auf der Londoner Folgekonferenz im Herbst 1947 nicht mehr gegeben waren; mit Marshall-Plan und bizonalem Industrieniveauplan seien die sowjetischen Ansprüche ,noch mehr als bisher“ zunichte gemacht worden. Tägliche Rundschau, 13. 8. 1947. 
der britische Vorsitzende es für unwahrscheinlich erachtete, daß der Kontrollrat in der Lage sein werde, der nächsten Session der Außenministerkonferenz in London konkrete Vorschläge zu unterbreiten, bestand der sowjetische Delegierte darauf, auch die Teile weiterzuberaten, über die in Moskau keine Einigung erzielt worden war.

Die Skepsis der Westmächte sollte bald bestätigt werden. Der Kontrollrat war außerstande, selbst die im Grundsatz unstrittigen Fragen in die Praxis umzusetzen. Der erste Konfliktpunkt war die Bestimmung von Obergrenzen für die Besatzungstruppen $^{45}$. Das Militärdirektorat erzielte keine Einigung, ob nur die Besatzungstruppen oder auch die Militärverwaltungen in die Obergrenzen mit einzubeziehen seien. Während die USA den drei großen Mächten je 150.000 und Frankreich 60.000 Mann zugestehen wollten, verlangten die Briten für sich 156.000, die Franzosen eine Flexibilisierung dieser Zahlen als Jahresdurchschnittswerte, während die Sowjets für sich und die Bizone Parität mit je 200.000 Mann forderten, den Franzosen aber nur 50.000 Mann zugestehen wollten. Im Koordinationskomitee wurden die Argumente lediglich wiederholt, so daß am 31. Mai der Kontrollrat die Frage an sich zog. Unabhängig von allen Zahlenspielen und Prestigefragen scheiterte eine Lösung an der unnachgiebigen Haltung der Sowjets, die mit der Begründung, Berlin als strategisch wichtige Hauptstadt und als Verkehrsknotenpunkt gegen deutsche Aufstandsversuche schützen zu müssen, jetzt ein Mehr von 100.000 Mann gegenüber der Gesamtsumme der britischen und amerikanischen Truppenstärke forderten. Obwohl die Westmächte ihre Mitverantwortung für Berlin geltend machten und den Bedarf von 100.000 zusätzlichen Verteidigungskräften gegen die entwaffneten Deutschen als unglaubwürdig ablehnten, blieb Sokolowski unbeweglich, so daß die Frage schließlich an die Regierungen zurückverwiesen wurde, d. h. unerledigt blieb ${ }^{46}$. Clay schob allerdings den Briten die Schuld am Scheitern zu, die die Parität zur Grundsatzfrage erhoben, obwohl das Angebot der Sowjetunion zur Halbierung der Roten Armee geführt hätte und obwohl die Briten selbst nicht in der Lage waren, die von ihnen beanspruchte Mannschaftsstärke bereitzustellen ${ }^{47}$. Obwohl im Grunde alle Mächte aus finanziellen Gründen an einer Reduktion ihrer Truppen interessiert waren, gelang es nicht, dies zum Gegen-

15 Ein entsprechender amerikanischer Antrag war zum Abschluß der Konferenz positiv beschieden worden, der als Ziel die Reduzierung der Besatzungskosten benannte, ,in order that the German economy may become self-supporting at the earliest possible date and to expedite the availability of products for export“. FRUS, 1947/II, S. 389. Die Westmächte befürchteten, die Sowjetunion könnte statt einer Begrenzung den völligen Rückzug aller Besatzungstruppen vorschlagen, wie seit der Moskauer Konferenz diskutiert wurde. In dem Fall würde sie sich nur hinter die deutsche Ostgrenze zurückziehen, während die USA faktisch Europa verlassen müßten. NA, RG 59, 740.00119 Control(Germany)/11-647 und /11-1047. FRUS, 1947/II, S. 896 ff. Vom Eingehen auf einen Totalrückzug rieten die JCS und Clay ab; da die Westeuropäer nicht in der Lage seien, die Sowjetunion zu stoppen, müßten die amerikanischen Truppen vorläufig bleiben. Die Sowjets bauten 1947 „seit einigen Monaten“ eine zentrale Verwaltung des Inneren in der SBZ auf, um „eine zentralisierte, schlagkräftige Polizeitruppe zu schaffen, damit die SMAD nach und nach auch ihre Truppen verringern und schließlich ganz zurückziehen könne“. Gniffke, Jahre, S. 262. Zugleich befürchteten die JCS, die Sowjets könnten in der Hinterhand über eine deutsche Befreiungsarmee unter General von SeydlitzKurzbach von 150.000 Mann verfügen, und begannen seit Dezember 1947 über einen deutschen Verteidigungsbeitrag nachzudenken. NA, RG 218/JCS 1946-1947 Geographic, box 109: CCS 383.21 Germany (JCS 1811/1). Auch die Franzosen kannten Gerüchte, die Sowjets rekrutierten Deutsche für eine in Südrußland aufgestellte „armée von Paulus“. AMAE, Y 201, Bl. 83 ff. (Botschaft London, 31. 10. 1947).

46 BA, Z 45 F/OMGUS, 2/118-3/10-21 (CORC/P(47)128, 23. 5. 1947).

47 CP, S. 368, 393, 492. 
stand eines offiziellen Abkommens zu machen ${ }^{48}$. Das wechselseitige Mißtrauen war so stark geworden, daß es selbst Regelungen verhinderte, die von beiden Seiten als vorteilhaft angesehen wurden.

Während die Rückführung der Kriegsgefangenen kein Problem darstellte, begannen bei der Frage des Bevölkerungstransfers erneut die alten Grundsatzdebatten. Erst Ende November 1947 lagen die Berichte aller Zonenkommandeure vor, nachdem die Briten die Frist vom 1. Oktober absichtlich hatten verstreichen lassen. Da sie - als kleinliche „Retourkutsche“ für die sowjetische Weigerung im Vorfeld der Moskauer Konferenz - dem Kontrollrat das Recht bestritten, in diese Zonenangelegenheit hineinzuregieren oder auch nur hineinzudiskutieren, verweigerte die CCG zunächst einen Bericht, erklärte sich aber bereit, der Außenministerkonferenz direkt die Zahlen vorzulegen. Erst nachdem sichergestellt war, daß ihr Bericht dem Kontrollrat lediglich für den Fall zur Verfügung gestellt wurde, daß die Minister ihn doch noch anfordern sollten, legte sie diesen innerhalb von zehn Tagen vor. Da das zuständige Direktorat aufgrund sowjetischer Nachbesserungswünsche zu keinem „einvernehmlichen Bericht" gelangte, kam es im Koordinationskomitee zu erbitterten Wortwechseln, die endgültig jede Einigung unmöglich machten ${ }^{49}$.

Selbst dort, wo - wie im Falle der Entnazifizierung - die Außenminister Übereinstimmung erzielt hatten, kam die Kontrollratsarbeit nicht voran. Nach langer Verfahrensdiskussion überwies das Innendirektorat am 6. Oktober 1947 einen Direktiventwurf an das Koordinationskomitee, der jedoch in den entscheidenden Fragen nicht einvernehmlich war: Die Westmächte wollten es der Entscheidung des Zonenkommandeurs überlassen, ob er verurteilte Kriegsverbrecher an die Länder auslieferte, in denen die Verbrechen begangen worden waren, während die Sowjetunion auf einer Auslieferungspflicht beharrte. Zudem verlangten die Westmächte, daß die Entnazifizierungsbescheide der einen Zone automatisch und uneingeschränkt in den anderen anerkannt werden müßten, was die Sowjetunion strikt ablehnte ${ }^{50}$.

Die Methode, politische Rahmenvereinbarungen durch Verfahrensfragen zu blokkieren, ,bewährte" sich auch bei der Frage der Zerstörung der Rüstungsbetriebe und der Auflösung deutscher (para-)militärischer Einheiten - ergänzt durch wechselseitige Vorwürfe, die Beschlüsse der Potsdamer Konferenz systematisch mißachtet zu haben oder die Direktive der Außenminister bewußt fehlzuinterpretieren. Immerhin gelang es der Sowjetunion, die USA, vor allem aber Großbritannien zu dem Eingeständnis zu zwingen, daß der von der Außenministerkonferenz geforderte Abschluß der Zerstörung reiner Rüstungsbetriebe bis zum 1. Juli 1948 in ihren Zonen nicht eingehalten werden könne. Am 15. Januar 1948 verwies das völlig zerstrittene Koordinationskomitee den gesamten Fragenkomplex an den Kontrollrat.

48 In den USA war im Oktober 1946 darüber debattiert worden, aus finanziellen Gründen die „military occupation forces to $1 / 4$ or $1 / 3$ of the present number $-65,000$ to 80,000 man with additional troops needed to handle DPs“ zu reduzieren. NA, RG 59, 740.00119 Control(Germany)/11-446 (Claxton an Hilldring). Murphy verwies in dem Zusammenhang auf die Tschechoslowakei 1945, als die Sowjetunion ihre Truppen kurze Zeit nach den USA zurückzog, obwohl bzw. weil man (bewußt) zu keiner vertraglichen Regelung gekommen war. Jedenfalls bemerkte Murphy, „that Sokolovsky was careful not to slam door on this question". FRUS, 1947/II, S. $871 \mathrm{f}$.

49 $\mathrm{BA}, \mathrm{Z} 45$ F/OMGUS, 2/108-3/4 (CONL/M(47)24 und 25); 2/108-2/3-7 (CONL/P(47)58); 2/1183/2-9 (CORC/M(47)49, 8./9. 12. 1947, mit Appendix ,A').

50 FRUS, 1947/II, S. 250. BA, Z 45 F/OMGUS, 2/102-3/7 (DIAC/Memo(47)227 und 241, 15. und 27. 8. 1947); 2/118-3/10-21 (CORC/P(47)233 und 233/1). 
Dort gab die Sowjetunion im Dezember 1947 noch einmal zu Protokoll, daß sie (wie Frankreich) im Oktober im Koordinationskomitee und im November bei den Deutschland-Stellvertretern in London vergeblich angeregt habe, den Außenministern einen "gemeinsamen Bericht" über die Umsetzung der Moskauer Entscheidungen vorzulegen $^{51}$. Doch hätte der nur aus dem Satz bestehen können, daß nicht über einen einzigen Punkt Übereinstimmung erzielt worden war, geschweige denn über gemeinsame Maßnahmen im Kontrollrat ${ }^{52}$. Der Kontrollrat war damit in allen Punkten gescheitert. Er mußte scheitern, weil er ohne politische Vorgaben der Regierungen bzw. der Außenministerkonferenz nicht von sich aus kompromißfähige Lösungen erarbeiten konnte. So weit reichte die Macht der Militärgouverneure nicht (mehr), daß sie im Jahre 1947 noch entscheidenden Einfluß hätten nehmen können. Die Kontrollratsarbeit wurde zusätzlich dadurch eingeschränkt, daß parallel zu den Versuchen, die Moskauer Direktive umzusetzen, bereits die Vorplanungen für die nächste Konferenz der Außenminister in London eingesetzt hatten. Aufgrund der Erfahrungen von Moskau richteten sich die USA auf ein erneutes, diesmal endgültiges Scheitern ein. Da der Widerstand der Sowjetunion gegen den Marshall-Plan die ökonomische Spaltung Deutschlands und Europas schon in dieser Vorbereitungsphase weiter vertiefte, planten die Angelsachsen im Sommer 1947 zweigleisig: einmal für eine separate Bizonenentwicklung, zum anderen, und das mit deutlich weniger Nachdruck, für die VierMächte-Ebene ${ }^{53}$. Das schränkte die Bereitschaft bzw. die Fähigkeit zum Kompromiß abermals ein, zumal sich die Debatte jetzt mehr und mehr von der wirtschaftlichen auf die politische Ebene verlagerte, obwohl noch in Moskau weitgehend Einigung bestanden hatte, daß realistischerweise letztere nur auf der Grundlage der ersteren möglich war. Doch der Mangel an Konsensfeldern auf der wirtschaftlichen Ebene ließ die Fragen eines Friedensvertrages, einer (provisorischen) deutschen Regierung und einer erweiterten deutschen Selbstbestimmung oder doch Mitwirkung immer mehr in den Vordergrund rücken - als Kampf um die Zustimmung der Deutschen, nicht als Bemühen um eine Lösung zwischen den Alliierten.

\section{b. Die Auflösung Preußens: Staatliche Neuordnung zwischen Dismemberment und europäischer Integration}

Die Auflösung Preußens war mehr als nur eine Frage der politischen Symbolik. Wohl gab es Nachwehen der Dismemberment-Diskussion, der eigentliche Kern war aber die Frage nach der zukünftigen territorialen Organisation deutscher Staatlichkeit und der Ausgestaltung eines deutschen Regierungssystems. Schon die Verknüpfung der beiden Sektionen „Territoriale Reorganisation“ und „Auflösung Preußens“ im Kontrollratsbericht ließ erkennen, daß es weniger um die bloß verwaltungstechnische Gliederung und die vermögensrechtlichen Ansprüche bzw. Verpflichtungen der alten

51 BA, Z 45 F/OMGUS, 2/108-3/4 (CONL/P(47)25, 21. 11. 1947). Zu Frankreich vgl. FRUS, 1947/II, S. 708.

52 BA, Z 45 F/OMGUS, 2/102-3/10 (Lt.Col. Gerhardt, Critique on Studies on the London Conference of the Council of Foreign Ministers, Dezember 1947).

53 BA, Z 45 F/OMGUS, 3/162-1/21 (Litchfield an Bard, 8. 7. 1947). FRUS, 1947/II, S. 887 ff. 
preußischen Provinzen oder der Nachfolgeländer ging, sondern mehr noch um deren Verhältnis untereinander: also um Zentralismus oder Föderalismus ${ }^{54}$.

Die Auflösung Preußens als Alternative zum Dismemberment wurde in Großbritannien seit dem Sommer 1944 diskutiert. Schon der Titel des ersten konkreteren Entwurfs vom 27. November 1944 („Konföderation, Föderation und die Dezentralisierung des deutschen Staates und das Dismemberment Preußens") ließ erkennen, daß das Dismemberment in zunehmendem Maße als föderale Zergliederung des Reiches und Zerteilung Preußens verstanden wurde. Durch die Wiederherstellung der von Preußen 1866/71 inkorporierten historischen Einheiten, durch die Aufwertung der preußischen Provinzen zu Ländern sollte eine Verankerung regionaler Machtpositionen erreicht und die Aufsplitterung in wenig lebensfähige Teilstaaten vermieden werden. Frühzeitig zeichnete sich dabei die Bildung eines neuen Bundesstaates Rheinland-Westfalen als Möglichkeit ab, um eine Ausgliederung des Ruhrgebiets aus dem Reichsverband bzw. die Entstehung eines separatistischen Rheinstaates unter französischem Einfluß zu verhindern, wie es Frankreich seit August 1944 verlangte $^{55}$. Demgegenüber sprachen sich die britischen Militärs für einen Rheinstaat im französischen Sinne aus, der nach dem Ende der direkten Besatzung Deutschlands als Schutzschild Westeuropas dienen konnte, doch wurde diese Vorstellung zugleich durch die Forderung erweitert (und kompliziert), aus diesem Grund eine Beteiligung der Sowjetunion an der militärischen Besetzung und wirtschaftlichen Kontrolle des Ruhrgebiets zu verhindern ${ }^{56}$. Der schwankende Eden, der zeitweise dem französischen RheinstaatsKonzept zuneigte, leitete nach der Konferenz von Yalta dem Armistice and Post-War Committee einen Vorschlag zu, der die Zerteilung Deutschlands in drei oder fünf Staaten vorsah. Neben der Bildung eines Südstaates sollte Preußen im Osten durch Gebietsabtretungen an Polen beschnitten ${ }^{57}$ und - gleich, ob in drei, vier oder fünf Teilstaaten - entlang der Zonengrenze zur SBZ geteilt werden: „Der Hauptzweck einer Zerteilung der östlichen Region wäre es, das alte Preußen, den Hort des deutschen Militarismus, von dem reichen Industriegebiet der Provinz und des Staates Sachsen abzutrennen", in jedem Fall aber vom Rheinland, das der britischen Zone zugeschlagen worden $w^{5}{ }^{58}$. Für den Fall, daß die Teilstaaten in unterschiedliche Interessensphären einbezogen würden, ging man in London stillschweigend davon aus, daß der preußische Militarismus durch sowjetische Transformationsmaßnahmen vernich-

${ }_{54}$ BA, Z 45 F/OMGUS, 2/118-3/10-21 (CORC/P(47)46).

ss Die Ruhrfrage 1945/46, S. $251 \mathrm{ff} ., 290-314$.

56 Steininger, Deutsche Geschichte, Bd. 1, S. 170-86.

57 Bei seinem Besuch in Moskau im Oktober 1944 hatte Churchill zugestimmt, daß ,territory of Poland in west will include Free City of Danzig, the regions of East Prussia, West and South Konigsberg, the administrative district of Oppeln in Silesia and lands desired by Poland to east of line of Oder“. Dazu gehörte die Aussiedlung der Deutschen aus diesen Gebieten, die Repatriierung der Polen aus Deutschland und eine britisch-sowjetische Garantie dieser Veränderungen. TL, Elsey Papers, box 55, folder: Berlin Conference 2 (Churchill an Roosevelt, 18. 10. 1944). Seit 1946 plädierten die USA und England im Interesse der wirtschaftlichen Lebensfähigkeit Deutschlands für eine Korrektur der Oder-Neiße-Grenze zugunsten Deutschlands. NA, RG 59, 740.00119 Control(Germany)/91546 (Report of the Secretary's Policy Committee on Germany, S. 26), /11-446 (Claxton an Hilldring) und /2-1147 (Murphy an Hilldring). FRUS, 1947/II, S. 204 ff. Auch Bevin vertrat am 24. 3. 1947 gegenüber Stalin die Auffassung, man habe die Oder-Neiße-Grenze „too far to the West“ gezogen; ,it might foster an irredentist movement which might lead to an explosive situation in the future“. PRO, FO 800/502/SU/47/24.

s8 PRO, FO 942/66 (APW(45)40, 19.3. 1945). 
tet, die in der liberalen Tradition stehenden Gebiete West- und Süddeutschlands ökonomisch wie politisch in den westeuropäischen Kulturkreis integriert würden. Es waren nicht zufällig die Sozialisten Attlee und Bevin, die neben der Zerschlagung Preußens vor allem auch die Ausschaltung der Schwerindustrie und ihrer Führungselite um jeden Preis forderten. Bevin befürwortete in diesem Zusammenhang eine separate Verwaltung der Ruhr; deutsche Zentralverwaltungen vor dem Abschluß des Dismemberment lehnte er zu diesem Zeitpunkt vehement $a^{59}$.

Frankreich hatte von Anfang an die Zerschlagung Preußens mit seinen radikalen Föderalisierungs-Vorstellungen verknüpft, die einem „de facto Dismemberment“ nahekamen. „Es genügt nicht, Deutschland von Preußen zu trennen [!], man muß PreuBen auseinanderbrechen und es daran hindern, als geschlossene Einheit fortzubestehen.“ Frankreich beharrte auf einer zielgerichteten Förderung „von autonomistischen und selbst separatistischen Tendenzen" wie nach dem Ersten Weltkrieg. Angesichts der britischen Absichten, über eine effektive Vier-Mächte-Kontrolle in Berlin die deutsche Einheit im Grundsatz zu erhalten, blieb das Mißtrauen wach, der Föderalismus sei nur eine Tarnung, um „den Separatismus zu vermeiden und die deutsche Einheit zu erhalten, deren zunächst gelockerte Bande bei der ersten Gelegenheit wieder enger werden" ${ }^{\text {600 }}$. Insofern gab Paris seine Hoffnungen auf eine Abtrennung der Ruhr nicht auf, die Bidault am 25. April 1946 auf der Pariser Außenministerkonferenz erneuerte ${ }^{61}$. Um den französischen Bedenken entgegen- und weitergehenden Hoffnungen zuvorzukommen, begannen die Briten mit dem „Bevin-Plan“ und die Deutschen mit dem „Zuhorn-Plan“ unabhängig voneinander, aber weitgehend übereinstimmend, konkretere Pläne zu entwickeln: Durch die Untergliederung der britischen Besatzungszone in drei neue Länder sollte eine Zwischeninstanz geschaffen werden, die als Träger der Sozialisierung der Ruhrindustrie fungierte und jede direkte sowjetische Einflußnahme mit Hilfe der möglicherweise kommunistisch dominierten Zentralverwaltungen ausschloß. Die Grundsatzentscheidung für die Bildung des Landes Nordrhein-Westfalen fiel am 28. Juni 1946, die Bekanntgabe wurde aber mit Rücksicht auf die Pariser Außenministerkonferenz verschoben ${ }^{62}$.

59 Deighton, Impossible Peace, S. 21. Kettenacker, Krieg, S. 486 ff. Nach Kettenacker (Preußen, S. 332) ging die Idee auf einen Vorschlag Orme Sargents vom 9. 9. 1944 zurück, den Eden am 20.9. aufgriff und der zu dem Memorandum vom 27. 11. führte. Ältere Dismemberment-Vorstellungen von Roosevelt, Churchill und Lord Halifax gingen zumeist von einer Aufteilung des Reiches aus, in der Preußen auf seinen Status von 1864/66 reduziert werden sollte. FRUS, Cairo and Teheran, S. 600. Kettenacker, Preußen, S. 323 ff. Vgl. die Diskussion in PRO, FO 371/46871. Die Ruhrfrage 1945/46, S. 258. In einer extremen Variante hatte das später auch eine „europäische“ Dimension. Sollte Deutschland geteilt werden, bliebe Westdeutschland eine „financial burden“. Um die inneren Ungleichgewichte und äußeren Schwächen zu kompensieren, könnten die Westzonen (,to bolster the Marshall Plan“) an benachbarte Staaten angeschlossen werden: der Süden an Österreich, der Norden (wirtschaftlich oder gar politisch) an die Benelux-Länder, die zusammen mit Skandinavien einen „solid bloc“ bilden würden, die Pfalz eventuell an Frankreich. BA, Z 45 F/OMGUS, 3/1622/11 (Mattusch an Litchfield, 13.9. 1947, mit Kartenbeilage).

60 AMAE, Y 650, Bl. 11 ff. (SGAAA, Document No. 3: Note sur le problème allemand, 19. 7. 1945); auch: Y 282, Bl. $61 \mathrm{ff}$.

61 AMAE, Y 389, Bl. 193 ff. (Note, 15. 1. 1946). FRUS, 1946/II, S. 110, 394 ff., 426 ff. Die Ruhrfrage 1945/46, S. 681 ff. Catroux, Rideau de fer, S. 143: „Si la Ruhr demeurait allemande, nous aurions perdu la guerre."

62 Hüttenberger, Nordrhein-Westfalen, S. $196 \mathrm{ff}$. passim. Först, Nordrhein-Westfalen, S. $81 \mathrm{ff}$., $93 \mathrm{ff}$. Die Ruhrfrage 1945/46, S. 713 ff., $904 \mathrm{ff}$. Vgl. die Diskussion über eine „Decentralization of Germany's Political Structure“ im Umfeld der Pariser Außenministerkonferenz in: PRO, FO 371/ 55843 . 
Zur Vorbereitung dieses Schrittes ergriffen die Briten am 17. Mai 1946 im Kontrollrat die Initiative, um mit dessen Billigung ihr Besatzungsgebiet neu gliedern und derart die formalen Voraussetzungen für die Gründung des Landes Nordrhein-Westfalen schaffen zu können. Ihr Antrag wurde am 12. Juni vom Zivilverwaltungskomitee im Innendirektorat behandelt. Hinter der intensiven Debatte um Verfahrensfragen, ob nämlich die Materie ins Politische Direktorat gehöre, wie der sowjetische Delegierte forderte, oder ob die Verweisung in die Arbeitsgruppe für Regierungsstruktur angemessen sei, wie der amerikanische Delegierte befürwortete, ließen sich die unterschiedlichen Absichten unschwer erkennen. Der britisch-amerikanische Verfahrensvorschlag war darin begründet, daß der britische Gesetzentwurf mit der Auflösung Preußens („zusammen mit seiner Zentral-Regierung und Verwaltung“) den Zonenkommandeuren Handlungsfreiheit für eine politische und nicht nur verwaltungsrechtliche Neugliederung einräumen wollte. Das war der eigentliche Grund für die Sowjetunion, durch eine Revision dieses Entwurfs diese Bestimmung zu Fall zu bringen und nach der „Bereinigung“ die Überweisung an das Politische Direktorat zu fordern. Die drei Westmächte gaben dem insoweit nach, als beide Entwürfe dem Innendirektorat mit der Empfehlung zugeleitet wurden, sich mit dem Politischen Direktorat zum Zwecke der Kompetenzabstimmung ins Benehmen zu setzen. Nachdem sich ersteres ebenfalls nicht einigen konnte, schob es dem Politischen Direktorat die Verantwortung zu. Das erklärte sich zwar einhellig für zuständig, blieb aber handlungsunfähig, da der sowjetische Delegierte im Gegensatz zu seinen Kollegen am 1. August noch immer ohne Anweisungen war. Daraufhin trugen die Briten die Materie direkt in das Koordinationskomitee, da die faktische Auflösung und Neuordnung in der britischen Zone „bereits im Gange“ sei. Als die formelle Zustimmung des Kontrollrats ausblieb, setzten die Briten ihren vorbereiteten Befehl Nr. 46 am 23. August 1946 einseitig in $\mathrm{Kraft}^{63}$.

Im Koordinationskomitee begründete der britische Vertreter sein Drängen mit dem Auftrag des Potsdamer Abkommens, Deutschland zu dezentralisieren und zu demilitarisieren. „Das Überleben des Preußischen Staates, auch wenn nur dem Namen nach, würde die Grundlage für irredentistische Ansprüche bieten, die das deutsche Volk später vorzubringen versuchen könnte, würde militaristische Ambitionen bestärken und das Wiederentstehen eines autoritären, zentralisierten Deutschlands fördern, das es im vitalen Interesse aller zu verhindern gilt." Der Bezug auf das Potsdamer Abkommen und der Appell an das Sicherheitsbedürfnis der Alliierten sollte das eigentliche Ziel dieser Initiative verschleiern, das den französischen und sowjetischen Interessen an der internationalen Ruhrkontrolle zuwiderlief: die Gründung des Landes Nordrhein-Westfalen. Prinzipiell waren, wie Clay am 13. Februar 1947 im Koordinationskomitee feststellte, die Auflösung Preußens und die territoriale Neuordnung Deutschlands nicht miteinander verknüpft, doch in den britischen Vorstellungen war dieser Konnex dominant. Anders als in den Direktoraten legten die Briten daher jetzt nicht nur den Entwurf für ein Kontrollratsgesetz zur Auflösung Preußens vor, sondern

$63 \mathrm{BA}, \quad \mathrm{Z} 45$ F/OMGUS, 2/112-3/1-11 (DIAC/P(46)198, 20.6. 1946); 2/112-1/13-16 (DIAC/ Memo(46)254, 3. 7. 1946); 2/127-1/12-19 (DPOL/M(46)27-30). Steininger, Rhein-Ruhr-Frage, S. $131 \mathrm{ff}$. 
„als Information“ auch den Entwurf ihres Zonenbefehls zur Auflösung bzw. Umwandlung der preußischen Provinzen ${ }^{64}$.

Die Sowjets wiesen den Antrag zurück. Nicht aus prinzipiellen Gründen, wie sie betonten, sondern weil sie das als eine Maßnahme betrachteten, die in die Kompetenz der Außenministerkonferenz, nicht des Kontrollrats falle. Letzterer könne in dieser "wichtigen Verfassungsfrage“, die - wie sie sofort erkannt hatten - über eine reine Verwaltungsmaßnahme hinausgehe, nicht mehr als eine Empfehlung an die Minister aussprechen. Mit ihrer Stellungnahme, die ausdrücklich als Instruktion aus Moskau bezeichnet wurde, hatten sich die Sowjets viel Zeit für eine Grundsatzentscheidung gelassen, wohl auch um Zeit zu gewinnen. Mit unveränderter Argumentation erhielten sie ihren Widerstand im Koordinationskomitee bis zum 17. Februar 1947 aufrecht. Bei der Beratung des Kontrollratsberichts versuchten sie zunächst, im Innendirektorat eine ausführliche Debatte mit dem Hinweis zu verhindern, die Außenminister hätten zu dieser Frage keinen Bericht angefordert ${ }^{65}$. Dann aber schlossen sie sich innerhalb von Tagen den westlichen Vorschlägen an und stimmten am 20. Februar dem Gesetz Nr. 46 zu.

Frankreich bot sich mit der Auflösung Preußens die Chance, erneut den zukünftigen Status der Ruhr zur Diskussion zu stellen, solange die deutsche Frage noch „formbar" war. Das bedurfte zunächst einer internen Klärung des eigenen Standpunkts: Sollte das Ruhrgebiet politisch endgültig vom Reich abgetrennt oder aber dauerhaft einer Vier-Mächte-Verwaltung unterstellt werden? Sollte es, falls es territorial Bestandteil des Reiches blieb, eine separate wirtschaftliche Verwaltung in Form einer internationalen Behörde erhalten, dem neuen Bundesland Nordrhein-Westfalen unterstellt bleiben oder dem Zugriff des zukünftigen Zentralstaats offenstehen? Nach der Gründung der Bizone konnte man in Paris endgültig nicht mehr mit einer Unterstützung der USA für die eigenen Ruhrstaats-Pläne rechnen. Und eine Beteiligung der Sowjetunion an der Kontrolle und Verwaltung des Ruhrgebiets wäre ein zu hoher Preis gewesen, den Frankreich aus prinzipiellen Gründen auch für die Unterstützung in anderen Fragen nicht zu zahlen bereit war. Neue Lösungen waren gefragt.

Allmählich setzte sich in Paris die Überzeugung durch, daß eine Politik des „Poincarisme" nicht mehr genügte, wie sie noch immer von Saint-Hardouin propagiert wurde. Dieser befürwortete - unter Bezug auf das Motto Richelieus, „Deutschland im größtmöglichen Zustand der Desorganisation zu halten“ - eine extreme Dezentralisierung Deutschlands, da „eine nach dem amerikanischen Modell zentralisierte Regierung früher oder später in Deutschland zu einer totalitären Regierung führen würde“. Er empfahl, die festgefahrene Strategie des Status quo im Kontrollrat fortzusetzen und ein „faktisches Protektorat" anzustreben, „ohne den Rückzug von den interalliierten Verträgen auf die Tagesordnung zu setzen" ${ }^{\text {"66 }}$. Ähnlich immanent argumentierte der Oberkommandierende in Baden-Baden, der aus besatzungspraktischen Gründen „eine gewisse wirtschaftliche Vereinigung " Deutschlands für unumgänglich erachtete, aber durch eine komplizierte politische Struktur Gegengewichte zu schaffen forderte. Die Deutschen dürften nicht in die Lage versetzt werden, über föderale Strukturen die alliierte Kontrolle zu unterlaufen; doch müsse Deutschland ökonomisch so lebensfähig

64 BA, Z 45 F/OMGUS, 2/118-2/8-20 (CORC/P(46)266, 8. 8. 1946).

$65 \mathrm{BA}, \mathrm{Z} 45$ F/OMGUS, 2/118-3/10-21 (CORC/P(47)33 und 33, 1st Revise).

66 AMAE, Y 288, Bl. 345 ff. (Bouchacourt/Saint-Hardouin, 26. 10. 1946). 
bleiben, daß in den Ländern keine Zentralisierungstendenzen aufkämen, die - wie seinerzeit über den Zollverein - zu einem neuen Reich führten. Zur Verwirklichung des Balanceaktes wurde anstelle eines zentralisierend wirkenden Wirtschaftsministeriums ein kompliziertes Zuteilungsverfahren im Rahmen eines losen Wirtschaftsrates vorgeschlagen, in dem manche Rohstoffe nach Bundesländern, andere nach Branchen zugeteilt werden sollten, damit jederzeit eine strategische Kontrolle gewährleistet blieb. Zusätzlich wurde über einen „gestuften Föderalismus“ nachgedacht: Drei Konföderationen von West-/Südwest-, Nord-/Mittel- sowie Ostdeutschland sollten als eine weitere Stufe zwischen Länder und Zentrale treten, die durch Verflechtung (des Südens mit der Schweiz, des Westens mit Frankreich) in zusätzlicher Abhängigkeit von den Nachbarn zu halten seien ${ }^{67}$. So diffus und realitätsfern diese Vorstellungen auch sein mochten, sie wiesen doch auf zukünftige Lösungsmodelle voraus, die übernationale Verflechtung der Eisen- und Stahlproduktion in Mittel- und Westeuropa zum politischen Rahmen für die künftige Erhöhung des deutschen Industrieniveaus zu machen $^{68}$. In dem Sinne drängte auch der Generalstab auf konstruktive Lösungen: Angesichts des prekären Gleichgewichts zwischen dem anglo-amerikanischen Block und der Sowjetunion hänge die Sicherheit Europas in erster Linie von dem deutsch-französischen Verhältnis ab. Solange es keine Vereinigten Staaten von Europa gebe, habe Frankreich die Wahl, sich hinter einer „chinesischen Mauer“ vor den Problemen zu verstecken oder über den Friedensvertrag mit Deutschland eine neue Lösung zu suchen, auch wenn gewährleistet sein müsse, daß dieses ökonomisch und personell entmilitarisiert, durch Entautarkisierung mit Westeuropa unlösbar verflochten bleibe. Ohne Kooperation werde es langfristig eine neue deutsche Gefahr geben ${ }^{69}$.

Damit kündigte sich eine Modifikation der französischen Position an: der Übergang von der politischen zur wirtschaftlichen Internationalisierung der Ruhr ${ }^{70}$. Am 17. Januar 1947 wurden diese Vorstellungen in drei Memoranden präzisiert: Die wesentlichen staatlichen Aufgaben und Rechte sollten bei den Ländern verbleiben; die unvermeidliche „Koordination auf der zentralen Ebene“ blieb der alliierten „Lenkung“ (mit deutscher Beratung) vorbehalten; soweit sie deutscher Planung und Exekution „anvertraut" wurden (z. B. bei Ernährung, Landwirtschaft, Transport oder Telekommunikation), kam dem Kontrollrat das Recht zur nachträglichen Billigung zu. Insofern waren keine zentralen Ministerien, sondern lediglich Komitees der Länderminister vorgese-

${ }^{67}$ AMAE, Y 370, Bl. 408 ff. (Filippi an CGAAA, 12. 12. 1946); Y 290, Bl. 166 ff. (CCFA/Cabinet, 18. 12. 1946).

${ }_{68} \mathrm{AN}, 457$ (Bidault) AP 7/Problème allemand (Le Problème Sidérurgique).

69 AMAE, Y 290, Bl. 40 ff. (Etat-Major, 6. 12. 1946). „La neutralisation du potentiel militaire de l'Allemagne sera mise en péril le jour où ce pays deviendrait l'associé de l'un des blocs Atlantique ou Soviétique." Y 292, Bl. $201 \mathrm{ff}$.

$7^{70}$ NA, RG 165/014(Germany)/2-1947 (Smith an Marshall). Weydert, Ruhr, S. 40. Die Briten sahen nur eine Internationalisierung der Verteilung vor, während Frankreich bis zur Londoner Außenministerkonferenz Ende 1947 die Internationalisierung des Managements anstrebte. FRUS, 1947/II, S. 684, 695, 720 ff. Die Franzosen verfochten mit ihrer ständigen Drohung, ohne Zugeständnisse in der Ruhr- und der Kohlefrage würden sie in anderen Fragen nicht mit den Bizonen-Mächten gehen, derart massiv ihre Interessen, daß sie ein Abkommen zwischen den drei Mächten erreichten (,sliding scale"), das ihnen einen „unfair share" an der Ruhrkohle sicherte. AMAE, Y 91, Bl. 88 ff. PRO, FO 371/65020; FO 800/460/Eur/47/1. Bidault glaubte, die Bizonen-Mächte wollten über die Kontrolle der Kohle Frankreich erpressen, „en vue d'obtenir d'elle une acceptation rapide sans réserve de l'unité économique allemande et en tout cas l'acceptation de la fusion des 3 zones occidentales". AMAE, Y 91, Bl. 31. Er bezog sich auf eine Äußerung Marshalls vom 10. 3. 1947. AN, 457 (Bidault) AP 7. 
hen; ebenso kein direkt gewähltes Parlament, sondern eine - nach dem Vorbild des Länderrats der amerikanischen Zone strukturierte - Kammer, „zusammengesetzt aus Mitgliedern, die von den verschiedenen Länderregierungen ernannt werden“. Frankreich beharrte unnachgiebig darauf, „daß die allgemeine Politik Deutschlands vom Kontrollrat bestimmt werden wird"; lediglich die praktische Arbeit, vor allem im Bereich der Wirtschaft, könne durch eine nach Bedeutung gestaffelte Rangfolge entweder von deutschen Zentralverwaltungen oder von Bureaux alliés erledigt werden ${ }^{71}$. Frankreich hatte seine Forderung nach Gebietsabtrennungen an Rhein und Ruhr stillschweigend begraben, wollte aber die extreme Föderalisierung als „de facto Dismemberment" verankern ${ }^{72}$.

Mit Zurückhaltung reagierten die Briten auf den französischen Vorschlag, noch vor der Moskauer Konferenz in Vier-Mächte-Sondierungsgespräche über die zukünftige politische Struktur Deutschlands, deutsche Zentralverwaltungen und die Ruhrkontrolle einzutreten. Sie plädierten für bilaterale Informationsgespräche. In den britischfranzösischen Verhandlungen, die am 17. Februar 1947 in London begannen, prallten die unterschiedlichen Ansätze aufeinander ${ }^{73}$. Die Frage, welches Föderationsmodell sich als längerlebiger, weil für die Deutschen akzeptabler erweisen könnte oder ob die Deutschen beide Lösungsangebote ablehnen würden, war ebenso sekundär wie die Debatte, ob man Sanktionen vorsehen sollte, falls die Deutschen das von den Alliierten festgelegte Verhältnis von Zentralregierung und Ländern einseitig aufkündigten. Die Diskussion über die optimale Organisationsform eines friedlichen und demokratischen Deutschland, sozusagen über dessen verfassungspolitische Entwaffnung, war der Grundfrage untergeordnet, welches Organisationsmodell der Sowjetunion eher nütze bzw. dem Westen abträglicher sei. Die Franzosen sahen eine Rücksichtnahme auf die Sowjetunion für weniger wichtig an, weil es voraussichtlich ohnehin zu einer längeren Teilung Deutschlands kommen werde! Die Briten waren jedoch nicht bereit nachzugeben und hielten an dem neuen Land Nordrhein-Westfalen fest, da sie seit dem Mai 1946 die Föderalisierung Deutschlands als Schutz vor einer kommunistischen Machtergreifung betrieben ${ }^{74}$. Letztlich war die Regierung in London überzeugt, daß Frankreich auf der westlichen Seite stehen werde, auch wenn die prinzipielle Differenz zwischen Staatenbund und Bundesstaat bestehen bleibe, und bemühte sich,

71 AMAE, Y 291, Bl. 152 ff. (Mémorandum relatif à l'organisation provisoire de l'Allemagne, 17. 1. 1947). Anfang 1947 stellte die GFCC die „economic unification“ über die politische und verlangte deutsche Zentralverwaltungen: „The Allied Control Authority must be enabled to concentrate on major policy decisions und overall control functions." Die Routinearbeit müsse deutschen Experten überlassen bleiben. Im folgenden wurde über die Beziehungen zwischen Kontrollrat und Zentralverwaltungen im Falle der Existenz bzw. Nichtexistenz einer Zentralregierung nachgedacht, wurden Organisationsschemata für die verschiedenen Zentralverwaltungen entworfen. NA, RG 43/ WWII\&PWConf, box 186, folder: Central German Administrative Agencies (CGAA. The Need for Central German Agencies, 21 S., ca. Anfang 1947). Im August 1947 wurden im Bereich der Landwirtschaft deutsche Zentralorgane abgelehnt, „qui posséderaient renseignement à réserver aux Autorités Alliées“, dafür „organismes communs“, „Laboratoires de Contrôle“ oder „Bureaux de Vérifications" vorgeschlagen. AO, Berlin/3270/1/2309 (25.8. 1947).

72 AMAE, Y 296, Bl. 149 ff. Botschafter Massigli nannte als Vorbild die Konstruktion des österreichungarischen Kaiserreichs; dort habe jeder Landesteil sein eigenes Parlament und seine „Delegierten" im Wiener Zentralparlament gehabt. PRO, FO 371/64243/C3063 (24. 2. 1947).

73 PRO, FO 371/64243.

74 Die Ruhrfrage 1945/46, S. 718. Frankreich hätte einen kleineren Ruhrstaat und ein größeres Rheinland vorgezogen, ersteres mit, letzteres ohne alliierte Besatzung. PRO, FO 371/64243/C2935 (Massigli, 17. 2. 1947). 
Frankreich vor Augen zu führen, daß es mit seinen Vorschlägen zu sehr auf Sicherheit vor Deutschland fixiert sei und zu wenig die gesamteuropäische Lage, die sowjetischen Absichten, die Haltung der Deutschen zwischen den konkurrierenden Blöcken und die ökonomische Effizienz in Rechnung stelle ${ }^{75}$.

Auch wenn Frankreich mit seinen Forderungen scheiterte, so konnte es doch der weiteren Entwicklung ruhig entgegensehen, da es in Moskau keinesfalls eine Einigung zwischen Briten und Sowjets zu seinen Lasten geben würde. Denn Bevin war lediglich zu marginalen Zugeständnissen bei der politischen Organisation oder dem Wahlrecht bereit, ,um die russische Zustimmung zu wichtigeren Fragen zu sichern“; er blieb indes äußerst zurückhaltend gegenüber allen Vorschlägen für eine „mächtige Zentralregierung“. Man müsse den Russen klarmachen, daß Deutschland selbst mit einer kommunistischen Regierung für die Sowjetunion eine Gefahr darstelle. Bereits im September 1946 hatte er vom Kabinett die Billigung für eine Direktive an die CCG erhalten, die im Hinblick auf die New Yorker Außenministerkonferenz nicht nur eine Bestandsaufnahme der zonalen Entwicklung einforderte, sondern zugleich den Zonenkommandeur anwies, durch eine Beschleunigung laufender Maßnahmen, z. B. der Dezentralisierung, der Länderbildung oder der Übertragung von Verwaltungsaufgaben an die Deutschen, vollendete Tatsachen zu schaffen ${ }^{76}$. Das Overseas Reconstruction Committee drängte unter seinem Einfluß auf eine weitere Stärkung der dezentralen Elemente in den britischen Planungen, um - ergänzt durch eine europäische Kontrolle des Verkehrssystems - ein Gegengewicht gegen die zentralistischen Tendenzen einer eventuellen Behandlung Deutschlands als Wirtschaftseinheit zu schaffen. Das schloß neben den traditionellen britischen Forderungen nach gleichmäßiger Verteilung aller Ressourcen und einem Export-Import-Plan auch interimistische Zentralverwaltungen ein, die aber als Übergangsmaßnahme bis zur Einsetzung einer deutschen Regierung nur akzeptabel seien, wenn sie „die sowjetische Zone penetrieren und wirklich ganz Deutschland einschließen ${ }^{477}$. Während die zentralistischen Elemente der Öffnung der SBZ dienen sollten, war die Dezentralisierung als Schutz vor sowjetischer Einflußnahme bzw. vor kommunistischer Unterwanderung gedacht. Indem für das Ruhrgebiet weiterhin die Ländersozialisierung, aber keine Internationalisierung nach französischem Wunsch vorgesehen war, wurde der Sowjetunion eine Kompensation für die Öffnung der SBZ durch Beteiligung an der Ruhr-Kontrolle ebenso verweigert wie auch die Einflußnahme der zukünftigen, möglicherweise unter kommunistischem Einfluß stehenden, deutschen Zentralregierung: Das lief sehr gezielt auf eine „Revision von Potsdam“ hinaus ${ }^{78}$.

75 PRO, FO 371/64362/C1137 (22. 1.-6. 2. 1947).

76 PRO, FO 800/466/Ger/46/31 (Directive for Commander-in-Chief on Policy to be pursued in British Zone in anticipation of Meeting of Council of Foreign Ministers on Germany in November, 6. 9 . 1946).

77 PRO, FO 371/64243/C1099 (Hall-Patch, 18. 1. 1947), C2935 (17. 2. 1947), C2950 (Playfair an Dean, 19. 2. 1947; Wilson 22. 2. 1947). NA, RG $165 / 014$ (Germany)/2-1947 (Gallmann an Marshall).

${ }_{78}$ PRO, FO 371/64243/C3248 (ORC(47)2, 24. 2. 1947); FO 944/761 (Draft Revision of the Potsdam Agreement). Der Entwurf, am 31.3. 1947 der Moskauer Konferenz vorgelegt, in: Docs. Int. Aff., 1947/48, S. 453-62. Bevin deklarierte die Revision als „supplementary principles“, die „not constitute revision of Potsdam Agreement but contain certain additions and clarifications necessary in view of experience and are designed to provide firm basis of quadripartite agreement and to define more clearly points on which Germans can reconstruct their political and economic life". NA, RG 59, 740.00119 Council/4-1447. Deighton, Impossible Peace, S. $115 \mathrm{ff}$. 
Ganz in diesem Sinne bot Bevin in Moskau Stalin an, sollten Wirtschaftseinheit und Zentralverwaltungen zustande kommen, „würden wir zulassen, daß die Produktion und Verteilung aller Güter an der Ruhr durch deutsche Zentralverwaltungen unter alliierter Aufsicht geregelt wird, ebenso“ - das meinte die chemischen oder agrarischen Produkte der SBZ - „wie die Produktion und Verteilung aller anderen Güter überall in Deutschland als Ganzem“. Doch galt es, eine zusätzliche Sicherung gegen sowjetische Einfluß- und Eingriffsmöglichkeiten, konkret das Vetorecht des Zonenkommandeurs, einzubauen; „solange alliierte Beamte in der Lage sind, in die Kette deutscher Verantwortlichkeit einzugreifen, kann die Wirtschaftseinheit immer noch vereitelt werden.“ Gleichwohl durften die Zentralverwaltungen ,aus Sicherheitsgründen" nicht wie im sowjetischen Modell starke zentralistische Elemente enthalten, die Bevin gegenüber Molotow offen als „an Hitlers Methoden erinnernd“ bezeichnete. Dieses Sicherheitsdenken bezog sich, anders als bei den Franzosen, inzwischen mehr auf die sowjetische als auf die deutsche kommunistische Gefahr ${ }^{79}$. Gleichzeitig wurde intern empfohlen, durchaus konsequent, die Bizone durch „engere Verschmelzung und Integration“ zu festigen, z. B. durch räumliche und fachliche Konzentration der deutschen Behörden, „von deren Arbeit und Kooperation wir abhängig sind, wenn die Verschmelzung ein Erfolg sein soll“. Dabei wurde in Kauf genommen, daß eine Verknüpfung zentralistischer Organisation im eigenen Herrschafts- und Einflußbereich mit einer föderalistischen Struktur in ganz Deutschland eher trennend als vereinend wirkte, da „diese Schritte die schließliche Vier-Mächte-Einigung zweifellos sehr viel schwieriger machen werden“. Bevin wußte im Grunde längst, daß ein papierener Kompromiß über die politische Struktur nutzlos war, da nicht mit den divergierenden Vorstellungen zur Wirtschaftseinheit kompatibel, zumal wenn die Sowjetunion als Einstandspreis noch einen Teil der westlichen Defizite für Importe nach Deutschland übernehmen sollte. Die Briten sahen sich in einer Notwehrsituation, solange die Wirtschaftseinheit nicht realisiert war; und sie wußten, daß die Sowjetunion diese Bedingungen nicht akzeptieren konnte. Die gern (zumindest nach außen) gepflegte Illusion, der Erfolg der Bizone werde die Sowjetunion doch noch zum Einlenken veranlassen, legitimierte den Entschluß, in Moskau nicht unbedingt eine Lösung suchen zu wollen ${ }^{80}$.

Es war nicht erst in Konkurrenz zu Molotows aufsehenerregendem Statement vom 10. Juli 1946 auf der Pariser Außenministerkonferenz, daß Byrnes in seiner Stuttgarter Rede die „Vereinigung“ Deutschlands in den Vordergrund rückte. Es entsprach vollauf der amerikanischen Ausgangskonzeption wie ihrer Bizonenpolitik, zunehmend Verantwortung auf die Deutschen zu übertragen und den Kontrollrat vom Regierungs- zum Kontrollorgan zu machen ${ }^{81}$. Ende Juni 1946 begannen die USA mit ihren

79 PRO, FO 800/502/SU/47/24 (25. 3. 1947); CAB 21/1874 (Bevin, 8. 4. 1947). Kessel, Westeuropa, S. 210 .

${ }^{80}$ PRO, FO 371/65052 (Makins an Hall-Patch, 9. 4. 1947).

81 NA, RG 59/ASSOA, box 2, folder: Currency Reform (David Harris, Policy Statement on Germany [2. Entwurf], an Rudlin und Gross übersandt von Kindleberger, 26. 6. 1946); RG 59, 740.00119 Control(Germany)/7-146 (Claxton an Hilldring); RG 59/CED, box 2, folder: G 710 (David Harris, Plans for Reconstruction of Central German Government, 8. 7. 1946). Am 15. 3.1946 war das interdepartmentale Litchfield-Committee bei OMGUS/CAD gegründet worden, „[to] prepare plans for several aspects of governmental organization in Germany“. Dessen Vorstellungen wurden mit denen eines britischen Pendants vom 10.-31.7. im Hinblick auf eine bi- oder trizonale Fusion diskutiert. RG 59/ASSOA, box 1, folder: Bipartite Organization (Gantenbein an Murphy, 4. 9. 1947). 
Überlegungen für eine Sonderkonferenz über Deutschland. Da zunächst erhebliche Unsicherheit über die Grundlinien des möglichen Kompromisses mit der Sowjetunion bestand, ob Friedensvertrag oder neues Kontrollabkommen, ob von den Deutschen erarbeitete oder von den Alliierten oktroyierte Verfassung, ob föderales oder zentralistisches Prinzip ${ }^{82}$, wurde am 31. Juli ein Komitee für Deutschlandpolitik beauftragt, die Ziele der USA zu definieren, Vorschläge für die nächste Außenministerkonferenz zu entwickeln und eine neue Direktive für OMGUS vorzubereiten ${ }^{83}$. Als langfristige Ziele der Deutschlandpolitik wurden vom Komitee - wenngleich teilweise durch Byrnes' Stuttgarter Rede korrigiert und überholt - vier Punkte formuliert: „ein neutrales Deutschland, eines, das effektiv entwaffnet ist, ein Versprechen zur Gesundung sowohl für Deutschland als auch für Europa und die Entwicklung einer kraftvollen deutschen Demokratie“. Diese Ziele seien möglichst im Einvernehmen mit der Sowjetunion zu realisieren, so daß ein neuer, letzter Anlauf empfohlen wurde. Bis zum Abschluß eines Friedensvertrages sollte dem Kontrollrat die Aufgabe zukommen, zum einen die Entmilitarisierung durchzuführen, zum zweiten die Wirtschaftseinheit und den Wiederaufbau einvernehmlich zu koordinieren, entweder durch Zentralverwaltungen, falls die Sowjets das wünschten, oder durch einen „reichsweiten Länderrat“ beim Kontrollrat nach dem Vorbild der amerikanischen Zone. Für ein solches Programm, das die Revision des Industrieniveauplans und eine Regelung der Reparationsfrage einschloß, wurden in Molotows Statement vom 10. Juli Anknüpfungspunkte gesehen. Eine Lösung, die hinter den Stand der Bizone zurückfiel, war jedoch nicht mehr akzeptabel ${ }^{84}$. Nahm die Sowjetunion das Angebot nicht zu „vernünftigen“ Bedingungen an, war der westliche Alleingang unvermeidlich. Vor einem Rückzug der Alliierten mußten jedoch Sicherheiten geschaffen werden, die die Friedensfähigkeit Deutschlands garantierten: von außen durch den Byrnes-Plan, im Inneren durch einen föderalen Staatsaufbau ebenso wie durch eine ausgewogene Wirtschaftsstruktur. Dabei war eine sowjetische Beteiligung an der internationalen Ruhr-Kontrolle anfangs nicht ausgeschlossen, ebensowenig ein Arrangement in der Reparationsfrage: als Voraussetzung und Ergebnis einer einvernehmlichen Besatzungspolitik. Eine Abtrennung der Ruhr wurde jedoch von Beginn an abgelehnt ${ }^{85}$.

Bereits Byrnes war von einer derart konzilianten Position abgerückt. Der Ausgleich mit der Sowjetunion galt noch immer als wünschenswert, doch rückte eine rein westeuropäische Lösung zunehmend in den Vordergrund der Überlegungen. Das fand lebhafte Unterstützung bei den Militärs, die die Ruhr weder Deutschland noch Frank-

82 NA, RG 59, 740.00119 Control(Germany)/7-1146 (O'Sullivan an Hilldring), /7-1646 (Cramer an Hilldring), /7-1546 (Kindleberger an Riddleberger); RG 59/ASSOA, box 1, folder: 010.1/214(Germany) (Hilldring an Riddleberger, 22. 7. 1947).

${ }^{83}$ Der 37-seitige Abschlußbericht in: NA, RG 59, 740.00119 Control(Germany)/9-1546; RG 59/CED, box 2, folder: G 710 (31. 7. 1946). Vgl. oben S. 156 mit Anm. 26.

${ }^{84}$ Zur Diskussion in OMGUS Kindleberger, Letters, S. 57, 59, 64 f. Henry Parkman (CAD) lehnte im März 1947 Zentralverwaltungen ab. „Experiences of American Military Government in connection with ACC direction of the conduct of government, and, more especially, experience in Berlin make any set-up of central agencies operating directly under ACC direction most unpromising. It is to be feared that such agencies would be unable to take even the most vital decisions. The present deadlock would, in other words, continue with a German adjunct to complicate matters and deprive the zone commanders of their freedom of action. In effect, we would substitute inoperative central agencies for operating bizonal agencies." NA, RG 43/WWII\&PWConf, box 192, folder: US Proposal on Central German Government.

85 Endgültig legte sich Marshall gegen eine Abtrennung in Moskau fest. FRUS, 1947/II, S. 326. 
reich oder der Sowjetunion zur alleinigen Kontrolle überlassen wollten. Sie befürworteten frühzeitig eine europäische Lösung, ohne konkrete Organisationsmodelle zu benennen ${ }^{86}$. Insofern tendierten auch die USA zu einer Kontrolle der Ruhr durch das Land Nordrhein-Westfalen; das werde das föderale Element stärken und das wirtschaftliche Potential leichter einem „gesamteuropäischen“ Zugriff eröffnen. Sie plädierten für eine internationale Überwachungskommission nach dem Ende der Besatzung, an der die Sowjetunion beteiligt werden sollte, aber wohl nur, um auf diesem Wege für die USA einen vergleichbaren Anspruch zu begründen. Doch durfte, darin bestand Einigkeit mit den Briten, in all diesen Konstruktionen die föderale Dezentralisierung nicht zu weit vorangetrieben werden, etwa im französischen Sinne, da im Falle einer weitgehenden Unabhängigkeit der neuen Länder von der Zentralregierung eine „russisch geförderte Irredenta“ entstehen könnte ${ }^{87}$.

Damit standen drei Modelle für die zukünftige Gliederung der (provisorischen) politischen Struktur Deutschlands zur Diskussion: ein Bundesstaat nach anglo-amerikanischem Vorschlag, ein Staatenbund nach französischem Wunsch sowie ein „dezentralisierter Einheitsstaat“ nach den Vorstellungen der SED, der an den ersten Entwürfen für die Weimarer Verfassung vom Dezember 1918 orientiert war. „Eine überzentralisierte deutsche Regierung“, so warnte Stalin, werde „die Errichtung eines Großdeutschland anstreben“, eine Föderalisierung komme dagegen einem „Dismemberment" gleich; Napoleons entsprechende Versuche hätten letztlich zu Bismarck, Militarismus und Krieg geführt! Die Zentralregierung müsse „über“ den Ländern stehen, nicht zuletzt aufgrund ihrer Zuständigkeit für die Reparationslieferungen ${ }^{88}$. Die Sowjetunion konnte sich aber dem Zwang nicht entziehen, mit der Entwicklung in den Westzonen Schritt halten zu müssen und diese damit nachträglich zu legitimieren, nachdem sie vergeblich gegen die Bildung der Kunstländer Nordrhein-Westfalen am 23. und Rheinland-Pfalz am 30. August 1946 protestiert hatte, die ihr die „Vorbereitung zur Aufteilung Deutschlands nach föderalen Prinzipien“ signalisierte ${ }^{89}$. Zwar verzichtete sie nach Diskussionen innerhalb der SMAD gegen die Empfehlung des Politischen Beraters Semjonow darauf, einen Zonenrat für die SBZ und ein Exekutivkomitee dieses Rates einzusetzen, doch wurden vom 3. bis 12. Dezember 1946 Pro-

86 FRUS, 1946/II, S. 486 ff. (Patterson an Byrnes, 11.6. 1946).

87 NA, RG 59, 740.00119 Control(Germany)/2-547 (Rudlin an Claxton). Zu den Versuchen der USA, zwischen britischen und französischen Vorstellungen zu vermitteln, vgl. AMAE, Y 296, Bl. $149 \mathrm{ff}$. (Saint-Hardouin, 27. 10. 1947).

88 FRUS, 1947/II, S. 342 (Stalin, 15. 4. 1947). Im Juni 1946 „karikierte“ Pieck die westlichen Föderalismus-Vorstellungen als „Aufteilung, Staatenbund und Zollverein“. NA, RG 59/Bohlen, box 2, folder: Correspondence - Murphy's Office (POLAD/Trivers an Riddleberger, 27.6. 1946). In der SMAD war die Föderalismus-Frage im Herbst 1946 umstritten. Laufer, Ursprünge, S. 152 f. (mit Anm. 24). Am 31. 1. 1947 lehnte Stalin den Föderalismus gegenüber der SED ab, „weil dieser [die] Schwächung Deutschlands bedeutet" und den ökonomischen Interessen der USA entgegenkomme. Badstübner, Beratungen, S. 108. In Moskau wußte man „damals wenig von den Differenzen zwischen CDU und SPD, von [...] ihren unterschiedlichen Standpunkten zu einem föderalistischen oder zentralistischen Staatsaufbau“. Tjulpanow, Deutschland, S. 300. Tjulpanow fragte sich indes bereits im Juli 1947, „ob Föderalismus besser als Spaltung in zwei Teile“. Badstübner/Loth, Pieck, S. 128. 1950/51 akzeptierte die Sowjetunion einen deutschen Föderalismus, um im Falle der Wiedervereinigung eine Koexistenz kapitalistischer und sozialistischer Bundesstaaten aufrechterhalten zu können. AMAE, Eu(1944-60)Généralités/137, Bl. $60 \mathrm{ff}$.

89 BA, Z 45 F/OMGUS, 2/134-2/10-13 (Section VIII). 
vinzial- und Länderregierungen gebildet, mit einer begleitenden Verfassunggebung ${ }^{90}$; die Umwandlung der preußischen Provinzen Sachsen-Anhalt und Mark Brandenburg in Länder wurde erst mit Befehl Nr. 180 vom 21. Juli 1947 vollzogen. Im Hinblick auf eine mögliche Einigung der Außenminister in Moskau war die Sowjetunion auf Strukturangleichung bedacht, um mit dem Konsolidierungsprozeß in der Bizone Schritt zu halten ${ }^{91}$. Sie konnte nun auf Länderebene den Westzonen gleichartige Organe entgegensetzen, ohne im Vorfeld der Konferenz den westlichen Vorstellungen einer Föderalisierung Vorschub zu leisten, die sie als „Zersplitterung“ bekämpfte, mit deren Hilfe - wie Molotow am 17. März kritisierte - die Briten die Ruhr, die Franzosen die Saar und die Anglo-Amerikaner die Bizone einseitig dem Kontrollrat und damit dem sowjetischen Reparationsanspruch entzogen hätten ${ }^{92}$. Erst nach dem Marshall-Plan öffnete sich die Sowjetunion föderalen Organisationsmodellen: als Angebot an die Deutschen, um die Konsolidierung der Bizone durch ein Eingehen auf westliche Strukturvorstellungen zu verhindern bzw. deren Wiederauflösung zu erreichen und um der Einbeziehung des westdeutschen Potentials in den „Westblock“ einen Riegel vorzuschieben ${ }^{93}$.

Auf der Moskauer Außenministerkonferenz geriet die Deutschlanddebatte rasch an den Punkt, an dem die mögliche Struktur einer ,provisorischen politischen Organisation Deutschlands“ angesprochen werden mußte. Marshall schlug die Bildung eines Länderrats vor, unter dessen Ägide eine Verfassung zu erarbeiten sei, die eine ausgewogene Machtbalance zwischen Zentralregierung und Ländern gewährleiste. Der Kontrollrat solle einen Plan zur Errichtung des Länderrats erarbeiten, der dessen Verhältnis zu den Zentralverwaltungen und die Stellung des Kontrollrats zur provisorischen Regierung definiere. Dieser „Plan“ müsse keine Verfassung sein, eher eine „Charta an das deutsche Volk“, also eine Art Rahmenvorgabe. Ähnlich wollte Bevin nach Rahmensetzung durch den Kontrollrat es den Deutschen überlassen, eine Verfassung zu erarbeiten, die von diesem zu genehmigen sei. Auch er favorisierte die stufenweise Übertragung der politischen Verantwortung, zunächst unter alliierter Kontrolle, von unten nach oben. Die deutsche Zentralregierung, darin war er präziser, würde in der ersten Phase ,unter völliger Kontrolle des Kontrollrats“ stehen, dem in der zweiten Phase nur noch ein nachträgliches Vetorecht zukommen sollte ${ }^{94}$. Wäh-

90 Am 6. 2. 1946 hatte Stalin der SED angedeutet, daß er nicht für die Bildung von mehreren Landtagen, sondern für einen „zentralen Landtag“ in der SBZ eintrat. Badstübner, Beratungen, S. 106.

91 Semjonow unterstützte Bestrebungen der SED, die mit dem Angebot der Erfüllung der Reparationsforderungen auf dem Wege zur separaten Oststaatsbildung voranzuschreiten hoffte. Vgl. oben S. $407 \mathrm{f}$.

92 Docs. Int. Aff., 1947/48, S. 429, 450.

${ }^{93}$ FRUS, 1947/II, S. 396, 419. NA, RG 165/014(Germany)/2-1947 (Smith an Marshall).

94 Das entsprach den Empfehlungen des Deutschlandkomitees im State Department vom 15. 9. 1946. Da die Vier-Mächte-Kontrolle Deutschlands für „eine lange Zeit“ bestehen werde, sollten die Deutschen unter der Aufsicht des Kontrollrats zunehmend Verantwortung übernehmen, indem sie "durch eine vorläufige Vereinigung in der Kontrollratsperiode mittels Konföderierung der Länder Regierungen und einen Länderrat bilden, der die Zentralverwaltungen lenkte, wie sie das Potsdamer Abkommen vorsah". Im Friedensvertrag würde sich Deutschland alliierten Sicherheitskontrollen gemäß dem Byrnes-Plan unterwerfen, der Kontrollrat im Rahmen eines „Vier-Mächte-Inspektionssystems“ rudimentär als „Kontrollkommission“ weiterbestehen. „In der Kontrollratsperiode können zweifellos Anpassungen vorgenommen werden, um der russischen Auffassung entgegenzukommen, wenn die Sowjets es ernst meinen mit ihren Forderungen nach einer Zentralregierung. Obwohl ein reichsweiter Länderrat das natürliche Ergebnis der derzeitigen Entwicklung in der amerikanischen Zone wäre, könnten wir zustimmen, wenn die Russen Zentralverwaltungen bevorzugen, die direkt 
rend (politische) Zentralverwaltungen für die Anglo-Amerikaner bestenfalls eine Übergangslösung waren, wollte Bidault, wieder einmal „unverbindlich“, höchstens wirtschaftliche Zentralverwaltungen zugestehen. Molotow forderte nicht allein die Einrichtung von Zentralverwaltungen und einer provisorischen Regierung, sondern wollte auch dem Kontrollrat die Ausarbeitung einer Verfassung (nach Weimarer Vorbild, allerdings ohne starken Präsidenten) übertragen, unter Heranziehung eines deutschen Beirates, dem auch die Massenorganisationen angehörten. Er lehnte den britischen Vorschlag eines bloß nachträglichen Vetorechts des Kontrollrats kategorisch ab, weil ein solches die Einigkeit der Alliierten voraussetze, also die Sowjetunion ihres Vetorechts beraubt hätte ${ }^{95}$. Molotows wichtigstes Argument für eine starke Zentralregierung war deren Fähigkeit, neben der Entmilitarisierung durch Transformation und „Demokratisierung“ auch „die bedingungslose Erfüllung der deutschen Verpflichtungen gegenüber den alliierten Staaten“ sicherzustellen, d. h. die Reparationen. Er ließ sich von dem Angebot der Westmächte nicht umstimmen, daß der Kontrollrat die Ausführung dieser Verpflichtungen gewährleisten werde. Während die Westmächte der Zentralregierung nur die Rechte belassen wollten, die ausdrücklich nicht den Ländern vorbehalten waren, sahen die sowjetischen Vorstellungen bei der Zentralregierung auch „die Verantwortung gegenüber den alliierten Mächten, die Staatssicherheit zu garantieren“, also ein polizeiliches Interventionsrecht vor. Insgesamt war Molotow hinter sein Statement vom 10. Juli 1946 zurückgegangen, indem er die Bildung einer deutschen Regierung jetzt auf die lange Bank zu schieben suchte ${ }^{96}$.

Nach dieser Vorabklärung der prinzipiellen Standpunkte im Hinblick auf die Bildung und Organisation einer provisorischen deutschen Regierung kam eine intensive Beratung des Verhältnisses zwischen einer solchen und dem Kontrollrat erst gar nicht zustande. Denn das hätte den Kern eines Friedensvertrages ausgemacht. Trotzdem hatte sich sowohl in den amerikanischen Vorschlägen ${ }^{97}$ als auch in französisch-sowjetischen Gesprächen am 20. Februar 1947 die Vorstellung abgezeichnet, daß der Kontrollrat auf seine eigentliche Funktion reduziert werden sollte: die Kontrolle der in der alliierten wie der deutschen Diskussion neue Bedeutung gewinnenden Zentralverwaltungen oder gar einer provisorischen Regierung. Molotow reagierte nicht ablehnend auf die französische Vorstellung, einen Staatenbund mit „einer koordinierenden Regierung“ einzurichten, die jedoch „für lange Zeit [...] vom Kontrollrat der Vier gebil-

unter der Anleitung des Kontrollrats von Berlin aus arbeiten." NA, RG 59, 740.00119 Control(Germany)/9-1546 (Report, S. 12, 36). Botschafter Douglas griff die Überlegung auf, die punktuellen Kontrollen des Byrnes-Plans durch eine erweiterte Vier-Mächte-,,Kontrollkommission“ zu ergänzen, deren Aufgaben sich auf den Bereich der wirtschaftlichen Entmilitarisierung, der Ruhrkontrolle u.ä.m. erstreckten. FRUS, 1947/II, S. 676 ff. (2.6. 1947). Auf eine Re- bzw. Neukonstruktion des Kontrollrats zielten die Forderungen der kleineren Alliierten, deren Stellungnahmen die Deutschland-Stellvertreter seit der New Yorker Konferenz eingeholt hatten. Diese forderten fast einhellig, die alliierte Kontrolle aufrechtzuerhalten, eventuell durch eine Kontrolle der Ruhr zu ersetzen oder zu ergänzen. Während einige westliche Staaten nach dem Vorbild Japans eine Ergänzung des Kontrollrats durch ein beratendes Gremium anregten, betonten die östlichen Länder stärker die strikte Überwachung durch den Kontrollrat. FRUS, 1947/II, S. 40-104.

${ }^{95}$ Das war das österreichische Modell, dessen Brisanz die Sowjets zu spät erkannt hatten. Vgl. unten S. 494 Anm. 18.

96 FRUS, 1947/II, S. 271 f., 277 f., 304 ff., 318. Die Einsetzung eines deutschen Verfassungsausschusses unter Aufsicht des Kontrolirats hatte Clay im Juli 1946 vorgeschlagen, ebenso die wichtigsten Verfassungsprinzipien. NA, RG 59, 740.00119 Control(Germany)/7-2646. CP, S. 236 ff., 240 f. Die sowjetischen Vorschläge in: Um ein antifaschistisch-demokratisches Deutschland, S. $448 \mathrm{ff}$.

${ }^{97}$ FRUS, 1947/II, S. 201 ff., 223 ff. (OMGUS), 409 ff., 452 ff. Germany 1947-49, S. 179 ff., 444 f. 
det sein muß“: „Der Kontrollrat [kann] weiterhin die Rolle der Zentralmacht behalten." Allerdings wich er der Frage aus, ob die Grundstruktur des deutschen Staates zentral oder föderal organisiert sein sollte, sondern stimmte pauschal der Frage des französischen Botschafters zu, daß „wir uns einig [waren], die (wirtschaftliche) Einheit unter der Hoheit des Kontrollrats zu verwirklichen“. Nach den vorangegangenen Gesprächen war jedoch zu erwarten, daß die Sowjetunion im Interesse der zonalen Kontrolle und der Reparationsentnahmen jede weitreichende Föderalisierung aus Angst vor einer Spaltung und der Einbeziehung der Westzonen in eine antisowjetische Front ablehnen würde ${ }^{98}$. Die schließlich erreichte Grundsatzeinigung blieb ein hohler Formelkompromiß. Zentralverwaltungen konnten nicht „in der kürzestmöglichen Zeit" errichtet werden, solange die Franzosen auf den Bureaux alliés ebenso beharrten wie auf der Saar-/Ruhr-Klausel und die Sowjets auf dem Vetorecht des Zonenkommandeurs bestanden. Beide Vorbehalte waren für Briten und Amerikaner inakzeptabel, auch wenn sie sich den französischen Organisationsvorstellungen annäherten und die Zentralverwaltungen unter der Leitung von Staatssekretären durch „Vollzugsausschüsse" aus Ländervertretern zu ersetzen bereit waren. Das entwertete von vornherein den weiteren Beschluß, drei Monate nach Einsetzung der Zentralverwaltungen einen deutschen (Verfassungs-)Beirat zu bilden, da die skeptischen Franzosen diesen ersten Schritt jederzeit verhindern konnten. Es war daher ohne Bedeutung, daß dem Beirat gewisse Beratungsrechte im Hinblick auf die „allgemeinen Aspekte“ der Arbeit der Zentralverwaltungen übertragen werden sollten, da die sowjetische Forderung nach Einbeziehung der Massenorganisationen von allen Westmächten prinzipiell abgelehnt wurde. Insofern war es unerheblich, daß keine Übereinstimmung erzielt wurde, ob das Verhältnis von föderalen und zentralen Elementen in der auszuarbeitenden Verfassung von den Alliierten vorgegeben oder, so die Sowjets, von den Deutschen durch Plebiszit entschieden werden sollte" ${ }^{99}$.

Mit dieser Forderung nach einem Plebiszit brachten die Sowjets einen Faktor ins Spiel, der bei den bisherigen Kontroversen im Kontrollrat von allen vier Besatzungsmächten stets übereinstimmend ausgeklammert worden war: die Deutschen. Allerdings weniger als potentielle Verhandlungspartner des Kontrollrats oder gar der Außenministerkonferenz denn als Instrument, die Blockade des Kontrollrats von außen zu überwinden. Auf diesen Vorstoß hatte man sich in der SBZ bereits im Vorfeld der Moskauer Außenministerkonferenz vorbereitet. Die SED und parallel die anderen Blockparteien hatten eine Initiative „von unten“ zugunsten von Reichseinheit und Friedensvertrag gestartet, die die Massenorganisationen einschloß. Demgegenüber war Clay noch immer eher zurückhaltend gegenüber deutschen Initiativen eingestellt und sah die Aktivitäten der Ministerpräsidenten als störend an, weil sie die alliierten Bemühungen beeinträchtigten ${ }^{100}$. Aber es ließ sich allein aus taktischen und propagandistischen Gründen gar nicht länger vermeiden, die Deutschen in diese interalliierten Auseinandersetzungen einzubeziehen.

98 AN, 457 (Bidault) AP 61/VI (Saint-Hardouin, 19. 1. 1947; Botschaft Moskau, 2. und 20. 2. 1947). PRO, PREM 8/791 (C.P.(47)88, Bevin, 20. 2. 1947).

99 FRUS, 1947/II, S. 311-15, 318, 411, 436-46. Erneut überlegten Mitglieder der amerikanischen Delegation, ob man Zentralverwaltungen für drei Zonen ohne Frankreich bilden sollte; doch glaubte im Grunde niemand an die sowjetische Zustimmung zu einer solchen Lösung. NA, RG 59, 740.00119 Control(Germany)/2-1147 (Murphy an Hilldring).

${ }_{100}$ Piontkowitz, Anfänge, S. 38. 
Diese hatten sich angesichts der britischen Vorstöße zur Auflösung Preußens und der Neugliederung ihrer Besatzungszone in dieser wie in der amerikanischen Zone im Sommer 1946 mit Fragen der „Reichsreform“ befaßt. Im August/September 1946 trafen sich zwei Initiativen. Der hessische Ministerpräsident Geiler wollte, auf amerikanisches Drängen ${ }^{101}$, zu einer Vier-Zonen-Konferenz nach Wiesbaden einladen, während die Ministerpräsidenten der britischen Zone in Bremen zu tagen vorschlugen. Der Zonenbeirat der britischen, der Länderrat der amerikanischen Zone und selbst Ulbricht stimmten öffentlich derartigen Vorschlägen zu, doch zur Konferenz in Bremen am 4. und 5. Oktober 1946 erschienen nur die Vertreter der Bizone sowie ein Beobachter aus der französischen Zone. Die Ministerpräsidenten von Thüringen und Sachsen-Anhalt zogen ihre Zusagen zurück ${ }^{102}$. Da auf westdeutscher Seite die Herstellung der Wirtschaftseinheit im Vordergrund stand, nicht zuletzt durch Errichtung deutscher Zentralverwaltungen, appellierten die bizonalen Ministerpräsidenten in ihrer Abschlußerklärung vom 5. Oktober (im Sinne der amerikanischen Vorstellungen) an ihre Militärregierungen, dem Kontrollrat „die Bildung eines deutschen Länderrats aus allen deutschen Gebieten zur ständigen Unterrichtung und Beratung des Alliierten Kontrollrats in wirtschaftlichen Fragen" vorzuschlagen ${ }^{103}$. Auf dieser Grundlage trieb Pollock (RGCO) seine Bemühungen voran, daß der Kontrollrat von sich aus bzw. aufgrund einer Anweisung der Außenministerkonferenz einen gesamtdeutschen Nationalrat aus Vertretern entweder der Länderregierungen oder der Landtage errichtete, der - selbst unter Aufsicht des Kontrollrats - die deutsche Zentralregierung kontrollieren würde ${ }^{104}$. Nachdem die Außenministerkonferenz von New York die deutsche Regierungsbildung und einen Friedensvertrag auf die Tagesordnung gesetzt hatte, intensivierten sich die Bemühungen aller Deutschen, wenngleich mit unterschiedlicher Rückendeckung durch die jeweiligen Besatzungsmächte, Einfluß auf diese Entwicklung zu nehmen ${ }^{105}$. Die konkreteren Initiativen in der SBZ zwangen die Westmächte, ihrerseits den Deutschen in den Westzonen mehr Spielräume zu eröffnen, als sie wohl ursprünglich beabsichtigt hatten, da sie offenbar von der Möglichkeit eines genuinen sowjetischen Einigungswillens ausgingen. Amerikanische Geheimdienstberichte spekulierten über eine „neue sowjetische Linie“ in Deutschland, die als mögliche Vorbereitung für eine gesamtdeutsche Lösung nach der Moskauer Konferenz gedeutet wurde. Nach Angaben aus Kreisen der SED hatten die Sowjets Anfang Dezember 1946 der Parteiführung überraschend mitgeteilt, „daß sie beschlossen hätten, einer solchen Vereinigung zuzustimmen“106.

101 BA, Z 45 F/OMGUS, 2/95-2/5. Clay hatte dem Koordinationskomitee am 28. 8. 1946 eine solche Einladung avisiert. Die anderen Delegationen hatten im Prinzip zugesagt.

102 AVBRD, Bd. 1, S. 656 ff., 775 f., 869 f., 878 ff. Gimbel, Besatzungspolitik, S. 124 ff. Grünewald, Ministerpräsidentenkonferenz, S. 15, 33. Den Ministerpräsidenten der französischen Zone war die Teilnahme verboten worden, weil der Kontrollrat nicht „mit der Genehmigung der Konferenz befaßt worden ist“. Quellen zur Geschichte von Rheinland-Pfalz, S. 224.

103 Deutsche Ministerpräsidenten-Konferenz, S. 108. Zu weiteren Appellen, auch zur Kritik am Kontrollrat, vgl. ebenda, S. 32, 79, 95 ff.

104 NA, RG 43/WWII\&PWConf, box 192, folder: Provisional Government (Draft Directive of the Allied Control Authority on the establishment of a provisional German Government, 15. 10. 1946); box 192, folder: U.S. Proposal (Pollock, 3. 2. 1947); box 147, folder: State Department Brief.

105 Piontkowitz, Anfänge. Overesch, Gesamtdeutsche Illusion.

106 NA, RG 59, 740.00119 Control(Germany)/1-2047 und /1-2947. 
Obwohl die SED seit dem Sommer 1946 davon ausging, daß „es gegenwärtig nicht zu einem einheitlichen Deutschland kommen wird“107, bestand doch auf der anderen Seite die Hoffnung fort, das höhere Produktionsniveau in der SBZ einerseits und der nationale Appell andererseits könnten die „Spaltungsabsichten“ der Westmächte überwinden. Nachdem Ulbricht am 12. September vorgeschlagen hatte, die deutschen Parteien sollten sich auf die Errichtung von Zentralverwaltungen einigen und dann „dem Kontrollrat entsprechende Vorschläge unterbreiten“, veröffentlichte die SED am 18./19. September die „Grundrechte des deutschen Volkes“. Ziel dieser Initiative war es, den erwarteten Vorschlägen der Westmächte (die angeblich vom ehemaligen Reichskanzler Wirth einen Entwurf „auf föderalistischer Grundlage“ erbeten hatten) für die New Yorker Konferenz zuvorzukommen und den eigenen Entwurf zur Grundlage der öffentlichen Diskussion zu machen. Nachdem auf dem Pariser Außenministerrat „erste Umrisse“ festgelegt worden seien, werde in New York die zukünftige Gestaltung Deutschlands in ihr „akutes Stadium“ treten, da dort über verfassungsrechtliche Fragen „gesprochen und entschieden“ werden solle. „Uns hatte vorgeschwebt, diese Diskussion [über den Grundrechtskatalog] so zu steigern, daß eventuell ein interzonaler Kongreß erwachsen könnte“, der im Falle eines Erfolges der „Weltöffentlichkeit als Willensausdruck des deutschen Volkes“ präsentiert werden könne. In Erweiterung ihres ersten Vorschlages legte die SED am 14. November einen Verfassungsentwurf vor, der sich, „soweit es überhaupt möglich war“, an die Weimarer Verfassung anlehnte, um die „psychologischen Voraussetzungen“ für eine breite Resonanz auch in Kreisen des Bürgertums zu schaffen und in den Westzonen „einen starken moralischen Gewinn [zu] buchen“. Allerdings waren an zentralen Punkten Sicherungen gegen die Rückkehr zu einer bloß „formalen“ Demokratie eingebaut. Zum einen sollte die „Untergrabung“ der Staatsmacht durch eine Verwaltungsgerichtsbarkeit ausgeschlossen werden. Zum zweiten wurde die Fortschreibung der „materiellen Demokratisierung von Wirtschaft und Verwaltung und der rechtsstaatlichen Entwicklung“ angestrebt, d. h. durch „die Liquidierung der Konzerne und die Säuberung des Wirtschaftsapparats von Faschisten“ sowie durch Etablierung einer „Volkskontrolle“. Zum dritten wurde ein föderalistischer Staatsaufbau kategorisch als Ausdruck des partikularistischen Prinzips von „teile und herrsche“ abgelehnt; es sei denn infolge einer Volksabstimmung, die Molotow schon in Paris als „Kardinalpunkt“ bezeichnet hatte. Zum vierten ergab sich daraus die Aufgabe für die Arbeiterklasse, das zentralstaatliche Prinzip als eine „der nationalen Ideen Deutschlands über die gegenwärtige Zeit hinwegzuretten“. „Wir stehen wieder einmal an einem Punkte, wo das Bürgertum zu wiederholten Malen beweist, daß es nicht fähig und nicht willens ist, die deutsche Nation als eine Einheit zu konstitutieren und zu vertreten. [...] So muß die Arbeiterklasse diese Aufgabe übernehmen." ${ }^{108}$ Wie der Gründungsaufruf der KPD vom 11. Juni 1945, so sollte auch der Verfassungsentwurf der SED durch das formale Anknüpfen an die Weimarer Republik lediglich propagandistischer Publizität dienen. Denn seit dem Sommer 1946 war mehr oder minder entschieden - und diese Linie zog sich bis in die letzten Erklärungen Sokolowskis im Kontrollrat durch - , daß es ohne „Demo-

107 Badstübner, Friedenssicherung, S. 264 ff.

108 SAPMO, ZPA, Nl 90/287, Bl. 21 ff. (Stenographische Niederschrift über die außerordentliche [7.] Tagung des Parteivorstands der SED, 14. 11. 1946; Zitate nach Grotewohl, Ulbricht und Koenen). 
kratisierung“ im kommunistischen Sinne keine „Einheit“ geben werde ${ }^{109}$. Dies unterstrich der Entschluß des Parteivorstandes der SED vom 22./23. Januar 1947 zur bevorstehenden Moskauer Konferenz. Darin sprach sich dieser, umrahmt von nationalen Appellen, „für den Aufbau einer einheitlichen, unteilbaren Deutschen Demokratischen Republik bei dezentralisierter Verwaltung“ aus. Gegen die „sogenannte ,autoritäre" Demokratie“ in den Westzonen, für deren wirtschaftliche Probleme die Bizone „kein Ausweg“ sei, wurde eine durchgreifende Demokratisierung gefordert. „Eine erträgliche Gestaltung der Friedensbedingungen, - ob in Bezug auf die Grenzen, die Reparationen oder das Industrieniveau oder die Außenhandelsmöglichkeiten - wird damit gefährdet“. „Unsere Sorge [...] gilt dem Vaterland, das Deutschland heißt." ${ }^{\text {“10 }}$

Die Initiative der SED blieb nicht ohne Resonanz. Die Ost-CDU um Jakob Kaiser suchte überzonale Organisationsformen, um sich frühzeitig auf derartige Entwicklungen vorzubereiten. Vor allem die LDPD (Eugen Schiffer), die im November 1946 den Antrag auf Bildung einer "Reichspartei“ an den Kontrollrat gerichtet hatte, ergriff, „anknüpfend an Vorschläge der SED“, um die Jahreswende 1946/47 mehrere Initiativen zur Vorbereitung von „Friedensverhandlungen “11. Nach dem ergebnislosen Ausgang der New Yorker Konferenz mußte ein Weg gesucht werden, um gegen die wachsende Zurückhaltung der Westmächte doch noch zum Erfolg zu kommen. Diesem Ziel diente eine neuerliche Konferenz der SED-Führung mit Stalin vom 30. Januar bis 7. Februar 1947. In den Vorstellungen der Sowjets war jetzt die deutsche Nationalrepräsentation, mit dem taktischen Zwischenschritt einer deutschen Zentralverwaltung, als Mittel zur Abwehr der Bizone und zur Herstellung der Wirtschaftseinheit gedacht. Letzteres hatte der SMAD-Vertreter Kowal seit Mitte Oktober 1946 in Berlin gegenüber Deutschen und Alliierten bereits lanciert ${ }^{112}$. Die USA, so Stalin am 31. Januar 1947, wollten ein „schwaches Deutschland“ - ohne Zugang zum Weltmarkt, ohne Zentralregierung. Die Sowjetunion wünsche dagegen den deutschen (und japanischen) Wiederaufstieg. Dieser - das spiegelte die Furcht vor einer Wiederholung der Entwicklung nach 1918 - werde die „ungeteilte Herrschaft der amerikanischen Monopole“ brechen und damit die Weltmarktpreise senken, insofern den „Werktätigen“ wie der „Menschheit“ zugute kommen sowie einen abermaligen deutschen Revanchismus verhindern. Voraussetzung sei die deutsche Wirtschaftseinheit. „Die wirtschaftliche Einheit ist ohne eine einheitliche Regierung, ohne die volle Vereinigung nicht möglich. Eine nur wirtschaftliche Vereinigung, das wäre nur eine Vereinigung der Besatzungsmächte. Je früher die Zentralregierung gebildet wird, desto schneller wird

109 SAPMO, ZPA, Nl 90/634, Bl. 13 f. (Erklärung zur Londoner Konferenz vom 25. 11. 1947 unter Bezug auf Sokolowskis Erklärung vom 21.11. vor dem Kontrollrat).

110 SAPMO, ZPA, Nl 90/287, Bl. 57 ff.

111 Badstübner, Friedenssicherung, S. $267 \mathrm{ff}$.

112 Am 18. 10. 1946 erklärte Kowal deutschen Vertretern: „Das Ziel sei eine deutsche Regierung, die den vier Besatzungsmächten genehm sei und das Vertrauen des übrigen Auslands besitze. Er habe nicht die Kompetenz, eine solche Regierung zusammenzurufen. Aber es wäre wichtig, einen solchen Apparat [Zentralverwaltung für Industrie] zu schaffen, aus dem sich später einmal eine derartige Regierung bilden kann. Ein Staatssekretariat werde gegenwärtig trotz der Potsdamer Beschlüsse von den Alliierten nicht erstrebt, aber eine gut funktionierende DZVI sei dasselbe.“ BAP, G-2/ $1044, \mathrm{Bl}$. 114. Wenig später äußerte Kowal gegenüber seinem amerikanischen Kollegen, „that he thought the time for central German administrative agencies had passed and they alone would not suffice“. "He saw it as inevitable that one way or other, the provisional government will be created out of sheer necessity.“ NA, RG 43/WWII\&PWConf, box 187, folder: Misc., Economics (19. 12. 1946; 21. 1. 1947). 
Deutschland wiederhergestellt werden. Die Losung der Vereinigung Deutschlands muß in ihren [der SED] Händen liegen. Falls wir nicht demnächst die Schaffung einer Zentralregierung erreichen, dann muß die Vereinigung (das wäre der ungünstigere Fall) in der sowjetischen Zone vor sich gehen." Realistischerweise sah Molotow viele „Schwierigkeiten“, die zu „Verzögerungen“ führen könnten; obwohl er sich überzeugt gab, daß „einige Chancen“ für Fortschritte auf gesamtdeutscher Ebene bestünden, so war hier doch gedanklich der Weg zu einem ostdeutschen Teilstaat (endgültig) beschritten. Das Ziel für die Moskauer Außenministerkonferenz blieb jedoch: „Einheitl[iche] Zentrale Verwaltung für ganz Deutschland bis zur Bildung der Regierung, sofort Plattform als Etappe für Regierung." ${ }^{113}$ Diese Vorgaben setzte der Parteivorstand der SED auf seiner 9. Tagung am 14. Februar 1947 fast wörtlich in eine Kampagne um, die eine Einheitsbewegung unter Führung der SED als der „einzige[n] konsequente[n] Verfechterin der nationalen Einheit“ forderte. „Die deutsche Zentralverwaltung könnte in der Weise geschaffen werden, dass sich die demokratischen Parteien, Gewerkschaften und anderen Massenorganisationen darüber verständigen und einen entsprechenden Vorscblag an den Kontrollrat richten“, der zugleich Maßnahmen zur Überwindung der Not durch einen gesamtdeutschen Wirtschaftsplan und eine einheitliche Währungsreform einschloß. „Wenn auch die höchste Regierungsgewalt in Deutschland von den Besatzungsmächten ausgeübt wird, so werden die Ansichten und Absichten des deutschen Volkes doch Berücksichtigung finden, wenn es seinen Willen einig und zielbewußt zum Ausdruck bringt. ${ }^{\text {"114 }}$ Ihren Höhepunkt erreichte die Kampagne mit dem Vorschlag der SED vom 1. März 1947, einen Volksentscheid für die Einheit Deutschlands durchzuführen, von dem sie sich mindestens 30 von 50 Mio. Stimmen für die Einheit versprach ${ }^{115}$. Die Volkskongreß-Bewegung zeichnete sich ab, wurde aber erst im Vorfeld der Londoner Folgekonferenz ins Leben gerufen.

Nachdem die Moskauer Konferenz gescheitert war, sahen auch Teile von OMGUS (Pollock, mit Verzögerung Clay) in solchen Initiativen der Deutschen eine letzte Möglichkeit, die Blockade des Kontrollrats doch noch aufzubrechen ${ }^{116}$. Das war der

113 Bonwetsch/Bordjugov, Stalin und die SBZ, S. 299 f. Badstübner, Beratungen, S. 107. SAPMO, ZPA, N1 36/694, Bl. 2-23 (Hervorhebung im Original).

114 SAPMO, ZPA, Nl 90/287, Bl. 68 ff. (Thesen über die Lage und die Aufgabe der SED; Hervorhebung im Original), 77 ff. (Diskussion), 89 (Erklärung des Parteivorstandes für den 2. Parteitag [Entwurf] auf der Grundlinie des 9. Parteivorstandes).

115 Der Verfassungsentwurf, der mit der SMAD (Semjonow) abgestimmt war, in: Dokumente der SED, Bd. 1, S. 114 ff. Gniffke, Jahre, S. 209. Staritz, Parteien, S. 262 ff. Laufer, Ursprünge, S. 152 f. In der westzonalen öffentlichen Meinung gaben 31-49\% der Befragten der Sowjetunion die Schuld am Scheitern der Konferenz. 49\% glaubten nicht mehr an einen baldigen Friedensvertrag. Merritt/ Merritt, Public Opinion, S. 23 f., 164 ff. Noch 1952 spekulierten Stalin und die SED auf eine „Aktionseinheit der Arbeiterklasse“ und den "Zusammenschluß der patriotischen Kräfte“, die den „Massenkampf“" gegen Adenauer tragen würden. Gesamtdeutsche Wahlen müßten „unausweichlich zum Sturz Adenauers“ führen. Otto, Deutschlandnote, S. 377, 382.

116 Grünewald, Ministerpräsidentenkonferenz, S. 73, 76 f., 107. Gniffke, Jahre, S. 234, 273. Im Oktober 1946 sah Robertson gegenüber den Ministerpräsidenten die Chancen für die Errichtung von Zentralverwaltungen „größer, als viele denken“. Bereits 1947 könnten die Zonen „verwaltungsmäßig zusammengefaßt“" sein. AVBRD, Bd. 1, S. 884 f. In die Richtung deuteten Äußerungen Clays und Murphys am 7. 1. 1947 auf einer Pressekonferenz. Zu der Zeit war Clay strikt gegen alle Versuche der Deutschen, Einfluß auf die amerikanische Politik oder den Kontrollrat zu nehmen. Zwar gestattete er am 11.3., einen Tag nach Beginn der Moskauer Konferenz, die Gründung des Büros für Friedensfragen in seiner Zone, aber aufgrund seiner Intervention untersagten die Briten in ihrer Zone die Gründung als bizonales Büro. Die Deutschen der britischen Zone wollten in Überein- 
Grund, warum beide Seiten im Mai 1947 den Ministerpräsidenten ihrer Zonen den politischen Freiraum gewährten, sich Anfang Juni in München zu einer gemeinsamen Konferenz zu versammeln. Erstmals schienen mit dieser „Fanfare [...], die im Kontrollrat gehört wird“ (Ehard), die Deutschen überhaupt die Chance zu erhalten, direkt und öffentlich auf diesen Einfluß zu nehmen. Doch zeigte sich bereits im Vorfeld der Konferenz, daß diese nicht über die engen Grenzen hinaustreten durften, die ihnen von ihren jeweiligen Militärregierungen gesetzt wurden. Die westzonalen Vertreter wollten die Konferenz auf Fragen der wirtschaftlichen Not konzentrieren, d. h. nicht mehr als die Wirtschaftseinheit diskutieren, dazu eventuell einen gesamtdeutschen Länderrat nach amerikanischen Vorstellungen. Das ging den Franzosen im Grunde schon zu weit. Die ostzonalen Vertreter, die zunächst weitgehend vorbehaltlos für eine Teilnahme votiert hatten, zielten dagegen gemäß den Anweisungen ihrer Besatzungsmacht auf die politische Einheit, und das unter Einbeziehung der Massenorganisationen ${ }^{117}$. Insofern war der Bruch vorprogrammiert. Und es war kaum fraglich, daß auch das „Nachspiel“ im Kontrollrat nicht anders enden würde. Die westzonalen Ministerpräsidenten leiteten diesem ihre Entschließungen $\mathrm{zu}$, in denen sie $\mathbf{u}$. a. einen wirtschaftlichen Länderrat forderten ${ }^{118}$. Die Beratung dieser Entschließungen lehnten die Sowjets am 17. Juni im Koordinationskomitee ab, nicht zuletzt um Zeit zu gewinnen, damit auch die ostzonalen Ministerpräsidenten mit einer eigenen Erklärung an den Kontrollrat herantreten konnten. Nach längeren Debatten einigte sich dieser, beide Delegationen gleichzeitig zu empfangen und sich die vorher einzureichenden Statements anzuhören, ohne mit den Deutschen darüber offiziell zu diskutieren. Die Westmächte weigerten sich jedoch am 30. Juli, die mit Angriffen auf ihre Politik in den Westzonen versehene (nach ihrer Ansicht damit unter Direktive Nr. 40 fallende) Erklärung der SBZ-Ministerpräsidenten zuzulassen ${ }^{119}$.

Die SMAD hatte sich in ihrer Analyse der Ausgangslage gründlich getäuscht. Sie hatte gehofft, „daß wir bei den Bemühungen um die Herstellung der Einheit Deutschlands durch aktive Mitwirkung des deutschen Volkes selbst mit der Unterstützung der Ministerpräsidenten der westdeutschen Länder rechnen könnten, selbst wenn diese

stimmung mit der CCG auf der Münchner Konferenz die Gründung eines gesamtdeutschen Friedensbüros anregen. Overesch, Gesamtdeutsche Illusion, S. 54 ff., 81 ff., 102.

117 Ministerpräsidenten-Konferenz, S. 9, 15, 21 ff. Tjulpanow, Deutschland, S. 294 ff. SAPMO, ZPA, Nl 36/753, Bl. 6, 12. Der Parteivorstand der SED hatte am 21./22. 5. 1947 erklärt, die Ministerpräsidenten könnten sich nur mit Fragen der wirtschaftlichen Not befassen; die politischen Fragen müßten den Parteien und Massenorganisationen vorbehalten bleiben. Letzteres war von Ulbricht gezielt als Bruchpunkt durchgesetzt worden. Demnach waren Pieck und Grotewohl für ein Eingehen auf das Angebot ohne Vorbedingungen, Ulbricht dagegen nicht. Der stellvertretende Politische Berater der SMAD (Iwanow) empfahl Moskau, der SED-Führung ,nochmals zu verstehen zu geben, daß die SMAD nie und in keinem Fall eine Beteiligung der sowjetischen Zone an der beabsichtigten amerikanischen Beratung billigen wird, wenn nicht in der von uns vorgeschlagenen Weise der Teilnehmerkreis [um Vertreter der Parteien, Landtage und Massenorganisationen] erweitert wird und der Tagungsort nach Berlin verlegt wird“. Laufer, Auf dem Wege, S. 43 ff., Zitat S. 47.

118 Ministerpräsidenten-Konferenz, S. 106 ff., bes. S. 108, 114, 120. Nachdem im Vorfeld die Tagesordnung eng mit OMGUS abgestimmt worden war, war dieses am 20.6. gewillt, die Münchner Resolutionen auch ohne Einbeziehung der Deutschen im Kontrollrat einzubringen.

119 BA, Z 45 F/OMGUS, 2/108-3/4 (CONL/M(47)14, 15 und 17 mit $\mathrm{P}(47) 37$ und 37/1); 2/118-3/2-9 (CORC/M(47)29, 30 und 34 mit $\mathrm{P}(47) 149$ und 149/1). Eine Zusammenstellung in: 2/96-1/39. Während die Zivilverwaltungsabteilung von OMGUS (CAD) bei einer „Reinigung“ der SBZ-Resolution eine "slight possibility for quadripartite agreement" sah, plädierte Murphy dafür, diese „should be rejected in its entirety“. Die Erklärung der SBZ-Ministerpräsidenten vom 4. 7. ist abgedruckt in: Um ein antifaschistisch-demokratisches Deutschland, S. $474 \mathrm{ff}$. 
nicht ganz konsequent wäre. Wir überschätzten das Nationalgefühl der deutschen Bourgeoisie. Kompromisse in Richtung einer wahren Demokratisierung des gesellschaftlichen Lebens und einer Wahrung der Interessen der Nation auf dieser Grundlage stießen auf engstirnige Klassengrenzen. Es stellte sich heraus, daß nicht das Gesamtnationale, sondern die Klassenfrage bei ihnen eindeutig Priorität besaß." ${ }^{120}$ Zwei Tage nach der Konferenz forderten Ulbricht und Friedrich Ebert auf einer Kundgebung in München zum offenen Widerstand der Deutschen nicht nur gegen ihre Ministerpräsidenten, sondern auch gegen die Besatzungsmächte auf. Der Westen habe „Angst vor der Initiative des Volkes“, so Ulbricht. „Mir scheint die Grundfrage in Deutschland zu sein, daß sich das Volk diese demokratischen Freiheiten erkämpft“, unter Führung der SED, wie Ebert hinzufügte ${ }^{121}$. Bei den Kommunisten lebte noch einmal die Hoffnung auf, infolge des Scheiterns sei „vielen vieles klarer geworden“. Die Konferenz schien nur ein „Intermezzo“ im Kampf um die Einheit, in dem man sich der Unterstützung des deutschen Volkes sicher glaubte, zu dessen Mobilisierung die Volkskongreß-Bewegung als eine im Ansatz zonen- und parteienübergreifende Basisopposition ins Leben gerufen wurde. Aber es zeigte sich, daß im Gegenteil die Lage für die SED in der SBZ schwieriger wurde, da Teile der SED, vor allem die ehemaligen Sozialdemokraten, begannen, „die Politik der SMA als eine Politik zu betrachten, die den wahren Interessen des deutschen Volkes entgegen läuft“122.

Angesichts der prinzipiellen Unvereinbarkeit der Positionen konnten die amerikanischen Versuche im Sommer 1947, die Verfassungsfrage vor den Kontrollrat zu bringen, kaum mehr als ein propagandistisches Nachhutgefecht sein. Ein Bericht an die Außenministerkonferenz über die „Regierungsorganisation“ in den vier Zonen scheiterte am 6. August im Koordinationskomitee am Veto der Sowjets, das diese mit dem (allgemein immer beliebter werdenden) Argument begründeten, die Außenminister hätten Derartiges nicht verlangt ${ }^{123}$. Der Vorstoß, ein einheitliches Wahlverfahren festzulegen $^{124}$, war ebenso von Mißerfolg begleitet wie die Bemühungen, eine Direktive $\mathrm{zu}$ verabschieden, die für alle Länder- und Staatsverfassungen eine Grundrechts-Charta verbindlich vorschreiben sollte ${ }^{125}$. Unter Berufung auf das Selbstbestimmungsrecht der Atlantik-Charta antwortete die SED auf ihrem II. Parteitag vom 20. bis 24. September mit einem Vorschlag an den Kontrollrat, der neben Einheitsstaat und Zentralverwaltungen auch Bodenreform und Sozialisierung, Wirtschaftsplanung

120 Tjulpanow, Deutschland, S. 301. Im Mai 1947 erwartete Pieck von der Londoner Konferenz, „daß sie zur Herstellung der wirtschaftlichen und politischen Einheit Deutschlands kommt“. „Sollte sich unsere Annahme nicht bestätigen“, damit rechnete man immerhin, so daß „Deutschland also in zwei Teile aufgespalten wird, so werden wir auf Grund der neuen Lage neue Beschlüsse fassen müssen“. Badstübner, Friedenssicherung, S. 292. Nach Berichten aus der SBZ waren Teile der SMAD, darunter Sokolowski, noch im August 1947 bereit, ihrer Regierung einen Kompromiß mit dem Westen zu empfehlen. FRUS, 1947/II, S. 885, 890.

121 Warum mußte die Münchener Konferenz scheitern?, S. 22, 24, 31.

122 Zitiert nach: Laufer, Auf dem Wege, S. 49 (25.6. 1947).

123 BA, Z 45 F/OMGUS, 2/118-3/10-21 (CORC/P(47)171).

124 BA, Z 45 F/OMGUS, 2/118-3/10-21 (CORC/P(47)28 und 28/1).

125 Diese hatte Marshall bereits in Moskau gefordert. FRUS, 1947/II, S. 304. BA, Z 45 F/OMGUS, 2/ 127-2/1-7 (DPOL/P(47)63). Der Direktiventwurf stand im Politischen Direktorat von September bis November 1947 bei insgesamt zehn Sitzungen auf der Tagesordnung. Ausgangspunkt waren Verhaftungen von Personen aus dem amerikanischen Sektor Berlins durch die Sowjets. Die Briten schlossen sich prinzipiell an. PRO, PREM 8/791 (C.P.(47)68, 20. 2. 1947). 
und gesellschaftliche Kontrolle einforderte ${ }^{126}$. Auf der Londoner Außenministerkonferenz wurden diese Fragen ernsthaft kaum mehr diskutiert. Während die USA abermals eine Direktive der Außenministerkonferenz an den Kontrollrat anstrebten, die „Garantien für die Demokratie“ enthalten sollte ${ }^{127}$, griff Molotow in seinen Gegenvorschlägen auf die SED-Initiativen zurück ${ }^{128}$. Es zeigten sich wieder die alten Grunddifferenzen, daß nämlich die Westmächte das föderale Prinzip faktisch als verfassungspolitische Auflage per Friedensvertrag den Deutschen vorschreiben wollten, während Molotow das als eine Beeinträchtigung der deutschen Souveränität ablehnte, da „diese Klausel Deutschland in eine alliierte Kolonie verwandeln würde“129.

Die Forderung der Sowjets, jede Veränderung im Status der Ruhr oder der Verwendung der Ruhrkohle dürften nur von der Vier-Mächte-Konferenz beschlossen werden, ihre Hoffnung, die „Massen“ in Westeuropa wie in den Westzonen würden diese Entwicklung nicht widerstandslos akzeptieren, ihre Wiederholung der alten Forderung nach direkter Vier-Mächte-Kontrolle des Ruhrgebiets, die sie im Juni 1948 noch einmal im Konzert mit ihren osteuropäischen Verbündeten vortrugen ${ }^{130}$ - all das verhallte ungehört. Erstaunlicherweise glaubte die SMAD noch immer, die deutschlandpolitische Initiative nicht verloren zu haben. „Je größer das Geschrei, desto näher die Verständigung“, gab Tjulpanow im August 1947 diesem Optimismus gegenüber Jakob Kaiser Ausdruck. Dazu wollte die SMAD neue Zugeständnisse machen. Sie hatte erkannt, daß sich die SED durch ihr Insistieren auf dem „demokratischen Einheitsstaat“ selbst isolierte. Jetzt war sie bereit, eine föderalistische Lösung zu propagieren. Da sie wußte, „daß die CDU die stärkste Partei ist“, sondierte Tjulpanow mehrfach bei dem Vorsitzenden der LDPD, Wilhelm Külz, ob dieser als Chef einer künftigen deutschen Regierung zur Verfügung stünde ${ }^{131}$. Doch kam dieses Angebot an die bürgerlichen Parteien der SBZ zu spät, um von diesen als Gegenleistung gesamtdeutschen Widerstand gegen die Teilung zu erwirken. Seit der Kominform-Rede Schdanows hatte diese Strategie kaum mehr Aussicht auf Erfolg. Die Interpretation des Marshall-Plans als offene Aufkündigung des Potsdamer Abkommens und als endgültige Verweigerung aller ihrer Reparationsforderungen ließ die Sowjetunion jetzt ihrerseits mit Nachdruck auf den Bruch zusteuern - um die Einheit wiederherzustellen: durch das Bündnis mit den „Massen“.

\footnotetext{
126 Um ein antifaschistisch-demokratisches Deutschland, S. $501 \mathrm{ff}$.

127 BA, Z 45 F/OMGUS, 3/162-1/19; 3/162-2/20.

$128 \mathrm{Um}$ ein antifaschistisch-demokratisches Deutschland, S. $560 \mathrm{ff}$. FRUS, 1947/II, S. $790 \mathrm{ff}$.

129 FRUS, 1947/II, S. $741 \mathrm{f}$.

130 Geschichte der KPdSU, Bd. 5,2, S. 135.

131 Die SMAD hatte nach den Wahlen in der SBZ 1946 erkannt, daß sich die SED nur im Falle größerer „Manövrierfähigkeit [...] in allen Fragen der Innen- und Außenpolitik“ gegen die Vorwürfe zur Wehr setzen konnte, ,sie sei eine russische Partei“. Zitiert nach: Laufer, Auf dem Wege, S. 35 (Bokow an Suslow, 18.11. 1946). In diesem Sinne forderte Ulbricht am 26.9. 1946 selbstbewußt von der KPdSU mehr Verantwortung für die Deutschen zumindest in der Wirtschaft der SBZ; das sollte auch „eine gewisse Veränderung des Charakters der Sowjetischen Militärorgane“ einschließen. Semjonow und Kowal unterstützten diesen Kurs. Ebenda.
} 


\section{Marshall-Plan, Revision des Industrieniveauplans und europäische Rekonstruktion}

Als „wirtschaftliche Ergänzung“ zum Byrnes-Plan war der Marshall-Plan ein letzter Versuch, die deutsche Frage gesamteuropäisch und einvernehmlich zu lösen; denn nur „innerhalb des Rahmens eines vereinten Europa kann die volle Ausschöpfung der deutschen Ressourcen [...] mit der Sicherheit vereinbart werden“132. Angesichts des Ausbleibens deutscher Reparationen und mehr noch des Ausfalls des deutschen Exports hatte sich endgültig die Erkenntnis durchgesetzt, daß allein amerikanische Kredite die immer größer werdende „Dollar-Lücke“ in der Handels- und Zahlungsbilanz der europäischen Staaten schließen konnten. Die Kredite sollten daher Frankreich, der Sowjetunion und den kleineren europäischen Gläubigernationen den Verzicht auf deutsche Reparationen und die Zustimmung zur Erhöhung des Industrieniveaus regelrecht abkaufen. Daß das Warten auf die Selbsthilfe der Europäer auf Dauer zu wenig sein würde, auf lange Sicht auch nicht der beginnenden Entfremdung im Verhältnis zur Sowjetunion entsprach, sahen bereits Mitte 1946 die ersten Kritiker innerhalb der amerikanischen Regierung. Vor allem die „Falken“, die für ein energischeres Auftreten gegenüber der Sowjetunion plädierten, erblickten in einem „wirtschaftlich vereinten Europa“ den Ausweg zwischen Appeasement und Krieg. In dieser Konzeption waren die amerikanischen Anleihen nur als „Initialzündung“ gedacht, die nicht den Regierungen, sondern einem „Wirtschaftsrat für Europa“ im Rahmen der Vereinten Nationen zur Verfügung gestellt werden sollten. Eine solche „wirtschaftliche Föderation“ schien ohne Westdeutschland undenkbar, sofern die Ruhr und die Saar als „Ressourcen für den Kontinent" und nicht als „potentielle Waffen für dessen Beherrschung“ behandelt wurden. Nicht die De-Industrialisierung Deutschlands und die Re-Allokation der demontierten Betriebe in den Nachbarstaaten, sondern die Ausdehnung der Produktion in Deutschland stand damit zur Debatte: „Es gibt keine Lösung für das deutsche Problem außer im Rahmen einer integrierten europäischen Wirtschaft. Der Industrieniveauplan, zugeschnitten auf die Bedürfnisse von Potsdam, legt die Grundlagen für eine neue Autarkie“ - in Deutschland wie in Europa. „Jede Demontage von Industrieanlagen, die auf Friedenszwecke umgerüstet werden können, wird die russische Position stärken [...]; in den kritischen Jahren, die vor uns liegen, sollte Produktion Vorrang gegenüber der Verlagerung haben“; „die planmäßige, permanente Depression in Deutschland, die wir gerade zu schaffen im Begriff sind“, stehe dem europäischen Rekonstruktionsbedürfnis entgegen ${ }^{133}$. Die „neuen Trends zur wirtschaftlichen Autarkie“, wie der französische Monnet-Plan, seien weniger Ausdruck nationalistischer Tendenzen als Folge fehlender internationaler Austauschbeziehungen. „Daher ist heute das gegenwärtige niedrige Volumen des deutschen Außen-

132 TL, Porter Papers, box 1, folder: Criticism (Porter an Murphy, 14. 1. 1947). Mai, American Policy.

133 TL, Porter Papers, box 1, folder: Criticism (The German Problem in the Light of Soviet Policy, 22. 8. 1946; Notes on some economic consequences of Allied occupation policy in Germany, o.D.). NA, RG 59, 740.0019 Control(Germany)/16-946 (Report of the Secretary's Policy Committee on Germany, S. 2: „Germany has been in the past so closely integrated with the economy of Europe that to stifle her recovery is to handicap the recovery of Europe." Die USA müßten einen Dreioder Fünf-Jahres-Plan vorfinanzieren, um ohne deutsche Exporte die Rohstoffversorgung sicherzustellen, wenn sich Frankreich und die Sowjetunion wenigstens symbolisch beteiligten (ebenda, S. $29 \mathrm{ff}$.). 
handels einer der wichtigsten Faktoren für die Wiederbelebung autarkistischer Tendenzen in ganz Europa. Eine bedeutsame Ausweitung der deutschen Exporte setzt jedoch eine stark ausgeweitete industrielle Produktion voraus, und das wiederum erfordert mehr Kohle für den deutschen Verbrauch. “" ${ }^{134}$

Eine solches Programm war ohne eine Totalrevision des Potsdamer Abkommens nicht möglich. Clay stand daher zunächst der Einbindung seiner Zone in westeuropäische Kooperationsansätze recht zurückhaltend gegenüber. Weniger weil dies seine Autonomie als Zonenkommandeur beeinträchtigte, sondern weil es seine Bemühungen unmöglich gemacht hätte, eine Kooperationslösung mit Sokolowski im Kontrollrat auszuhandeln. Allerdings wußte auch er, daß das Deutschlandproblem nur im europäischen Rahmen gelöst werden konnte. Das ausgeprägte Sicherheitsdenken, das dem ersten Industrieniveauplan zugrunde lag, hatte nach seiner Auffassung ein Defizit deutscher Produkte verursacht, das zum einen die Rekonstruktion Westeuropas hemmte, das zum zweiten die finanziellen Kosten für die Westmächte ständig heraufschraubte und das zum dritten die Befriedigung der sowjetischen Reparationsforderungen verhinderte ${ }^{135}$. Unter dem Schutz einer amerikanischen Sicherheitsgarantie schien die drastische Revision des Industrieniveauplans der geeignete Weg, allen Bedürfnissen entgegenzukommen, zumal die Sowjetunion seit der Pariser Außenministerkonferenz im Sommer 1946 ihr Interesse an einer solchen Lösung hatte erkennen lassen. Auf der Moskauer Außenministerkonferenz trat jedoch Clays besatzungspolitischer Pragmatismus erkennbar hinter die Entschlossenheit zurück, die Revision des Industrieniveauplans notfalls gegen, zumindest aber ohne die Sowjetunion zu realisieren, sollte die sich den als notwendig definierten Maßnahmen in Deutschland verweigern $^{136}$. Aber auch im Falle eines westlichen Alleingangs, darauf wies Clay hin, ließ sich eine Entscheidung nicht vermeiden, ob die Lebens- und Exportfähigkeit Deutschlands oder die Reparationsinteressen der IARA-Länder Vorrang genießen sollten. Obwohl sich seit der Debatte über den Hoover-Report vom März 1947 in Washington der Konsens herausbildete, vom Industrieniveauplan abzugehen, war bis zu Marshalls Harvard-Rede im Juni nicht endgültig entschieden, ob die Ausweitung der deutschen Industrieproduktion primär deutschlandpolitisch (mit der Sowjetunion) oder europapolitisch (ohne die Sowjetunion) genutzt werden solle ${ }^{137}$, ob deutsche Reparationen den Marshall-Plan begünstigten oder eher behinderten ${ }^{138}$.

Es war ein Indiz für die anhaltende interne Unsicherheit über die Gestaltung des Verhältnisses zur Sowjetunion, daß das Kabinett am 27. Juni 1947 gegen den Ein-

134 NA, RG 59, 740.00119 Control(Germany)/10-146.

135 NA, RG 200/Clay, box 2, folder: Moscow Conference March 1947.

136 FRUS, 1947/III, S. 212 f., 219, 237 ff., 273. Auf der Besprechung der Secretaries of Commerce, War, Navy, State, Budget Director und Herbert Hoover am 13. 3. 1947 wurden die Chancen für die wirtschaftliche Einheit Deutschlands als gering eingeschätzt; Deutschland müsse „self-supporting“ gemacht werden, besonders im Bereich der Schwerindustrie, „if Europe, particularly that part not under Soviet control, is to get the necessary steel and machinery. U.S. cannot with its present plan capacity supply this steel and machinery and it could never be paid for if supplied." NA, RG 59, 740.00119 Council/3-2047.

137 Hogan, Marshall Plan, S. 33-45.

138 NA, RG 59/ASSOA, box 4 (stellv. Außenminister an Truman, ca. Juli 1947, „not sent“, mit Anlagen, u. a. Pauley an Truman, 9. 6. 1947); RG 59/CED, box 2 (Kindleberger, 18. 6. 1947); RG 335, box 42, folder: 091.3 Germany/Rehabilitation (Report from State Department, 21. 9. 1948). FRUS, 1948/III, S. $308 \mathrm{ff}$. 
spruch Harrimans beschloß, Reparationslieferungen entweder überhaupt nicht zu liefern oder an Ost und West gleichermaßen ${ }^{139}$. Man einigte sich auf eine Vertagung der Entscheidung, indem die Lieferungen an die Sowjetunion und die osteuropäischen IARA-Länder zwar prinzipiell nicht eingestellt, sondern lediglich „auf unbestimmte Zeit" ausgesetzt wurden, um abzuwarten, ob es auf dem nächsten Außenministerrat zur Herstellung der Wirtschaftseinheit kommen werde ${ }^{140}$. Das bedeutete die faktische Einstellung dieser Lieferungen, ließ aber zugleich die Möglichkeit offen, die Wünsche der westeuropäischen Länder zu bedienen. Denn diese würden, so erwartete man in Washington, rücksichtslos auf deutsche Reparationen drängen, um eine Abhängigkeit vom Dollar zu vermeiden, gleichgültig, ob zu Lasten der deutschen Lebenshaltung oder der amerikanischen Finanzierung ${ }^{141}$. Wenn die USA auf die eine oder die andere Weise ohnehin für die Kosten aufkommen mußten, so war es politisch wie ökonomisch vorteilhafter, durch einen maximalen, gleichwohl kontrollierten Beitrag der Bizone "das europäische Bedürfnis nach Hilfe seitens der USA zu reduzieren“, auch wenn das vorübergehend zu steigenden Kosten in Deutschland führen werde: „Das Interesse der USA an den Vorteilen für die befreiten Gebiete muß gegen die Kosten der USA oder den Verlust für Deutschland aufgewogen werden, ehe eine Entscheidung gefällt werden kann." An diesem Punkt wurde die Verschiebung der Prioritäten in den amerikanischen Überlegungen hinsichtlich des deutschen Beitrags zur europäischen Rekonstruktion erkennbar: nicht mehr durch Demontagen und Reparationen, sondern durch Produktion und Handel ${ }^{142}$. Bereits im Herbst 1946 hatten vereinzelte Stimmen gefordert, zur Realisierung dieser Ziele Deutschland zu teilen und das Ruhrgebiet in eine zur "Westeuropäischen Union“ erweiterte Zollgemeinschaft einzubeziehen. Doch Byrnes war noch nicht bereit, einen derart „unwiderruflichen Schritt wie die Bildung eines westeuropäischen Blocks" zu akzeptieren, der den Verzicht auf Ostdeutschland mit seinen Ressourcen zugunsten der Sowjetunion einschlo ${ }^{143}$. Gleiches galt zunächst für Marshall ${ }^{144}$. Doch je intensiver die Umsetzung des nach ihm benannten Plans intern diskutiert wurde, desto deutlicher kristallisierte sich in Washington die Überzeugung heraus, daß die Besatzungspolitik in Deutschland nicht den wünschenswerten Beitrag zum Wiederaufbau Europas leistete: „Die Politik der USA in Deutschland kann die Politik der USA gegenüber Europa als Ganzem nicht ignorieren oder dieser widersprechen." Die auf Minimierung der Besatzungskosten ausgerichtete Politik der Militärs galt als „,anti-europäisch“, die - wollte man vom sowjetischen Veto unabhängig werden - nur durch Aufkündigung des Potsdamer Abkommens und des Industrieniveauplans vom März 1946 überwunden werden konnte; das hieß in der Konsequenz: durch Preisgabe der deutschen Einheit ${ }^{145}$.

139 NA, RG 59/CED, box 2, folder: G 400, Reparations (Marshall an Hilldring, Matthews, Thorp und Kennan, 27.6. 1947).

140 FRUS, 1947/II, S. 1123.

141 NA, RG 59/ASSOA, box 2, folder: memoranda \& despatches (Questions concerning [...], Juli 1947).

14 NA, RG 59/ASSOA, box 1 (Thorp an Marshall, 1. 7. 1947); RG 59, 740.00119 Control(Germany)/ 8-2247 (Edelstein an Saltzman).

143 NA, RG 59, 740.00119 Control(Germany)/9-2046.

144 TL, Acheson Papers, box 27, folder: State Department, General, 1948 (Rostow an Acheson, 20. 2. 1948); Oral History Collection, Kindleberger, S. 82. NA, RG 59/CED, box 2 (Kindleberger, 18. 6. 1947).

145 NA, RG 59/ASSOA, box 1, folder: Germany Place (Hilldring an Marshall 18. 6. 1947 und Anlagen; 1. 7. 1947). FRUS, 1947/III, S. 329, 332, 340, 347, 353. 
Bereits im Sommer 1946 hatten in London Überlegungen zur Revision des Industrieniveauplans eingesetzt. Zwar unterstellte der vom EIPS entwickelte (intern nicht unumstrittene) Plan eine vierzonale Einigung auf der nächsten Außenministerkonferenz, er sah aber bereits die Möglichkeit eines bizonalen Alleingangs vor, indem er eine Revision „mit oder ohne russische Kooperation“ forderte. Schon bei dem ersten Plan sei es unrealistisch gewesen zu erwarten, „diese ganze Ausrüstung zu entfernen und in den Empfängerländern so rechtzeitig wiederzuerrichten, daß sie sinnvoll genutzt werden könnte“. Nachdem die Sowjets in ihrer Zone exzessiv demontiert hatten, müsse - das bedeutete faktisch den Bruch - bei einer solchen Revision Vorsorge getroffen werden, „daß es in dem neuen Plan Spielraum geben wird für ausreichende industrielle Kapazitäten, die in den Westzonen verbleiben, damit diese als separate wirtschaftliche Einheit verwaltet werden können"146. Hinter diesen Überlegungen stand seit dem Sommer 1946 die Vorstellung, künftig auf Demontagen zu verzichten und statt dessen die deutsche Wirtschaft stärker auf die Bedürfnisse der britischen zu orientieren, indem bei der Durchführung des Industrieniveauplans eine engere „Liaison" mit der britischen Industrie gesucht wurde. Die Federation of British Industrialists (FBI) und andere Unternehmerorganisationen hatten zur Abstimmung mit dem COGA eigene Komitees eingesetzt, die mit der CCG „direkte Kontakte“ aufnehmen durften. Anfang Mai 1946 fanden erste Gespräche zwischen FBI und Board of Trade statt $^{147}$. Dabei waren der Industrie Konsultationen zugesagt worden, welche Betriebe zu erhalten bzw. zu demontieren seien, ebenso hinsichtlich „der geplanten und der tatsächlichen Produktion, die aus den zurückbehaltenen Betrieben gewonnen werden soll“. Mit dem Argument, die Lebensfähigkeit Deutschlands zur Begrenzung der Kosten für den britischen Staatshaushalt berücksichtigen zu müssen, wollten COGA und CCG der Industrie keine Garantie geben, daß ihre „Empfehlungen“ umgesetzt würden. Doch das Board of Trade, dem diese Linie zu zurückhaltend war und das seine Vorstellungen von Deutschland als "Nation von Unterlieferanten“ noch keineswegs aufgegeben hatte, setzte gegen den Widerstand der CCG Reisen von Industriellen nach Deutschland durch ${ }^{148}$. Im Oktober 1946 wurde die British Purchasing Agency eingerichtet, die durch gezielte Importe („z. B. Rohstoffe, Maschinen, Industriegüter, Verbrauchsgüter") die britische Industrie unterstützen bzw. für Exportoffensiven entlasten sollte. Deren zweite Aufgabe war es zu planen, welche neuen Produkte und Märkte für Deutschland zu entwickeln seien, die langfristig keine Konkurrenz für britische Exporte darstellten, auch wenn nicht völlig übersehen wurde, daß die deutsche „Selbsterhaltung“ einen gewissen „Konflikt“ mit britischen Interessen mit sich brin-

146 Der Bericht (EIPS/P(46)6, 22. 10. 1946) enthielt nur die Empfehlungen, die Foreign Office und COGA gebilligt hatten. PRO, CAB 21/1873; FO 943/488; FO 371/64451/C3182.

147 PRO, BT 211/73 (COGA-Meeting, 30. 4. 1946). Die CCG konnte Eingriffe von COGA, Board of Trade und FBI nicht verhindern. FO 942/498; FO 1034/37; FO 371/55379 (The Reparations Plan. Redraft of Paragraphs on British Commercial Interests). „British industry has been basing its development plans on the assumption that this industry [dye-stuffs] would either be eliminated or restricted to the needs of the domestic market." Eine Industrie-Delegation forderte, die Zahlen des Industrieniveauplans so anzusetzen, daß sich die deutschen Exporte um 85 Mio. RM reduziert hätten. CAB 21/1873 (C.P.(46)114, 16.3. 1946). Die kleineren Produzenten befürchteten, „that the presence on the Control Commission staff of ICI people may mean that Germany will be encouraged to produce those dyes which ICI would like her to make“. Es wurden Beratergremien eingesetzt, in denen die kleineren Produzenten als Aufpasser vertreten waren. Vgl. oben S. 369 mit Anm. 273.

148 PRO, FO 942/498; FO 943/201; FO 1034/37. Vgl. oben S. $307 \mathrm{f}$. 
gen werde ${ }^{149}$. Je mehr die Revision des Industrieniveauplans auf der politischen Ebene vorangetrieben, je dramatischer zugleich die Wirtschaftskrise im eigenen Lande wurde, desto ausgeprägter geriet der Einfluß der britischen Industrie auf diese Überlegungen. Um wettbewerbsfähig zu bleiben, verlangte sie Mitbestimmung, zumindest aber frühzeitige Information, um dem deutschen Export entweder aus dem Wege gehen oder ihm im Vorstadium begegnen zu können. Die deutsche Konkurrenz sollte ausgeschaltet werden, indem man mit ihr kooperierte und die langfristige Abstimmung von Wirtschaftsentwicklung und Modernisierung ins Auge faßte. Gemäß einer Empfehlung des EIPS vom 26. Februar 1947 war die CCG durch Kabinettsbeschluß gehalten, die „Ansichten“ der Chemischen Industrie zur Kenntnis zu nehmen, „ehe wir irgendwelche revidierten Kapazitätsniveaus für die chemische Industrie in Deutschland abschließend billigen“. Auch alle anderen Industriezweige hatten das Recht, entsprechende Informationen per Fragebogen über das Board of Trade bei der CCG einzuholen. Die Interessenten erhielten derart „detaillierte Informationen [...] über die gegenwärtige Produktion und über zukünftige Produktionspläne“, daß die Industrie „recht zufrieden“ war $^{150}$.

Bevin nutzte die Stagnation der Moskauer Außenministerkonferenz, die er selbst mit herbeigeführt hatte, um auf ein unilaterales Vorgehen in der Bizone zu drängen. Noch im November 1946 hatte er es als „größten Fehler“ bezeichnet, die Erhöhung des deutschen Industrieniveaus zu ventilieren und gar mit den USA oder Frankreich offiziell zu diskutieren ${ }^{151}$. Jetzt forderte und erhielt er Marshalls prinzipielle Zusage, einen bizonalen Reparationsplan auf der Basis einer Stahlproduktion von 10 Mio. $\mathrm{t} \mathrm{zu}$ entwickeln und die Demontagen fortzusetzen, um die Reparationsforderungen der Westeuropäer und der Sowjetunion teilweise befriedigen zu können. In diesem Sinne einigten sich Bevin und Marshall am 18. April sowohl auf eine Stahlproduktion von 10 Mio. $t$ als auch auf die Fortsetzung der Reparationspolitik auf Vier-Mächte-Ebene. Diese Übereinkunft wurde ergänzt durch das amerikanisch-französische Kohle-Abkommen vom gleichen Tage, das Frankreich am Erfolg dieser Revision interessiert sein lassen mußte. In der Tat konnte von den Franzosen die Zustimmung zur Erhöhung des Industrieniveaus um $25 \%$ erreicht werden, so daß eine derartige Maßnahme zumindest in der Bizone bzw. in den Westzonen gesichert schien ${ }^{152}$. Trotz heftiger Proteste, die vorrangig innenpolitisch motiviert waren, sah sich Frankreich immer stärker zum Anschluß an die Bizone gedrängt, wenn es die wirtschaftlichen Vorteile genießen und die politische Kontrolle über diese Entwicklung nicht verlieren wollte $^{153}$. Bevin und Marshall hatten zwar den offenen Bruch noch einmal vermieden, aber der Auftrag an Clay und Robertson, einen bizonalen Industrieniveauplan vorzubereiten, und die gesteigerten Bemühungen, Frankreich direkt oder indirekt an die Bizone zu binden, ließen erkennen, daß es sich nur um eine Vertagung handelte, die vor allem dadurch bedingt war, daß die internen Entscheidungsprozesse noch nicht abgeschlossen waren.

149 PRO, PREM 8/214 (Cabinet, 21. 10. 1946; Bezug: Board of Trade-Memorandum, 6. 10. 1946); CAB 21/1873 (EIPS/P(46)6, 22. 10. 1946). Turner, British Policy, S. 88. Vgl. oben S. 224.

150 PRO, FO 943/201.

151 PRO, FO 800/Ger/46/44. AVBRD, Bd. 1, S. 1060 (Sir Cecil Weir).

152 PRO, CAB 21/1874 (14. und 16.4. 1947).

is3 FRUS, 1947/II, S. 356 ff., 486 f., 979, 983 ff., 1004, 1012, 1028 ff. 
Während Clay zunächst mit Hilfe des bizonalen Industrieplans noch einmal Bewegung in die innerdeutschen Verhandlungen zu bringen hoffte und dementsprechend davor warnte, ,jetzt die Tür für Vier-Mächte-Verhandlungen zuzuschlagen“"154, brauchten die Briten angesichts der sich verschärfenden Wirtschaftskrise im eigenen Land und der wachsenden Abhängigkeit von den USA rasche Lösungen. Und die waren mit der Sowjetunion nicht zu haben; Rücksichten, auch nur formale, waren dieser gegenüber jetzt nicht mehr angebracht. Daher sollten, zur Entlastung der eigenen Volkswirtschaft, die einmaligen Reparationslieferungen aus der britischen Zone an die Sowjetunion eingestellt und ausschließlich den westlichen Besatzungsmächten zur Verfügung gestellt werden, „die sie als Exporte veräußern und die Erlöse nutzen könnten, um wichtige Importe zu finanzieren“; die benötigten Betriebe sollten „eher durch Kauf als durch Reparationen" erworben werden, um das laufende Defizit in Deutschland zu reduzieren und die eigenen „Verteidigungs- und industriellen Ziele“ zu realisieren ${ }^{155}$. Robertson empfahl, „zu beschließen, daß die ganze Idee von Demontagen und Reparationen jetzt nicht praktikabel ist und aufgegeben werden sollte", auch wenn, wie der EIPS bemerkte, das einem Bekenntnis gleichkam, „daß wir das Potsdamer Abkommen zu brechen gedenken“. Am Ende des internen Entscheidungsprozesses stand Bevins Vorschlag vom 1. Juli 1947 an das Overseas Reconstruction Committee, aus Gründen der Sicherheit gegenüber Deutschland weiterhin eine Obergrenze durch einen Industrieniveauplan festzulegen und die Kapazitätsüberschüsse zugunsten der Gläubigernationen zu demontieren. Jetzt war dieses Programm bereits als Ergänzung zum Marshall-Plan gedacht. Eine klare, endgültige Entscheidung werde diesem eine psychologische Hilfestellung gewähren, ,als Teil eines viel größeren Plans, um den Deutschen zu zeigen, daß wir ihre Wirtschaft zu verbessern und ihre Lebenshaltung in Zukunft zu heben beabsichtigen“. Der amerikanische ERP-Administrator solle entscheiden dürfen, daß der deutsche Beitrag ,zu einer allgemeinen europäischen Erholung" auch durch den Einsatz der über das bizonale Industrieniveau hinausgehenden Kapazitäten in Deutschland selbst geleistet werden konnte, allerdings ausschließlich für ERP-Zwecke und nicht für innerdeutsche Bedürfnisse ${ }^{156}$. Trotz des Scheiterns ihres „Multilateralen Lieferplans“ entschieden sich die Briten noch einmal für ein verdecktes Programm von Reparationen aus laufender Produktion $^{157}$. Der revidierte bizonale Industrieplan sollte dafür die Grundlage abgeben, dessen Vorgaben daher als endgültig angesehen wurden.

Nachdem sich Robertson und Clay bis zum 15. Juli auf den Industrieplan geeinigt hatten, wurde dieser mit Rücksicht auf die Pariser Verhandlungen über den MarshallPlan zunächst storniert, nachdem die französische Regierung ihren Rückzug von diesen Beratungen angedroht hatte, falls die Verhandlungen über den Bizonen-Plan in Berlin nicht suspendiert oder nach französischen Vorstellungen modifiziert würden. Angesichts der Proteste Frankreichs und der Benelux-Länder empfahl Hilldring, den

154 Statt dessen empfahl er, die zu demontierenden Überschußkapazitäten nach dem neuen Plan der IARA wie der Sowjetunion zuzuteilen, im Falle der letzteren aber die Demontage bis zur Herstellung der Wirtschaftseinheit zu vertagen. CP, S. 370 f. (13. 6. 1947), 411 (25. 8. 1947). FRUS, 1947/II, S. 1055 (Lovett, 23. 8. 1947).

155 PRO, FO 371/65012/CE516 (13.3. 1947); 65001/CE1031 (COGA, 2. 4. 1947). Der Kauf sollte durch Kredite ,als künftiger Anspruch gegenüber der deutschen Wirtschaft“ vorfinanziert und später von den Deutschen bezahlt werden. Das kam Reparationen gleich.

156 PRO, FO 371/64451/C9191 (ORC(47)31, 1. 7. 1947); FO 1036/748 (EIPS, 1. 7. 1947).

157 Vgl. oben S. $342 \mathrm{f}$. 
Industrieplan als Maßnahme zur Wiederbelebung brachliegender europäischer Produktionskapazitäten zu deklarieren. Der Industrieplan sollte gemäß seiner Empfehlung lediglich Zielperspektive für das unabdingbare Minimum im Interesse der Selbstversorgungsfähigkeit der Bizone sein, das zugleich Spielraum für Reparationslieferungen belasse ${ }^{158}$. „Die Erneuerung der deutschen Industrie könnte dann im Rahmen der Wiederbelebung Europas geprüft werden und würde keine Priorität erhalten, wie das durch die Berliner Entscheidungen geschehen ist.“" ${ }^{159}$ Angesichts der bevorstehenden Veröffentlichung des bizonalen Industrieplans mußte jedoch eine öffentliche Stellungnahme zur eventuellen Wiederaufnahme der Reparationen erfolgen. Der stellvertretende Außenminister Lovett plädierte am 23. August für eine Vertagung der Entscheidung bis zur nächsten Konferenz der Außenminister und schlug als Sprachregelung im Sinne Hilldrings vor, der Plan sei Grundlage einer neuen Reparationsliste, deren Fertigstellung bis zur Konferenz hinauszuzögern sei. Clay schloß sich diesem Vorschlag zwei Tage später an: „Die Zeit, die für die Zuweisung dieser Betriebe benötigt wird, läßt sich in den Vier-Mächte-Beratungen sehr leicht ausdehnen, um eine Entscheidung bis nach dem Novembertreffen des Rats der Außenminister zu vermeiden." Ohne Wirtschaftseinheit, so wies das State Department schließlich am 11. September Clay und Murphy an, werde es keine Reparationen mehr an die Sowjetunion geben; bis zur Außenministerkonferenz sei aus taktischen Gründen aber jede Verknüpfung von Wirtschaftseinheit und Wiederaufnahme der Reparationen zu vermeiden, um sich nicht dem Vorwurf aussetzen zu müssen, durch überzogene Pressionen die Spaltung zu provozieren. ${ }^{160}$ Damit war im Grunde der Bruch vollzogen. Denn auch wenn Lovett gewarnt hatte, man dürfe diesen Festlegungen keine vorschnellen Annahmen über den Ausgang der Außenministerkonferenz zugrunde legen, so war doch deutlich erkennbar, daß man in Washington im Interesse des MarshallPlans bereit war, Frankreich sehr weit entgegenzukommen, dagegen von der Sowjetunion faktisch die fast bedingungslose Preisgabe ihrer Positionen einforderte. Die Anpassung des bizonalen Industrieplans an die Bedürfnisse des Marshall-Plans führte dazu, daß entgegen Clays Mahnung vom Juni die Tür für eine Vier-Mächte-Lösung endgültig zugeschlagen wurde. Die reine Westlösung war damit faktisch beschlossen.

Die Franzosen erkannten die Gefahren, aber auch die Chancen dieser Entwicklung für ihre Interessen. Botschafter Massigli empfahl, von einer „simplen Position der Obstruktion" abzugehen und gewisse Offerten zu unterbreiten, um Einfluß auf die Revision des Industrieniveauplans nehmen oder das Inkraftsetzen des Bizonen-Plans wenigstens hinauszögern zu können; angesichts der Wirtschaftskrise im eigenen Land habe Frankreich keine Wahl mehr, sondern müsse ein ,in zwei Stücke geteiltes“ Deutschland als vorteilhafter akzeptieren. „Ich glaube, daß letztlich die Teilung besser für uns ist, denn schließlich liegen die Zonen in Westdeutschland, an deren Kontrolle wir unbedingt teilhaben müssen." ${ }^{161}$ Das Quai d'Orsay griff Massiglis Rat auf, band

158 NA, RG 59/ASSOA, box 6, folder: 386.3, vol. 3 (Hilldring, 25. 7. 1947); RG 59/CED, box 2, folder: G 400 Reparations (Hilldring an Marshall, o.D., nach 12.7. 1947).

159 NA, RG 59/CED, box 4, folder: Industrial Matters (Lovett-Bonnet, 18. 7. 1947); RG 200/Clay, box 5, folder: Telecomm. 1947 (31. 7. 1947). FRUS, 1947/II, S. $986 \mathrm{ff}$.

160 FRUS, 1947/II, S. 1055 (Lovett, 23. 8. 1947), 1060 (Clay, 25. 8. 1947), 1123 (Marshall, 11. 9. 1947). Clay schloß sich jetzt der britischen Auffassung an, den Plan als endgültig anzusehen. AVBRD, Bd. 3, S. 745 .

161 AN, 457 (Bidault) AP 60/IV (Privatbrief, 28. 7. 1947). Dagegen bewertete Seydoux resigniert und 
aber seine Zustimmung an fünf Bedingungen: Revision des Bizonenplans im Falle der Rückkehr zur (vierzonalen) Wirtschaftseinheit; dessen Verknüpfung mit dem Monnet-Plan; Internationalisierung der Ruhr (,internationale Sozialisierung“); Wiederaufnahme von Demontagen und Reparationen; Balance von Im- und Exporten ${ }^{162}$. In dem Rahmen schienen eine deutsche Stahlproduktion von 9 und Stahlimporte aus der Saar von 1 Mio. $t$ akzeptabel, wieder unter der Bedingung, daß Frankreich Ruhrkohle in einer Menge erhielt, die ihm eine Stahlproduktion von 12-14 Mio. t erlaubte; daß der deutsche Stahlverbrauch auf 10 Mio. t beschränkt blieb; daß Produktionsverbote (z. B. für synthetisches Gummi, Werkzeugmaschinen, Kugellager) verhängt wurden; daß die USA eine Sicherheitsgarantie im Sinne des Byrnes-Plans abgaben ${ }^{163}$. Als „einzige Gegenleistung“ bot man den Beitritt zur Bizone an, verbunden „mit der Übernahme einer gemeinsamen Politik in Deutschland und einer Integration Deutschlands in die westeuropäische Wirtschaft" ${ }^{164}$. Sicherheitsgarantie und internationale Verteilung der Ruhrkohle würden die Bedenken gegenüber dem deutschen Wiederaufstieg in Frankreich nicht beseitigen, aber doch mindern, ,unter der Voraussetzung, daß diese Rekonstruktion in einem europäischen Rahmen gemacht werden muß, unter Berücksichtigung der Bedürfnisse und Möglichkeiten nicht nur Deutschlands, sondern ganz Europas. [...] Europa aber ist die einzige Hoffnung, die sich, außer dem Reich, der germanischen Welt anbietet, und es ist auch für die Sieger von gestern das einzige Mittel, dem politisch dezentralisierten, aber wirtschaftlich prosperierenden Deutschland Leben und Konsistenz zu verleihen, die sie sich als Ziel setzen müssen.“ Eine Wiederholung des Fehlers von 1918, den Deutschen die internationale Gleichberechtigung zu verweigern, schien vermeidbar, indem man ihnen die Integration ,in eine europäische Organisation im Hinblick auf freien Warenaustausch und Solidarität der Interessen“ anbot ${ }^{165}$.

Hinter dem Rücken der Briten gelang es dem „hysterisch“ auf die anglo-amerikanischen Revisionsabsichten reagierenden Bidault Mitte August, von Will Clayton und Lewis Douglas (die damit ihre Verhandlungsvollmachten überschritten) eine amerika-

alarmiert zugleich den bizonalen Industrieniveauplan als den Versuch der angelsächsischen Mächte, angesichts der Schwierigkeit, ,ihren Ansichten in den Vier-Mächte-Organen zum Siege zu verhelfen“, sich „die exklusive Kontrolle ihrer Zonen zu sichern und die Zweiteilung Deutschlands herbeizuführen“ - gegen und ohne Frankreich. AMAE, Y 296, Bl. 2 f. (6. 9. 1947).

162 AMAE, Y 91, Bl. 139 (Bidault-Bevin, 4. 7. 1947).

163 Für Frankreich würde eine solche Garantie „eine sofortige Revision seiner gesamten Sicherheitspolitik“ bedeuten, etwa durch Errichtung einer doppelten europäischen Sicherheitsordnung um Deutschland herum, über das Ende der eigentlichen Besatzungsphase hinaus: einerseits eine wirtschaftliche durch internationale Kontrolle der Ruhr und durch „Integration der deutschen Wirtschaft auf der allgemeinen Ebene in die westeuropäische Wirtschaft (Marshall-Plan)“; andererseits eine militärische, möglichst nach dem Muster des Byrnes-Plans unter Einschluß der USA, zur Garantie der anhaltenden deutschen ökonomischen wie materiellen Entmilitarisierung. Daraus entstand die Vorstellung, amerikanischen Schutz nicht nur vor Deutschland, sondern im Falle der zu erwartenden Spaltung Deutschlands auch vor der Sowjetunion zu erhalten. AMAE, Y 201, B1. $39 \mathrm{ff}$. (Bevin-Chauvel, 20. 10. 1947), 47 f., 56 ff., 103 ff., 222 ff. (Courzel, 20. 11. 1947), 232 ff. (Massigli, 22. 11. 1947). Das war der Weg zur NATO.

164 AMAE, Y 371, Bl. 229 ff.; Y 375, Bl. 5 ff. (Affaires économiques, financières et techniques; le Directeur Général, 21.7. 1947). Zur französischen Forderung nach Produktionsverboten vgl. Y 292, Bl. 132 f. (10. 2. 1947). BA, Z 45 F/OMGUS, 2/118-3/10-21 (CORC/P(47)166 und 166/1).

165 AMAE, Y 298, Bl. 34 (Bidault an Koenig, 4. 1. 1948). Frankreich war besorgt, Clay werde den Wünschen nach Produktionsverboten nur gemäß den „besoins de l'Europe“ zustimmen; man meinte in Bizone und SBZ zu erkennen, daß die deutsche Entmilitarisierung nicht zu Ende geführt, sondern im Gegenteil eine (wirtschaftliche) „Wiederbewaffnung“ betrieben werde. Y 372, Bl. 164. 
nische Absichtserklärung zur Internationalisierung der Ruhr zu erhalten, die diese nach zornigen Protesten der Briten auf Anweisung aus Washington wieder zurückziehen mußten ${ }^{166}$. Zwar hatte Bevin gegen das Drängen Clays ${ }^{167}$ und gegen gewisse Widerstände in State und War Department auf Konsultation der Franzosen bestanden, um sie politisch einzubinden und den Sowjets nicht in die Arme zu treiben. Aber zu weitreichenden Zugeständnissen war er nicht bereit, obwohl er selbst in der Folgezeit die Sozialisierung der Kooperation mit den USA opferte. Er akzeptierte Bidaults innenpolitische Nöte, wußte aber, daß Frankreich wegen des Monnet-Plans keine Einwände gegen eine Erhöhung der deutschen Produktion erheben konnte, solange seine ausreichende Belieferung mit Ruhrkohle gesichert war. Obwohl Frankreich nicht verhindern konnte, daß die Angelsachsen ihren Plan ${ }^{168}$ am 29. August mit geringen Korrekturen veröffentlichten, schloß es sich im Kontrollrat dem sowjetischen Protest nicht an, sondern führte in London die Gespräche über die Ruhr und die Verteilung der deutschen Kohle auf informeller Ebene weiter. Die potentielle Gefahr, daß bei Bildung einer Trizone die Sowjetunion einen eigenen Staat in der SBZ ausrufen könnte, galt in Paris als nicht so groß wie die reale Gefahr, jede Kontrolle über die Ruhr an die Deutschen $z u$ verlieren ${ }^{169}$. Obwohl sie sich faktisch festgelegt hatte, fiel der französischen Regierung die offizielle und öffentliche deutschlandpolitische Kurskorrektur schwer; aus Gründen der historischen Ressentiments, aus innenpolitischer Rücksichtnahme, aber auch aus Gründen des politischen Preises, den ihre westlichen Alliierten ebenso zahlen sollten wie die Deutschen. Fehlgeschlagen war der Versuch, im Interesse der Sicherheits- wie der Handelsinteressen durch Demontagen und Reparationen eine Verlagerung der europäischen Stahlproduktion von der Ruhr nach Frankreich zu bewirken. Fehlgeschlagen war auch die Hoffnung, den bizonalen Industrieniveauplan so weit in den Marshall-Plan zu integrieren, daß über die CEEC ein Mitbestimmungsoder gar Vetorecht gewonnen wurde. Längst hatte sich die Modernisierung mit Hilfe des Marshall-Plans als vielversprechender erwiesen als die Auffüllung der französischen Kapazitäten mit verbrauchten deutschen Maschinen und veralteter Technologie. Die Forderung nach einer politischen Lösung der Reparationsfrage, wie sie Ende 1946 im Vordergrund gestanden hatte, war der Einsicht in die ökonomische Rationalität einer autonomen Modernisierung gewichen ${ }^{170}$.

Gleichwohl hielten die Franzosen an der Hoffnung fest, Monnet-Plan, MarshallPlan und Reparationen zu einem Paket bündeln zu können, um auf diesem Wege doch noch die Internationalisierung der Ruhr mit alliierter Verteilung der Ruhrkohle,

166 FRUS, 1947/II, S. 1027-42. Deighton, Impossible Peace, S. 194 ff.

167 Clay drohte mit Rücktritt gegen die Verschiebung und mußte unter Hinweis auf den Vorrang des Marshall-Plans zur Ordnung gerufen werden. CP, S. 373 f., 388 f. FRUS, 1947/II, S. 1008 f.

168 Germany 1947-1949, S. 356 ff. Der Bizonen-Plan erreichte ein Produktionsniveau von 90-95\% von 1936 (gegenüber 70-75\% des ersten Plans); infolge der gestiegenen Einwohnerzahl lag die ProKopf-Produktion bei $75 \%$ von 1936. FRUS, 1947/II, S. 978, 990. Der Reparationsanteil in der Schwermaschinenindustrie wurde von 60 auf $35 \%$, in der Leichtmaschinenindustrie von 33 auf $23 \%$, bei Werkzeugmaschinen auf $35 \%$, in der chemischen Industrie um $40 \%$ reduziert. Die Produktionsverbote bzw. -kontrollen in Metall- und chemischer Industrie blieben bestehen. Da dies aber nur $65 \%$ der noch immer in Westdeutschland vorhandenen Kapazität waren, setzte jetzt eine große Demontagewelle ein. Baade, Demontage, S. 568.

169 NA, RG 59/OWEA/French Desk, box 2, folder: France, U.S. Policy Toward, 1945-46 (Lovett, 3. 8. 1947); RG 59, 740.00119 Control(Germany)/5-1747, /7-1847, /7-2247, /8-2747, /9-1547; RG 59, 862.60/9-2848.

$170 \mathrm{AN}, 457$ (Bidault) AP 61/V (Caractère politique du problème des réparations). 
eine alliierte Beteiligung an der Kontrolle der deutschen chemischen Industrie und einen von Deutschland zu garantierenden Primat der (west)europäischen Kohle- und Stahlinteressen zu erreichen ${ }^{171}$. Obwohl es im Quai d'Orsay seit Anfang 1947 zahlreiche Befürworter eines nur De-facto-, aber nicht De-jure-Anschlusses an die Bizone gab und obwohl auch Koenig der Bizonen-Gründung durch „einen gewissen Parallelismus“ zwischen französischer Zone und Bizone Rechnung tragen wollte, verweigerte Bidault aus persönlichen wie taktischen Gründen jedes Zugeständnis, obwohl er in Moskau Entgegenkommen signalisiert hatte ${ }^{172}$. Trotz aller Drohungen, der MarshallPlan werde scheitern, wenn der bizonale Industrieniveauplan durchgesetzt und die Regierung in Paris darüber stürzen werde, gelang es ihm jedoch nicht, sich der Entwicklung entgegenzustemmen. Jetzt gab es im Grunde für Frankreich keine andere Wahl mehr, als sich der Bizone anzuschließen. Obwohl zu befürchten stand, daß die Gründung einer Trizone das Ende des Kontrollrats (bzw. ihrer Einflußposition über das Vetorecht im Kontrollrat) bedeuten werde, kalkulierten die Franzosen nüchtern, daß die Kosten eines Beitritts zur Bizone durch den Marshall-Plan mehr als kompensiert werden würden. Selbst wenn die Bizonen-Mächte einen Solidarbeitrag zur Finanzierung des Importdefizits einforderten, so wog die in Aussicht gestellte Beteiligung an der Ruhrkontrolle und die Garantie der Kohlelieferungen aus Deutschland das politisch wie ökonomisch auf. Frankreich würde also, in diese Richtung neigte sich schließlich die Skala, bei einer Teilung Deutschlands mehr Vor- als Nachteile verzeichnen. Insofern wurde der Anschluß an die Bizone für den (erwarteten) Fall beschlossen, daß die nächste Außenministerkonferenz in London scheiterte, doch wollte man sich durch geschicktes Taktieren im Vorfeld der Konferenz so teuer wie möglich verkaufen $^{173}$. Solange keine Klarheit bestand, welche Möglichkeiten der Marshall-Plan eröffnete, konnte die Regierung den bizonalen Industrieplan nicht akzeptieren, da dieser - trotz gegenteiliger Beteuerungen - das Ende der Reparationen bedeutete. Wenn sie auf einer Revision des Bizonen-Plans beharrte und die „sofortige“ Wiederaufnahme der Reparationen verlangte, so war das mehr politische Taktik als prinzipielle Verweigerung ${ }^{174}$. Immerhin: Sie erreichte, daß sie mit der Saar als Kompensation „abgefunden“" wurde ${ }^{175}$.

Diese Taktik bewährte sich im Hinblick auf das interimistische Kohleprogramm für die Ruhr, das die Anglo-Amerikaner am 16. Juli als Kompensation zum bizonalen Industrieplan beschlossen hatten und das sie auf der Washingtoner Kohlekonferenz vom 12. August bis 10. September um die Fragen der Eigentumsverhältnisse, der Kontrolle und des Managements erweiterten. Frankreich protestierte zusammen mit den Benelux-Ländern gegen diese Maßnahmen und forderte eine Beteiligung an Verteilung und Management im Rahmen einer internationalen (westlichen) Behörde unter dem Dach einer amerikanischen Sicherheitsgarantie. Immerhin konnte Frankreich noch im August gewisse Absichtserklärungen der Bizonen-Mächte hinsichtlich der

171 AN, 457 (Bidault) AP 63/Désarmement Economique (MAE, 5. 8. 1947); AP 60/IV (Note pour le ministre, 25. 7. 1947).

172 AMAE, Y 298, Bl. 26 ff. NA, RG 59, 740.00119 Control(Germany)/1-347, /1-2747, /2-747 und /5-1747. FRUS, 1947/II, S. 396, 400 f., 813 f. Zum „parallélisme“ vgl. unten S. 452 Anm. 202.

173 AN, 457 (Bidault) AP 15. Lattard, Gewerkschaften, S. 56 ff., 60 ff. AMAE, Y 201, Bl. 222 ff. (Courzel, 20. 11. 1947). NA, RG 59, 740.00119 Control(Germany)/9-1547, /10-3047 und /11-1947.

174 FRUS, 1947/II, S. 1049 (22. 8. 1947). AMAE, Y 201, Bl. 101 (Instruktionen für die französische Delegation bei der Londoner Außenministerkonferenz, 4. 11. 1947).

$7^{175}$ AMAE, Y 296, Bl. 11 (Seydoux, 15. 9. 1947); Y 201, Bl. 83 ff. (31. 10. 1947), 222 ff. (20. 11. 1947). 
Ruhr erhalten. Bidault akzeptierte daraufhin eine Stahlproduktion von 10,7 Mio. t für die Bizone, behielt sich aber aus innenpolitischen Gründen vor, auf der Londoner Außenministerkonferenz gegen die Zahlen für Werkzeugmaschinen, Teer, Chlor und die verbotenen Industrien Einspruch zu erheben. Um der französischen Regierung weiter entgegenzukommen, wurden die Gespräche über die Ruhr auf verschiedenen Ebenen im September informell fortgeführt, in Paris wie in Berlin, zudem verknüpft mit der Saarfrage ${ }^{176}$. Aus innenpolitischen Gründen zögerte Frankreich mit seiner Kapitulation in dieser Frage bis zum Scheitern der Londoner Außenministerkonferenz.

Wollten sie Frankreich auf ihrer Seite halten, mußten Briten und Amerikaner bei den am 8. Oktober beginnenden Verhandlungen über eine Revision des Bizonen-Abkommens weitere Zugeständnisse machen. Trotz ihrer Verärgerung über die französischen Pressionen drängten Draper, OMGUS-Vertreter und das State Department zum Nachgeben: Wegen „der Bedeutung der generellen französischen Unterstützung für die amerikanische Position auf der Außenministerkonferenz und der prekären politischen Situation in Frankreich" müsse Paris durch ein Abkommen öffentlich festgelegt werden, „möglichst vor der Eröffnung der Außenministerkonferenz“, notfalls durch neue Zugeständnisse, indem es durch Detailregelungen und die Zusage einer neuerlichen Revision im Falle eines Friedensvertrages zusätzliche Garantien erhielt ${ }^{177}$. Die Verknüpfung von Marshall-Plan und Deutschlandfrage ließ den Handlungsspielraum gegenüber Frankreich und der Sowjetunion von vornherein gering werden - zugunsten des ersteren und zum Nachteil der letzteren. Zwar traten noch einmal Differenzen zwischen den USA und Frankreich auf, doch waren das, da erstere den Preis zu zahlen bereit waren, kaum mehr als Scheingefechte. In der Tat war mit der Einbindung der Bizone in den Marshall-Plan, mit der Zusicherung einer internationalen Kontrolle der Ruhr und der Sicherstellung der Belieferung Frankreichs mit Ruhrkohle für Bidault den französischen Interessen soweit Genüge getan, daß er auf die Abtrennung der Ruhr verzichtete und jede Grundsatzdebatte zu vermeiden suchte, die die Frage der sowjetischen Beteiligung an deren Kontrolle neu aufgeworfen hätte. Das hätte französischen Interessen jetzt nur geschadet. Bidault - von dem verärgerten Marshall ermahnt, auf der Londoner Konferenz seine Proteste gegen den bizonalen Industrieplan nicht $\mathrm{zu}$ wiederholen ${ }^{178}$ - verzichtete auf jedes Ausbrechen aus der westlichen Front, unternahm aber bald neue Versuche, den Einstandspreis zu drücken und den Beitritt zur Bizone zu verzögern.

Obwohl die Sowjetunion Anfang Juli auf der Pariser Vorkonferenz protestierte, der Marshall-Plan „bedeute das Ende der Reparationen und die Wiederherstellung der deutschen Wirtschaft vor der des restlichen Europa“, so hatte sie doch zunächst relativ ruhig reagiert. Beide Punkte entsprangen zweifellos realen Befürchtungen und wurden angesichts der Eckdaten des bizonalen Industrieplans von den Franzosen geteilt ${ }^{179}$. Die zeitliche Koinzidenz von Marshall-Plan (5. Juni), Münchner Ministerpräsidentenkonferenz (6./7. Juni) und Annoncierung des „halbparlamentarischen“ Wirtschaftsrats der Bizone (17. Juni) im Koordinationskomitee, der „praktisch eine Übergangsregie-

176 FRUS, 1947/II, S. 1021 ff., 1047-64, 1085 ff. AMAE, Y 372, Bl. 28 ff.

177 NA, RG 335, box 49, folder: 463.3 Germany (Draper an Clay, 22.11. 1947). Vgl. AMAE, Y 91, Bl. $203 \mathrm{ff}$.

178 FRUS, 1947/II, S. $738 \mathrm{f}$.

179 NA, RG 59, 740.00119 Control(Germany)/7-1747. 
rung" sei, dazu die Einbeziehung der Westzonen in den Marshall-Plan, die Erhöhung des bizonalen Industrieniveaus und die Bekanntgabe der neuen Direktive JCS 1779 am 15. Juli mußte den Sowjets als Ausdruck eines wohlabgestimmten Plans erscheinen, als radikaler Kurswechsel, als Aufkündigung von Potsdam. Aber noch wiesen Offiziere der SMAD das Argument der DWK zurück, der Marshall-Plan werde die Westzonen „mit Devisen überschwemmen“ und derart „eventuell einen Abbruch der Wirtschaftsbeziehungen mit dem Westen" nach sich ziehen ${ }^{180}$. Am 18. August erachtete es ein SMAD-Offizier „nicht für empfehlenswert“, einen Wirtschaftsplan für das gesamte Jahr 1948 aufzustellen: „Niemand wüßte, wie die Londoner Konferenz ausgehe. Die SMAD möchte sich auf keinen Fall vor dieser Konferenz irgendwie festlegen, denn wenn diese Konferenz die Einheit Deutschlands beschließt, was der dringende Wunsch von Molotow ist, wie er selbst bezeugen kann, da er $1 \frac{1 / 2}{2}$ Monate der Moskauer Konferenz beigewohnt hat, dann wird über die Planung im gesamtdeutschen Maßstab an einem anderen Tisch gesprochen als an dem, an dem wir jetzt sitzen.“181 Doch am selben Tag protestierte die Sowjetunion nach Äußerungen Bevins im Unterhaus am 4. August gegen die separaten Verhandlungen der drei Westmächte; eine Revision des Industrieniveauplans oder auch „die Errichtung einer Art von Sonderregime für das Industriegebiet der Ruhr“ könnten nur mit Zustimmung aller vier Mächte erfolgen. Am 30. August wiederholte die Sowjetunion im Kontrollrat ihren Protest gegen den am Vortag veröffentlichten Bizonenplan, der der „faktischen Teilung“, der „Aufsplitterung“ Deutschlands hinter dem Rücken des Kontrollrats gleichkomme. Sie habe in Moskau die Erhöhung des Industrieniveaus angeboten, doch gehe es den Westmächten offenkundig um die Auslieferung der Westzonen an ausländische Monopole ${ }^{182}$.

In ihrer Antwort in Moskau wie im Kontrollrat beriefen sich die USA auf die Handlungsunfähigkeit des Kontrollrats und ihr daraus entspringendes Recht auf unilaterales Vorgehen bzw. interzonale Arrangements ${ }^{183}$. Gedeckt durch die weitgehend einhellige Auffassung des Kabinetts beantwortete auch Robertson die sowjetischen Proteste mit der lapidaren Erklärung, der Industrieniveauplan von 1946 sei ein „toter Buchstabe“, den er als "nicht mehr in Kraft" ansehe, da die britischen Bedingungen hinsichtlich der Wirtschaftseinheit nicht erfüllt worden seien. Mit der Feststellung: „Es gibt zur Zeit keinen Vier-Mächte-Industrieniveauplan“, beendeten die Briten am 12. September im Koordinationskomitee die Debatte, was, wie die sowjetischen Proteste zu Recht bemerkten, einer einseitigen Aufkündigung gleichkam. In der Tat hatten die Briten, obwohl die Veröffentlichung des Bizonenplans wegen der französischen Proteste sich bis zum 29. August hingezogen hatte, seit Anfang des Monats im Kontrollrat alle weiteren Beratungen der Reparationsfrage blockiert. Das mußte der Sowjetunion ein Beweis für ihre These sein, die Revision des Industrieniveauplans stehe im engen Zusammenhang mit dem Marshall-Plan als der ökonomischen Ergänzung der Truman-Doktrin ${ }^{184}$. Gleichwohl unternahm die SMAD einen neuen Vorstoß. Nachdem sie sich bereits Anfang März 1947 für die Moskauer Konferenz von

180 BAP, L-2/3251, Bl. 431 ff. (Orlopp, 17. 7. 1947).

181 BAP, G-2/1044, Bl. 26 (Chemelewski, Planökonomische Abteilung, 18. 8. 1947).

182 Germany 1947-49, S. 362.

183 FRUS, $1947 /$ II, S. $1066 \mathrm{ff}$.

184 Tägliche Rundschau, 26.6. 1947 (nach Prawda vom 17.6. und TASS, also vor den Beratungen Molotows mit Bevin und Bidault), 18. und 22. 7. 1947. 
der DWK Material hatte erarbeiten lassen ${ }^{185}$, wurde diese im Juli 1947 angewiesen, einen „Wirtschaftsplan für Deutschland“ (ohne das Saargebiet!) zu entwerfen, „der eine Versorgung der Bevölkerung entsprechend einem ,mittleren europäischen Lebensstandard" ermöglicht". In ihrer Vorlage vom September schlug die DWK vor, nicht wie der Kontrollratsplan das Jahr 1932, sondern das Jahr 1928 als Ausgangsbasis zu wählen, in dem das Industrieniveau um ca. $6 \%$ höher gelegen hatte. Nach Absprache mit der SMAD wurden Lebensmittelimporte von 2,5 Mrd. RM und Rohstoffeinfuhren von 2,1 Mrd. RM vorgesehen, eine Erhöhung um 50\% gegenüber dem Kontrollratsplan. Diese Einfuhren waren nur für den Grundbedarf, „notwendig zur Herstellung eines minimalen Lebensstandards“, berechnet. „Kontrollratsplan, bizonaler Plan und Gegenvorschlag [der DWK] sehen keine Reparationen aus der laufenden Produktion vor. Eine Vereinbarung derselben in der endgültigen Regelung würde zu einer weiteren Erhöhung der Ausfuhr zwingen."186 Der bizonale Alleingang zerstörte die Entwürfe der DWK bereits im Ansatz, die die sowjetischen Reparationsforderungen auch aufgrund wachsenden Widerstands in den Betrieben - für nicht mehr verkraftbar hielt und daher bei Produktionsrückgang eine anteilige Reduktion der sowjetischen Bezüge forderte ${ }^{187}$. Auf Zonenebene war es ausgeschlossen, in absehbarer Zeit die Reparationslieferungen an die Sowjetunion auf die Ebene normaler Handelsbeziehungen umzustellen und zu diesem Zweck durch vorübergehendes Aussetzen der Lieferungen die Produktivität der ostzonalen Wirtschaft zu erhöhen ${ }^{188}$. Vielmehr sah sich die Sowjetunion endgültig auf die verstärkte Ausbeutung der eigenen Zone verwiesen, die daher nicht nur leistungsfähiger, sondern auch von westlichen Lieferungen unabhängig gemacht werden mußte ${ }^{189}$. Ungeachtet einer neuen Welle von Demontagen von Betriebs-,Resten“ zur „Komplettierung“ früherer Demontagen bestand die SMAD immer unnachgiebiger auf der vorrangigen Abdeckung des Bedarfs der Sowjet AGs, der SMAD und der Lieferungen in die Sowjetunion. Angesichts der zu erwartenden „ernsten Folgen“ für die „übrige Industrie“ drängten die Länder- bzw. Provinzialregierungen Ende September bei der SED auf Proteste bei der SMAD, Betriebsdelegatio-

185 BAP, G-2/1339 (Produktions- und Kapazitätsplan gemäß Kontrollratsplan 1949, 1. 3. 1947). Der Entwurf verzeichnete den „Produktionsumfang“ gemäß Kontrollratsplan, die erforderliche Produktionskapazität, die am 1. 3. 1947 „vorhandene“ Kapazität und die „bis zum 1. 1. 1949 erreichbare Kapazität“, mit separater Ausweisung der Daten der SBZ. Erhebliche Investitionen seien erforderlich, um angesichts der Demontagen die für 1949 vorgesehenen Kapazitäten zu erreichen, da sich in fast allen Bereichen die Position gegenüber den Westzonen verschlechtert hatte. Am 18. 12. 1946 bzw. 9. 1. 1947 verlangte die SMAD von der DWK die Beantwortung eines Fragebogens über Produktion und Kapazität für die Stichjahre 1936, 1938 und 1944, einmal für einen „Perspektivplan“ bis 1950, „der die Verwirklichung des Kontrollrats-Plans zum Ziel haben soll“, zum anderen „als Unterlagen für Besprechungen im Kontrollrat“. G-2/8724, Bl. 97; G-2/1280, Bl. 7 ff. (Der Kontrollratsplan 1949, 7. 3. 1947). Badstübner/Loth, Pieck, S. 99. Der Planentwurf zur „Realisierung des Industrieplans 1949“, der bis zum 5.3. vorliegen mußte, sollte den "gesamtdeutschen Wirtschaftsraum, zum Teil aufgeteilt nach Zonen“, berücksichtigen). G-2/1044, Bl. 46 (28. 2. 1947).

186 BAP, C-15/504 (3. 7. 1947) und 459 (10.9. 1947; Hervorhebung im Original).

187 BAP, C-15/678, Bl. 3 ff. (Skrzypczynski, 14. 10. 1947); C-15/282, Bl. 29 (24. 3. 1948).

188 BAP, C-15/231, 252, 459. Der Außenhandel mit der Sowjetunion entzog sich der Kenntnis der DWK. Eine Konferenz von SED-Mitgliedern verschiedener Zentralverwaltungen forderte: „Wir wollen deshalb nicht auf Reparationen exportieren, sondern auf Kompensationen im echten Außenhandel.“ "Was exportiert wird, wissen wir nicht. Wir müssen über alle aus der Zone herausgehenden Lieferungen Bescheid wissen, auch die Reparationen.“ SAPMO, ZPA, IV/2/602/70, Bl. 66 (Mai 1947).

189 Zur Ostorientierung der SBZ-Wirtschaft vgl. oben S. 186 mit Anm. 51. 
nen wurden beim Parteivorstand der SED vorstellig ${ }^{190}$. Doch auch diese Proteste der SED blieben vergeblich. Im Gegenteil: Mit Befehl Nr. 234 vom 9. Oktober 1947 verlangte die SMAD eine drastische Steigerung der Produktivität zu ihren Gunsten ${ }^{191}$ der zugleich die Anerkenntnis der wirtschaftlichen Spaltung, den Beschluß zum Alleingang bedeutete, einschließlich der Vorbereitung einer separaten Währungsreform. Zur Durchführung der Maßnahmen übertrug die SMAD mit Befehl Nr. 32 vom 12. Februar 1948 der DWK erweiterte Rechte. Dabei standen die Reparationen derart nachdrücklich im Vordergrund, daß die Aufwertung der DWK in erster Linie der neuen sowjetischen Politik entsprach und keine Ad-hoc-Reaktion auf die geplante, infolge der französischen Proteste zunächst ausgesetzte Bizonen-Reorganisation vom 8. Januar 1948 als „Programm der Spaltung Deutschlands“ war ${ }^{192}$.

Diese Maßnahmen mochten die Auffassung Clays bzw. die Vermutung der Briten nachträglich bestätigen, durch Zugeständnisse in der Reparationsfrage wäre ein Arrangement mit der Sowjetunion noch immer möglich gewesen. Doch hatte die Kursänderung noch vor der entscheidenden Tagung der Kominform am 22. und 23. September 1947 eingesetzt. Der gleichzeitig abgehaltene II. Parteitag der SED vom 20. bis 24. September spiegelte den Kurswechsel bereits wider. Am 27. Oktober erklärten Grotewohl und Pieck gegenüber dem Politischen Berater der SMAD, „daß die Arbeiterklasse Deutschlands in der gegenwärtigen Zeit nicht an einer Beseitigung der Zonengrenzen interessiert sei, weil die Demokratisierung nicht in ganz Deutschland durchgeführt wurde. Man brauche Zeit, damit die neue demokratische Ordnung in der sowjetischen Zone kräftiger werde. [...] Nach der Meinung Grotewohls werde die Londoner Konferenz nicht zu einer Lösung des deutschen Problems führen. Das sei sogar gut." ${ }^{193}$ Der Abschluß der Transformation und die Konsolidierung der sowjetischen Machtposition in Deutschland verlangten die Separation der SBZ. Damit war der Verhandlungsspielraum auch der Sowjetunion schon im Vorfeld der Londoner Konferenz sehr schmal geworden.

\section{Die Londoner Konferenz}

Seit Oktober 1947 richteten sich Briten und Amerikaner auf das Scheitern der Londoner Konferenz ein. Sie fühlten sich vom Kontrollrat in ihren Bemühungen behindert, die Bizone effektiv zu organisieren und die Kosten ihrer Besatzungsverwaltung zu reduzieren. Beide stellten ihre Planungen darauf ab, die Konferenz nur aus propagan-

190 SAPMO, ZPA, Nl 182/1189, Bl. 26 ff. (Befehl Nr. 1987 der SMA-Sachsen, 6. 9. 1947); IV/2/602/51, Bl. $62 \mathrm{f}$.

191 Nach Gesprächen mit Sokolowski und Kowal wurde die Prioritätenfolge bestimmt: 1. Bedarf der Sowjetunion und der SMAD, 2. „wirtschaftswichtiger Bedarf“ der SBZ, 3. Export, 4. Versorgung der Bevölkerung. Die Durchführungsbestimmungen für den Befehl Nr. 234 wurden „entsprechend den Wünschen des sowjetischen Sachreferenten“"gestaltet. BAP, C-15/133 (März 1948). „Es darf in keinem Fall der Zustand eintreten, daß die Zivilbevölkerung auf Kosten des wirtschaftswichtigen Bedarfs befriedigt wird, denn sonst entsteht ein Produktionsrückstand." C-15/510, B1. 27 (DZVI, 11. 11. 1947).

192 Um ein antifaschistisch-demokratisches Deutschland, S. 585 f. Zum Grad der „operativen Einmischung", den sich die SMAD vorbehalten hatte, ebenda, S. $610 \mathrm{ff}$.

193 Zitiert nach: Laufer, Auf dem Wege, S. 54. Zwar schien Pieck noch überzeugt: „London ist die letzte Chance“, doch wollte Külz (LDPD) bereits am 6.11. die „Verantwortung für London nicht übernehmen - Zonen schon auseinander“. SAPMO, ZPA, Nl 36/739, Bl. 18 (Külz), 22, 68R (Pieck). 
distischen Gründen abzuwarten, um sich nicht vorwerfen lassen zu müssen, die Spaltung Deutschlands unnötig herbeigeführt zu haben. England arbeitete auf eine Vertagung des Kontrollrats sine die hin. Eine britische Zusammenstellung der Fragen, über die im Kontrollrat Einigung nicht möglich war, unterstrich, „daß in der großen Mehrheit aller Fälle die Russen für das Scheitern von Vereinbarungen verantwortlich waren“. Nach der Londoner Konferenz sollten alle Vertreter der CCG in den Direktoraten und Unterorganen angewiesen werden, Debatten über die politischen Grundsatzfragen, die nur auf der Ebene des Kontrollrats oder der Regierungen gelöst werden konnten, als „Zeitverschwendung“ zu vermeiden. Derart ließe sich das Arbeitsvolumen des Kontrollrats um bis zu $75 \%$ reduzieren. Das hieß nichts anderes, als den Stillstand des Kontrollrats öffentlich zu dokumentieren, auch wenn man „zur Wahrung des Gesichts“ nicht umhinkonnte, „daß wir einige künstliche Anstrengungen unternehmen müssen, um diese Fassade so eindrucksvoll wie möglich zu machen“. Untrennbar mit einer solchen Strategie verbunden war eine „klare Neudefinition der Befugnisse von Kontrollrat und Zonenkommandeuren“, die angesichts des rapiden „Bedeutungsverlusts des Kontrollrats“ nur auf eine „Übernahme seiner Befugnisse durch die Zonenkommandeure" hinauslaufen konnte ${ }^{194}$. Derart festgelegt waren die USA noch nicht, obwohl sich das OMGUS auf fast allen Gebieten auf den bi- oder trizonalen Alleingang vorbereitete. Briten und Amerikaner nutzten den Oktober, um sich abzustimmen und Paris in ihren Konsens einzubeziehen. Denn es gab eine Reihe von Unwägbarkeiten. Nicht auszuschließen war, daß die Sowjetunion, um den Marshall-Plan und die Konsolidierung Westdeutschlands zu verhindern, korrumpierende Zugeständnisse machte. Ebenso ungewiß war, ob die Deutschen nicht der sowjetischen Einheitspropaganda erlagen. Gegenstrategien mußten entwickelt werden, um den zu erwartenden sowjetischen Anklagen begegnen zu können. Dazu gehörte, daß die Arbeit im Kontrollrat fortgesetzt wurde. Doch obwohl die Angelsachsen annahmen, daß Moskau vor dem totalen Bruch zurückschrecken werde, dürfe das die Westmächte nicht dazu verleiten, „die Maßnahmen auszusetzen, die sie unternähmen, um die Westzonen als eine Einheit zu organisieren“. Die Briten drängten die Franzosen bilateral zur vorherigen Abklärung der Streitpunkte, die auf der Moskauer Konferenz im Frühjahr eine geschlossene Front des Westens verhindert hatten: deutsche Zentralregierung und Zentralverwaltungen, Ruhr und Währungsreform. Am 24. Oktober schlug die britische Regierung ihren westlichen Partnern konkrete Maßnahmen für den Fall vor, daß die Konferenz scheitern sollte; die betonten in erster Linie die Notwendigkeit des Zusammenschlusses zur Trizone ${ }^{195}$. Vor allem Bevin bestand auf einer raschen Entscheidung und sprach sich gegen jede weitere Vertagung der Probleme

194 PRO, FO 1049/922 (CCG/ASEC, 1. 10. 1947; Minute, 6. 10. 1947; CCG/Political Division an FO, 21. 10. 1947); PREM 8/512 (Bevin: C.M.(47)90, 25. 11. 1947). Bevin hatte bereits in Moskau im April 1947 auf eine Vertagung sine die gehofft, um freie Hand in der Bizone zu haben, und Marshall am 8. 4. auf ein gemeinsames Programm für den Fall eines Scheiterns der Konferenz festlegen wollen. Deighton, Impossible Peace, S. 160 f., $202 \mathrm{f}$. Die Diskussion über eine faktische Stillegung des Kontrollrats war im April 1947 von der Political Division der CCG ausgelöst worden, die Unterstützung beim Leiter des British Element beim Alliierten Sekretariat, Raw, gefunden hatte. Die Liste Raws über die unerledigten Fragen umfaßte 40 Themen für die Zeit vom Dezember 1946 bis September 1947.

195 AMAE, Y 201, Bl. 39 ff. (Bevin-Chauvel, 20. 10. 1947); Y 296, Bl. 240 ff. Clay hatte Ende August 1947 auf eine Verschmelzung der britischen und amerikanischen Zonen gedrängt, um beim Scheitern der Londoner Konferenz handlungsfähig zu sein. CP, S. 416. 
aus. Am 3. November hatte er sich entschlossen, „die Sache schnell zu Ende zu bringen und den besten Grund zum Bruch zu finden“. Zehn Tage später schloß sein Mitarbeiter Dean „eine zeitweilige Spaltung“ Deutschlands nicht aus, in der Erwartung, daß die reicheren Westzonen dann so ausgebaut werden könnten, daß sie ,wie ein Magnet" auf die Ostzone wirkten ${ }^{196}$.

Gleichzeitig versuchte in Washington das State Department, die Franzosen zu überzeugen, daß die Ziele der drei westlichen Mächte weitgehend deckungsgleich seien und in prinzipiellem Gegensatz zu den sowjetischen stünden. Die interne Bestandsaufnahme der Franzosen zeigte in der Tat, daß sie in den meisten Grundsatzfragen mit den Angelsachsen übereinstimmten. Eine Abgleichung mit den sowjetischen Vorstellungen wurde gar nicht mehr unternommen, zumal man angesichts der Konstellationen zuversichtlich war, in den strittigen Fällen von den westlichen Verbündeten Nachbesserungen zu erreichen. Frankreich stand (wie die Sowjetunion auch) vor der Situation, daß es seine (reparations)politischen Vorteile ohne das Potential der Bizone einbüßte, bei einem Anschluß an diese aber die politische Handlungsfreiheit in seiner Zone verlor. Insofern hatte der innerwestliche Akkord auch seine Nachteile: Sollten die westlichen Alliierten den Franzosen wirtschaftlich und verfassungspolitisch ebenso entgegenkommen wie bei der Internationalisierung der Ruhr-Kontrolle („Alliierte Kontrollgruppe“), würde Paris kaum eine andere Wahl bleiben, als die VierMächte-Verhandlungen ebenfalls als endgültig gescheitert zu betrachten. Frankreich hätte dann die Voraussetzungen für eine Schaukelpolitik zwischen Ost und West verloren, keine Alternative mehr zum Beitritt zur Bizone; kurz: es wäre erpreßbar geworden. Die drohende Alternativlosigkeit schürte neue Debatten, wie weit Frankreich sich auf Vorabfestlegungen einlassen dürfe und ob es nicht vorteilhafter sei, den endgültigen Bruch zu verhindern. Doch abermalige Verzögerungen waren wenig hilfreich, da der Marshall-Plan drängte und die französische Zone zum Zuschußbetrieb zu werden drohte ${ }^{197}$. Aufschiebende Kompromißformeln, das wußte man in Paris, genügten den Anglo-Amerikanern nicht mehr, sondern diese verlangten konkrete Maßnahmen und offene Bekenntnisse. Der Ausweg schien die Vertagung sine die von Außenministerkonferenz und Kontrollrat zu sein. Dies hätte den Sowjets jeden Vorwand genommen, „einen Bruch der Kontrollabkommen geltend zu machen und den Aufenthalt der Vertreter der drei anderen Mächte in der alten Reichshauptstadt unmöglich zu machen “198, hätte eine Schaukelpolitik zwischen Ost und West zumindest als Drohpotential erhalten. Paris hielt daher an der Einheit Deutschlands als Besatzungsgebiet und damit am Kontrollrat fest, der es erlaubte, weiterhin die zonale Autonomie mit einem gesamtdeutschen Veto zu verknüpfen. Die Rechnung ging zumindest teilweise auf: Die Bizonen-Mächte waren bereit, Frankreich durch weitere Nachgiebigkeit im westlichen Lager zu halten, während sich umgekehrt die Sowjetunion erneut nicht in der Lage zeigte, Frankreich durch Zugeständnisse aus der westlichen Front herauszubrechen ${ }^{199}$.

196 Zitiert nach: Deighton, Impossible Peace, S. $202 \mathrm{f}$.

197 AMAE, Y 201, Bl. 56 ff. (21. 10. 1947), 63 ff. (28. 10. 1947); Y 296, Bl. 240 ff. (14. 11. 1947). Vgl. FRUS, 1947/II, S. 680 ff. (18. 9. 1947), 684 (8. 10. 1947).

198 AMAE, Y 201, Bl. $222 \mathrm{ff}$. (Courzel an Paris, 20.11. 1947).

199 Im Herbst 1947 bot Moskau erneut an, die Abtrennung der Saar anzuerkennen, wenn Frankreich der Vier-Mächte-Kontrolle der Ruhr zustimme. In London galt das offiziell nicht mehr. FRUS, 1947/II, S. 721, 736. Tägliche Rundschau, 5. 11. 1947. 
Dieses Zögern der Sowjetunion mochte in der Illusion begründet sein, mit den französischen Kommunisten und der deutschen Volkskongreß-Bewegung jeweils derart starke innenpolitische Bündnispartner zu haben, daß sie auf eine solche Rücksichtnahme nicht angewiesen war. Umgekehrt konnte die Sowjetunion bei den Franzosen immer weniger auf Entgegenkommen rechnen, je mehr diese sich, wie Seydoux Anfang September 1947 richtig voraussagte, mit Hilfe der SED und der VolkskongreßBewegung zum Wahrer der deutschen Einheit aufschwang. Während Seydoux das sowjetische Ziel begrüßte, die Wirtschaftseinheit zu erhalten, sah er das Mittel, nämlich den Appell an den deutschen Nationalismus, mit wachsender Skepsis. Seydoux war ratlos: „Nachdem es als einzige der Besatzungsmächte bis zum äußersten versucht hat, eine Vier-Mächte-Politik zu retten, deren Grundlagen es nicht mitberaten durfte, wird Frankreich sich in nächster Zukunft dazu veranlaßt sehen, sich an der Wiedergeburt Westdeutschlands zu beteiligen, das, weil es ohne [Frankreich] geschaffen wurde, sich gegen dessen Interessen zu entwickeln droht.“ Eine Spaltung Deutschlands schien ihm nicht vorteilhaft, weil ein von den Anglo-Amerikanern unterstütztes Westdeutschland kein „gefährlicher Feind“ wie ein sowjetisch beeinflußtes Gesamtdeutschland, wohl aber ein „ernsthafter Konkurrent“ werden würde. Insofern votierte er für die Fortsetzung des alliierten Vier-Mächte-Regimes. Paris hatte nach dieser Analyse kaum mehr Handlungsspielraum. Es war bezeichnend für die Ausweglosigkeit, daß Seydoux seiner Regierung vorschlug, den sonst wenig geliebten Clay zu hofieren, da er als einziger diese Entwicklung im Vorfeld der Londoner Konferenz noch stoppen könne: „Die Zeit arbeitet gegen uns, und zwar schnell.“200

Auch im Umfeld Koenigs ging man Ende Oktober 1947 vom Scheitern der Konferenz aus. Das werde Deutschland, Europa und die Welt in zwei Lager spalten. „Wenn das passiert, wird zweifellos in der näheren oder weiteren Zukunft ein Krieg die Folge sein." Das mochte Zweckpessimismus sein; denn man folgerte im Sinne der eigenen Interessen daraus, durch Vertagung der Entscheidung stabilisierend wirken zu können. „Solange die französische Zone nicht formell mit der Bizone fusioniert ist, kann die Spaltung Deutschlands vermieden werden.“ Koenig lehnte die Trizone als das Ende der französischen Zonenautonomie in Deutschland ab, wußte aber zugleich, daß seine Zone allein wirtschaftlich nicht lebensfähig war. Eine informelle Assoziierung der französischen mit der Bizone „würde das Leben der Vier-Mächte-Organisationen in Berlin verlängern, die kein raison d'être mehr hätten, wenn die französische Zone formell mit der Bizone fusioniert würde. [...] Solange sich die Oberkommandierenden in Berlin träfen, bestünde die Möglichkeit, eine Grundlage für die Verständigung mit den Russen zu finden. “201 Er suchte einen Weg, das Vetorecht im Kontrollrat zu sichern, das er in einer Trizone verlieren würde. Die Lösung schien ihm „die Festlegung eines gewissen Parallelismus zwischen der Wirtschaftspolitik in den zwei Zonen“ zu sein, die aber ,nicht zum Verzicht auf die Möglichkeit führen darf, in gewissen Punkten Vier-Mächte-Entscheidungen in Berlin herbeizuführen“202. Die Franzosen waren

200 AMAE, Y 296, Bl. 2 f., 10 ff. (15.9. 1947), 54 ff.

201 NA, RG 59, 740.00119 Control(Germany)/10-3047 (Hervorhebung im Original). Zur französischen Diskussion über den Bizonen-Beitritt vgl. AN 457 (Bidault) AP 15/Après CMAE London (Noiret, 17. 10. 1947; GMZFO, Oktober 1947; CCFA, 2. 11. 1947; René Mayer, 10. 12. 1947).

$202 \mathrm{AO}$, Berlin/3276/5/2019D (Mesures à prendre en vue de rendre parallèles les politiques française et anglo-saxonne dans la Zone occidentale; Entwurf, Januar 1948). Diese Politik sollte sich auf Repara- 
sogar bereit, den Ministerpräsidenten ihrer Zone die Teilnahme an einer neuen Vierzonenkonferenz zu ermöglichen, um ihrerseits durch Druck „von unten“ eine Spaltung zu verhindern ${ }^{203}$.

Trotz gewisser Annäherungen konnten die Westmächte keine Übereinstimmung über Tagesordnung und Taktik für die Londoner Konferenz erzielen ${ }^{204}$. Die Briten drängten, gleich die politischen Fragen anzuschneiden und die Entscheidung zu suchen. Mit der Diskussion der Wirtschaftseinheit riskiere man, Hoffnungen in der Öffentlichkeit zu erwecken, endlose Debatten im Kontrollrat zu provozieren und eine weitere Außenministerkonferenz abwarten zu müssen. Dagegen wollten die USA zunächst die Frage der Wirtschaftseinheit diskutieren, dazu notfalls „eine Überprüfung der Bedingungen und der Methoden zur Realisierung der wirtschaftlichen und politischen Einheit in ganz Deutschland durch den Kontrollrat" abwarten. Das wäre auf einen weiteren Kontrollratsbericht hinausgelaufen, obwohl an einer Detaildiskussion der Fragen, die in Moskau dem Kontrollrat zur Überprüfung bzw. Exekution übertragen worden waren, kein Interesse bestand. Sollten sich die Sowjets wider Erwarten kooperativ erweisen, waren die USA taktisch so flexibel, daß ad hoc auch ,andere Fragen, die nicht ausdrücklich erwähnt sind, [...] an die Tagesordnung unter der Rubrik ,Sonstiges" angehängt werden“" könnten ${ }^{205}$. Aus Berlin protestierte Clay gegen alle Ưberlegungen, die deutsche Frage auf eine weitere Außenministerkonferenz zu vertagen. Auch er drängte jetzt auf klare Entscheidungen. „Wir müssen den Mut haben, mit der Regierung für Westdeutschland schnell weiterzumachen, erst provisorisch und dann repräsentativ, falls der Rat der Außenminister nicht in der Lage ist, die Antwort für ganz Deutschland zu geben. Ich bezweifle sehr, daß ein solches Vorgehen den VierMächte-Apparat gefährden würde. Und wenn es das täte, würden wir immer noch die Russen zwingen, die Tür zuzuwerfen, und selbst wenn sie die Tür zuschlagen, könnten wir immer noch in Berlin weitermachen. Jedoch können wir nicht erfolgreich weitermachen, wenn wir keinen Regierungsapparat für Westdeutschland einsetzen. “206 Eine interne Analyse der Kontrollratstätigkeit seit der Moskauer Außenministerkonferenz und der Positionsbestimmungen der vier Mächte auf der vorbereitenden Tagung der stellvertretenden Außenminister kam zu dem Schluß, daß nicht die Wirtschaftsfragen, sondern die mögliche Einsetzung einer provisorischen deutschen Regierung die Kernfrage sein werde. Chancen für einen Kompromiß zwischen den westlichen (einschließlich, wenngleich etwas abgeschwächt, der französischen) und sowjetischen Positionen wurden nicht gesehen. Gefragt sei eine unnachgiebige, aber flexible Prinzipienpolitik. Ziel der USA auf der Londoner Außenministerkonferenz müsse es sein, „die wirtschaftliche und politische Vereinigung Deutschlands so schnell wie möglich zu erreichen, vorausgesetzt, daß dies erreicht werden kann, ohne den Erfolg des Marshall-

tionen, Restitutionen, Besatzungskosten, Statistik, Preise, Löhne, Dekartellisierung, Rationierung u. a. m. erstrecken.

203 Overesch, Illusion, S. 140 ff. Der Plan, eine Ministerpräsidentenkonferenz am Vorabend der Londoner Konferenz abzuhalten, scheiterte an den Ministerpräsidenten der englischen und amerikanischen Zone, nicht zuletzt auch am Widerstand Adenauers und Schumachers. Es kam nicht mehr als ein „Aufruf zur deutschen Einheit“ vom 9. 11. 1947 zustande, den zehn prominente Privatleute erarbeitet hatten und den alle Ministerpräsidenten der SBZ, aber keiner der Westzonen unterschrieben. Friedensburg, Einheit, S. 176 ff. Bender, Deutschland, S. 93 ff.

204 FRUS, 1947/II, S. $688 \mathrm{ff}$.

205 AMAE, Y 201, Bl. 87 ff. (Massigli, 4. 11. 1947).

206 CP, S. 476 (3.11. 1947). 
Plans zu gefährden, und vorausgesetzt, daß die Grundprinzipien der amerikanischen Politik nicht in Frage gestellt werden“. Angesichts der „momentanen Stimmung im amerikanischen Kongreß und im amerikanischen Volk" schien es gänzlich unmöglich, „mit dem Argument der Zweckmäßigkeit oder ähnlichem die Preisgabe irgendeiner politischen Grundposition zu rechtfertigen. Obwohl das zunächst darauf hindeuten könnte, daß dies eine ,Alles-oder-Nichts'-Konferenz ist, glauben wir nicht, daß die gegenwärtige Regierung, wenn sie tatsächlich mit einer endgültigen Teilung Deutschlands konfrontiert ist, diesen allerletzten Schritt zu einer solchen Spaltung tun würde.“ Der Widerstand der Sowjetunion gegen die Bizone, gegen jede Spielart der Föderalisierung, gegen den Byrnes-Plan und besonders gegen den Marshall-Plan weckte immer stärkere Vorbehalte gegenüber einer Lösung, die ihr (und Frankreich!) mehr als nur ein nachträgliches Veto eingeräumt hätte, sah die Analyse es doch inzwischen als Ziel der Sowjetunion an, „die Errichtung einer provisorischen Regierung für Deutschland zu erzwingen, dabei die starken zentralen Regierungsbefugnisse betonend, während der Kontrollrat seinen höheren Rang behält, so daß sie gemäß der Einstimmigkeitsregel die Interessen der Linkspartei wahren könnte, die sie eingesetzt hat ${ }^{\text {“207. }}$. Insofern war nicht die Suche nach deutschlandpolitischen Lösungen, sondern das globale Verhältnis zur Sowjetunion bestimmend für den Grundkurs. „Hauptprämisse“ war, „daß unsere Aufmerksamkeit der Zukunft Europas und nicht nur Deutschland als einem isolierten Problem gilt“. „Wir sind an der Integration Deutschlands in ein freies und demokratisches Europa interessiert. Wir machten und wir machen Fortschritte auf diesem Weg mit dem Teil Deutschlands, den wir kontrollieren, und wir werden diesen Fortschritt nicht gefährden, indem wir ein vereintes Deutschland als an sich richtig anstreben. Wenn wir einen größeren Teil Deutschlands integrieren können als den, den wir jetzt kontrollieren, unter Bedingungen, die das, was wir jetzt tun, fördern und nicht behindern, dann begrüßen wir das; aber nur, wenn die Umstände stimmen.“208

Anders als die Briten, die verfassungspolitische Vorstellungen für den Fall einer Einigung schon nicht mehr entwickelten, unternahmen die USA einen weiteren Anlauf, den Sowjets eine letzte Chance anzubieten: jedoch ultimativ und ausschließlich zu ihren Bedingungen. Sie entwickelten - in Weiterführung ihrer bereits auf der Moskauer Konferenz unterbreiteten Vorschläge - ein Modell, nach dem „der Kontrollrat eine weitgefaßte Charta erlassen sollte, die zuerst die Ernennung eines deutschen Regierungsorgans und danach die baldmögliche Abhaltung von Wahlen vorsieht“209. Die von amerikanischer Seite vorgesehenen sechs Direktiven des Außenministerrats an den Kontrollrat betrafen Grundzüge der Verfassungsprinzipien, die Regierungsbildung, eine sich selbst tragende Wirtschaft, eine dauerhafte Entmilitarisierung sowie die Grenzfragen und die Bevölkerungsverteilung. Danach waren alle Ad-hoc-Maßnahmen vom Kontrollrat bis zum 30. Juni 1948 selbst auszuführen und nur in der Ausnahme von der deutschen Regierung, die als provisorische bis zum 31. Januar $1948 \mathrm{zu}$ ernennen und aufgrund der vom Kontrollrat zu genehmigenden Verfassung bis zum

207 BA, Z 45 F/OMGUS, 2/102-3/10 (Lt. Colonel H.A. Gerhardt an Assistant Secretaries, Critique on Studies on the London Conference of the Council of Foreign Ministers, Dezember 1947).

208 TL, Truman Papers, President's Secretary's File, box 178, folder: Germany 1 (An Approach to the CFM, o. D.).

209 FRUS, 1947/II, S. 693 (30. 10. 1947). 
1. Januar 1949 zu wählen sei ${ }^{210}$. Diese Forderungen zielten auf die Deblockierung des Kontrollrats, freilich nach amerikanischen Vorstellungen. Und indem sie zugleich die Auflösung der Sowjet AGs und die Rechnungslegung über die Reparationsentnahmen forderten, verknüpften sie auch die Wirtschaftseinheit mit Bedingungen, die eine sowjetische Ablehnung mehr als wahrscheinlich machten. Dieser Vorstoß war insofern weniger ein „allerletzter Test“, sondern die taktische Vorbereitung für den „Bruch“, um der Sowjetunion gegenüber den Deutschen die Verantwortung für die kaum mehr vermeidbare Teilung zuzuschieben. Nach dem Eindruck der Franzosen hoffte man in Washington einerseits noch immer, daß die Sowjetunion vor einem vollständigen Bruch zurückschrecken werde; andererseits schien man dort zu radikalerem Handeln entschlossen, als Frankreich lieb sein konnte. „Wenn beim Ausbleiben einer Einigung über die Wirtschaftseinheit die Reorganisation der Bizonen-Verwaltung weitergeführt werden muß, wird das State Department nicht mehr den geringsten Wert darauf legen, in BERLIN wenigstens ,die Fassade“ einer Vier-Mächte-Kontrolle aufrechtzuerhalten."

Angesichts des Verlaufs der Vorkonferenz der Stellvertreter, von der man in Paris bereits im August keine Ergebnisse erwartet hatte ${ }^{212}$, richtete sich auch die französische Regierung auf das Scheitern der Hauptkonferenz ein. Die Anglo-Amerikaner würden sich nicht mit einer bloßen Einigung im Grundsatz zufriedengeben, sondern „die geeigneten Bedingungen, um diese Einheit zu realisieren“, festlegen wollen; dagegen werde die sowjetische Delegation "alle Arten von Obstruktion“ setzen. Das machte es der französischen Politik nicht leichter, ihren prekären Balanceakt glaubwürdig durchzuhalten, die Einheit der Alliierten mit der Teilung Deutschlands zu verknüpfen. Ein grundsätzlicher Kurswechsel kündigte sich an: „Was uns betrifft“, so wurde der französischen Delegation in ihren Instruktionen mit auf den Weg gegeben, „so muß man sich fragen, ob es nicht unser Interesse ist zu vermeiden, daß Deutschland wie eine wirtschaftliche Einheit behandelt wird, die das Vorspiel zu seiner politischen Einheit sein wird. Wir können keine Gewißheit haben, daß das vereinte Deutschland unter der Kontrolle der Westmächte bleiben wird. In der Tat kann man glauben und muß man in jedem Fall fürchten, daß es sich in der Zukunft letztlich zu Rußland hin orientieren wird. Das ist die größte Gefahr, die uns drohen kann. [...] Während die Sowjets keine andere Möglichkeit haben, als das Durcheinander fortbestehen zu lassen, könnten die USA und England glauben, daß es die bessere Politik ist, die wirtschaftlichen Institutionen ganz Deutschlands wieder in Ordnung zu bringen. Wenn das die Tendenzen der anglo-amerikanischen Politik sind, dann wäre nichts gefährlicher." Sollte es wider Erwarten zu einem Konsens über die Wirtschaftseinheit kommen, so war auf den Forderungen zu beharren, die innerwestlich nicht kompromißfähig waren, sondern teilweise in einer gewissen Nähe zu den sowjetischen Posi-

210 CP, S. 479 ff. (5. 11. 1947). Anfang September 1947 waren im State Department zwölf Studien für die verschiedenen Themenbereiche vorbereitet worden. OMGUS wurde gebeten, seine Vorstellungen in Kommentare zu den Entwürfen des State Department einfließen zu lassen. NA, RG 59, 740.00119 Control(Germany)/9-847.

211 AMAE, Y 201, Bl. 92 ff. (Massigli, 4. 11. 1947), 115 ff. (Saint-Hardouin, 6. 11. 1947). Beide wiesen darauf hin, daß beim OMGUS wie bei den Briten die Auffassung vorherrschend war, in jedem Fall den Kontrollrat in Berlin aufrechtzuerhalten und ihm trotz seiner weitgehenden Funktionslosigkeit prinzipiell „die Zuständigkeit für alle Fragen“ zu belassen, um den offenen Bruch zu vermeiden, aber auch, um über diesen Einzelfragen gemeinsam mit den Sowjets regeln zu können.

212 NA, RG 59, 740.00119 Council/8-847. AMAE, Y 201, Bl. 83 ff. (31. 10. 1947). 
tionen standen: Sicherstellung der Kohlelieferungen, Reparationen (auch aus laufender Produktion), Revision des bizonalen Industrieplans, Sonderrechte in der eigenen Besatzungszone (Besatzungskosten, chemische Produkte), Zentralverwaltungen im französischen (nicht im bizonalen) Sinne, Anerkennung der Oder-Neiße-Grenze und der Abtrennung des Saarlandes, militärische Besetzung des Rheinlands und internationale Kontrolle der Ruhrproduktion im Sinne des Byrnes-Plans sowie Klärung der Verfassungsfragen ${ }^{213}$.

Nach amerikanischen Geheimdienstberichten erwartete auch die Politische Abteilung der SMAD Anfang November 1947 „zu 90\%“ ein Scheitern der Londoner Konferenz und bereitete eine nationale Propagandakampagne vor, die vor allem an „kleinbürgerliche“ Schichten gerichtet war $^{214}$. Die Hoffnung vom August 1947, die Londoner Konferenz könnte doch noch die Einigung beschließen, war ebenso verflogen wie die Bereitschaft, „sich auf keinen Fall vor dieser Konferenz irgendwie fest[zu]legen“215. Molotow ließ gegenüber dem französischen Botschafter Catroux eine Verhärtung der Positionen durchblicken ${ }^{216}$. Nachdem Sokolowski am 21. November im Kontrollrat scharfe Angriffe gegen die Westmächte gerichtet hatte, begann in der ostdeutschen und sowjetischen Presse die erwartete Propagandakampagne, die das Selbstbestimmungsrecht der Deutschen den Spaltungsabsichten der Westmächte gegenüberstellte $^{217}$. Ausdrücklich wurde den USA die Hauptschuld für das Scheitern der Vorkonferenz der Stellvertreter zugeschrieben, die sich in 13 Sitzungen vom 6. bis 22. November nicht auf eine Tagesordnung hatten einigen können. Der MarshallPlan, so kommentierte die Prawda am 26. November Sokolowskis Statement im Kontrollrat, „ist die offene Ablehnung des Geistes und des Buchstabens von Potsdam“. Er mache Deutschland zum militärischen und wirtschaftlichen Aufmarschgebiet gegen die Sowjetunion, indem er nicht nur die Ruhr in den „Westblock“ einbeziehe, sondern zugleich „noch mehr als bisher“ die sowjetischen Ansprüche auf Reparationen aus der laufenden Produktion zunichte mache ${ }^{218}$. Daß die Sowjetunion ihre Taktik in diesen Tagen geändert hatte, läßt sich am deutlichsten daran erkennen, daß Molotow am 17. November über die SMAD eine deutsche Delegation nach London beorderte $^{219}$. Doch infolge ihrer Fehleinschätzung „des Nationalgefühls der deutschen

213 AMAE, Y 201, Bl. 96 ff. (4.11. 1947; Hervorhebung im Original).

214 NA, RG 59, 740.00119 Control(Germany)/11-547.

215 BAP, G-2/1044, Bl. 26 (18. 8. 1947). Vgl. oben S. 447.

216 AMAE, Y 201, Bl. 119 ff. (6. 11. 1947).

217 In einer Vorschau auf die Beratungen der Stellvertreter hatte die Tägliche Rundschau am 5.11. 1947 in einer insgesamt positiven Würdigung der Moskauer Konferenz objektiv über die offenen Probleme, die unterschiedlichen Begründungen und die strukturellen Hemmnisse berichtet. Eine Woche später war der Ton in der Fortsetzung schärfer. Ursache für die ausgebliebene Annäherung der Standpunkte seien die Tendenzen der Anglo-Amerikaner, „einen westdeutschen Staat zu bilden und die Sowjetunion auf diese Weise vor vollendete Tatsachen zu stellen“. Hatten die Westmächte in dem ersten Beitrag die Beschlüsse von Yalta und Potsdam „in Zweifel gezogen“, so standen sie nun „in schärfstem Widerspruch“ zu diesen. Das wurde nicht zuletzt dem Einfluß des „amerikanischen Monopolkapitals“ zugeschrieben, das die Briten aus dem Ruhrgebiet verdrängte und dort das Kommando übernahm. Der dritte Beitrag hob fast ausschließlich auf den inneren Zusammenhang von Friedensvertrag, politischer Organisation und Reparationsfrage ab, die "untrennbar" zusammenhingen. Tägliche Rundschau, 5., 13. und 21.11. 1947 (Zwischen den Konferenzen in Moskau und London, Teile I-III).

218 Tägliche Rundschau, 15.-26. 11. 1947 passim.

219 Bender, Deutschland, S. 107 (nach amerikanischen Geheimdienstberichten). 
Bourgeoisie“220 hatte die Sowjetunion zu viel Zeit verloren, um im Rahmen der eben formulierten Kominform-Strategie rechtzeitig zur Londoner Konferenz die Volkskongreß-Bewegung als zonal übergreifende Massenbewegung zu organisieren.

Angesichts des unnachgiebigen Beharrens auf den jeweiligen Positionen, an dem schon die Stellvertreter gescheitert waren, benötigten die Außenminister in London zwei Sitzungen, um sich über die Tagesordnung zu verständigen. Das bestärkte die westlichen Erwartungen, daß die Konferenz scheitern werde, auch wenn Molotow schließlich einlenkte, nicht ohne ein vorbereitetes Statement mit heftigen Beschuldigungen gegen die Westmächte zu verlesen ${ }^{21}$. Der Sowjetunion war nicht verborgen geblieben, daß es zwischen den Westmächten intensive Vorabstimmungen gegeben hatte. Sie durfte aber ihrerseits durch unbeugsame Intransigenz keinen vorzeitigen Abbruch der Konferenz riskieren. Diese Gefahr drohte, nachdem am 5. Dezember alle Mächte offiziell festgestellt hatten, daß sich ihre Positionen seit der Moskauer Konferenz nicht verändert hatten. Bevin hatte bereits am 28. November mit einem Alleingang gedroht, sollte die Konferenz scheitern. Im Gespräch mit dem gleichgesinnten Marshall am 6. Dezember sah er den Abbruch der Konferenz nur noch als „Frage der Taktik und des Zeitpunkts“ gegenüber der Öffentlichkeit, die er - anders als in Moskau - jetzt für den Bruch bereit glaubte ${ }^{222}$. Für diesen Schritt holte Bevin sich am 10. Dezember bei seinen Kabinettskollegen Rückendeckung; angesichts der Gründung des Kominform, der Verhärtung der sowjetischen Politik in Osteuropa, der Störversuche in Westeuropa seien Fortschritte in der Deutschlandfrage nicht mehr zu erwarten. Um den französischen Befürchtungen vor einer weiteren Zuspitzung der Lage in Europa entgegenzutreten, falls am Ende der Konferenz Drei-Mächte-Verhandlungen über Deutschland aufgenommen wurden, war Bevin bereit, militärische Garantien anzubieten. Er schlug vor, auf der Grundlage des Byrnes-Planes mit Frankreich und den USA entsprechende Verhandlungen aufzunehmen, die sich nicht direkt gegen die Sowjetunion wandten, dieser vielmehr formal die Chance zum Beitritt beließen, aber gleichzeitig die USA in Europa banden ${ }^{223}$. Marshall dachte ähnlich. Er sah die Gefahr, daß er gezwungen sein könnte, sollte er der emotionalen Stimmung in der amerikanischen Öffentlichkeit nachgeben, das dauerhafte Engagement in Europa aufzukündigen. Die Fortsetzung der Besatzung in Deutschland, in Abwandlung des Byrnes-Plans als Drei-Mächte-Pakt zu organisieren, galt ihm als Voraussetzung für eine Gewöhnung der amerikanischen Öffentlichkeit an überseeische Verpflichtungen $^{224}$.

Als am 8. Dezember die drei westlichen Außenminister beratschlagten, mit welcher Taktik sie am wirkungsvollsten und für sie am ungefährlichsten die Konferenz abbrechen könnten, warnte Marshall davor, den Bruch über Verfahrensfragen herbeizuführen; denn darauf schien Molotows Taktik hinauszulaufen. „Wenn ein Scheitern einträte, sollte es wegen substantieller Fragen geschehen, d. h. etwas von wirklicher

220 Tjulpanow, Deutschland, S. 294 ff., Zitat S. 301.

221 FRUS, 1947/II, S. 703-12, 731-34.

222 FRUS, 1947/II, S. 736 f., 748-52. Germany 1947-49, S. 448 f.

223 PRO, PREM 8/512 (C.P.(47)326, 10. 12. 1947). AMAE, Y 201, Bl. 39 f. (Bevin-Chauvel, 20. 10. 1947); Y 297, Bl. 109 f. (Bevin-Bidault, 17. 12. 1947). Dies wurde zum Ausgangspunkt der NATOInitiative Bevins.

224 FRUS, 1947/II, S. 751 f. AMAE, Y 296, Bl. 152 (Murphy, Oktober 1947); Y 201, BI. 41 (Chauvel, 20. 10. 1947), 47 ff. (Direction d'Europe, 24. 10. 1947). 
Bedeutung, und daß zusammen damit der klare Beweis geliefert werde, daß wir unser Bestes getan hätten, mit der Sache voranzukommen." Er schlug daher vor, in der nächsten Sitzung unter dem Vorsitz Bidaults eine Diskussion über die sowjetische Reparationsforderung von $\$ 10 \mathrm{Mrd}$. zu provozieren ${ }^{225}$. Molotow tat den Westmächten den Gefallen, am gleichen 8. Dezember einen Entwurf vorzulegen, der die Errichtung deutscher Zentralverwaltungen unter Aufsicht des Kontrollrats, aber ohne Eingriffsrecht in die Zonen, sowie die Anhebung der Stahlproduktion auf 10-12 Mio. t vorsah. Beide Maßnahmen sollten ebenso wie eine Währungs- und Finanzreform und die Anhebung des Exports ausdrücklich im Hinblick auf die Zahlung von Reparationen erfolgen. Noch einmal forderte die Sowjetunion ihren Anspruch auf \$10 Mrd. ein, die durch Kapitalgüter oder aber durch laufende Lieferungen, durch Auslandsguthaben und "verschiedene Dienstleistungen“ bis 1965 abzuleisten seien. Molotows Initiative beruhte auf einem Vorschlag des II. Parteitags der SED an den Kontrollrat vom 30. September, dem in einem Manifest des Volkskongresses die Selbstverpflichtung der Deutschen hinzugefügt war, sozusagen auf der Grundlage des Selbstbestimmungsrechts freiwillig die Lieferung der Reparationen zu garantieren. „Eine Aufteilung Deutschlands in Staaten oder Zonengebiete würde den Aufbau der deutschen Wirtschaft und die Erfüllung der Reparationsverpflichtungen gefährden." Von einer deutschen Regierung oder gar von einem Friedensvertrag war in diesem Zusammenhang jedoch nicht die Rede, sondern lediglich von der Auflösung der Bizone. Obwohl Molotow argumentierte, das westliche „first-charge-principle“ komme der sowjetischen Forderung nach laufenden Reparationen gleich, hatten die Westmächte eine attraktive Offerte an die Deutschen von seiner Seite nicht zu befürchten ${ }^{226}$.

Das Verhalten Molotows wäre der westlichen Taktik entgegengekommen, wenn der sowjetische Außenminister - der bis dahin auf Zeit gespielt hatte, um die Konstituierung des Volkskongresses am 6./7. Dezember abzuwarten - am gleichen 8. Dezember nicht plötzlich in allen Verfahrensfragen nachgegeben und inhaltliche Diskussionen der westlichen Vorlagen akzeptiert hätte und wenn nicht gleichzeitig die Pläne der Angelsachsen, im Falle des Scheiterns der Konferenz im Westen die Trizone bei Aufrechterhaltung des Kontrollrats anzustreben, durch Enthüllungen in britischen kommunistischen Presseorganen bekannt geworden wären. Plötzlich sahen sich die Westmächte in der Defensive. Marshall dementierte, daß derartige „Entscheidungen“ bereits gefallen seien, obwohl das nur formal, nicht aber de facto zutreffend war. Es zahlte sich aus, daß der vorsichtige Marshall schon vor Konferenzbeginn darauf bestanden hatte, anders als in Moskau während der Konferenz keine separaten Dreiergespräche der Westmächte über konkrete Fragen der Besatzungspolitik zu führen, um der Sowjetunion keinen Anlaß für Propaganda-Angriffe zu bieten; derartige Gespräche oder gar Entscheidungen sollten, zeitlich deutlich getrennt, erst nach Weihnachten stattfinden ${ }^{227}$. Marshall war aber so verunsichert, daß er bereits über eine weitere Außenministerkonferenz in Genf nachdachte ${ }^{228}$. Die sowjetische Propaganda konzentrierte sich nun völlig auf Molotows Bemühungen um die deutsche Einheit und auf die Konstituierung der Volkskongreß-Bewegung: gegen den „vorgefaßten Plan der

225 FRUS, 1947/II, S. 754 f.

226 FRUS, 1947/II, S. $756 \mathrm{ff} ., 790 \mathrm{ff}$.

227 FRUS, 1947/II, S. 698, 723.

228 Deighton, Impossible Peace, S. 217 f. 
Westmächte zur Spaltung Deutschlands“, die von vornherein keinen Erfolg der Konferenz gewollt hätten. Molotows Fazit nach dem Ende der Konferenz mündete dementsprechend in den Aufruf, das deutsche Volk und die Sowjetunion müßten gemeinsam gegen die Spaltung kämpfen ${ }^{229}$.

Angesichts dieser überraschenden Wendung schien der Kontrollrat zu neuer Bedeutung zu gelangen. Diesem wurden Grundsatzbeschlüsse über die Verteilung von Kohle, Stahl und Energie, die Fortführung der Demontagen und die Zuweisung von Rüstungsbetrieben für Reparationslieferungen sowie die Dekartellisierung übermittelt. Entgegen allen Erwartungen drohten nun Einigungen, die einen Bruch nicht länger gerechtfertigt hätten. Marshall sah die Fortsetzung der Debatten in London als gefährlich an; diese „würden nur Molotow endlos Gelegenheit für Propaganda bieten und würden darüber hinaus wahrscheinlich erhebliche Differenzen zwischen der französischen Sicht einerseits und der britischen und amerikanischen andererseits hinsichtlich der politischen Organisation und der Ruhrfrage zutage fördern“. Es sei völlig offenkundig, so das bemerkenswerte Fazit des amerikanischen Außenministers, „daß Molotow nicht nur auf Zeit spielt, sondern konsequent, fast verzweifelt, Einigungen zu erzielen versucht, die für uns in den nächsten vier bis sechs Monaten mehr eine Behinderung als ein wirklicher Beweis für eine Einigung wären." ${ }^{230} \mathrm{Da}$ Molotow jedoch seine Vorschläge mit scharfen Angriffen verknüpfte, bot er den Westmächten den ersehnten Anlaß, die Diskussionen als fruchtlos abzubrechen, wenn er eben das, nach den Attacken der vorangegangenen Tage, nicht als zusätzliche „Klarstellung“ hatte erreichen wollen. Sein Antrag, die Delegation des ostzonalen Volkskongresses unter Führung von Pieck, Grotewohl, Nuschke und Külz anzuhören, diente keinem anderen Zweck, als zu demonstrieren, daß die Westmächte sich festgelegt hatten, ohne den Deutschen die Gelegenheit zur Wahrnehmung ihres Selbstbestimmungsrechts zu geben. Am 13. Dezember entschieden sich die Westmächte, am übernächsten Tag die Konferenz zu beenden. Diese endete mit wechselseitigen Vorwürfen, der Spaltungsabsichten einerseits, der gezielten Verhinderung von positiven Entscheidungen andererseits, ohne daß ein Datum für ein nächstes Treffen festgelegt wurde. Die Entscheidung war gefallen, die Vertagung sine die erreicht ${ }^{231}$.

Angesichts dieses Konferenzverlaufs erwarteten die USA Ende Dezember 1947, daß die Sowjetunion in Deutschland eine Initiative starten werde: entweder durch die konsequente unilaterale Umgestaltung ihrer Zone, für die die Entlassung Kaisers und Lemmers als CDU-Vorsitzende das Signal zu sein schien, oder durch den Versuch, die Westmächte aus Berlin zu verdrängen. Die Sowjetunion schien drei Optionen zu ha-

229 Um ein antifaschistisch-demokratisches Deutschland, S. $501 \mathrm{ff} ., 558 \mathrm{ff}$. Tägliche Rundschau, 3. bis 19. 12. 1947. Nach amerikanischen Umfragen gaben $40 \%$ der Deutschen in ihrer Zone der Sowjetunion die Schuld am Scheitern, 42\% sahen die Schuld auf beide Seiten verteilt, aber mit stärkerer Verantwortung der Sowjetunion. OMGUS war sich insofern der deutschen Reaktion keineswegs sicher, obwohl $80 \%$ der Westdeutschen nicht mehr an die alliierte Kooperationsfähigkeit glaubten, sondern mit großer Mehrheit (70-80\%) die Bildung eines Weststaates befürworteten. Trotz des Festhaltens am Ziel der Einheit $(96 \%)$ war die Bereitschaft, sich dem Aufruf des Volkskongresses anzuschließen, deutlich geringer, wenngleich noch erheblich. Merritt/Merritt, Public Opinion, S. 23 ff., 193 f., 241.

230 FRUS, 1947/II, S. 763-66.

231 NA, RG 59/ASSOA, box 1, folder: Alternative Courses in Berlin (Breakdown of CFM London, 17. 12. 1947, S. 15: „Since then we have concluded that quadripartite military government is impossible, and United States policy has been directed toward the establishment of a separate Western state.“). Krieger, Clay, S. 314 (Byroade an Wedemeyer, 22. 12. 1947). 
ben: 1. zu fordern, der Kontrollrat (und ebenso die Kommandantur) „sollten, wenn nicht aufgelöst werden, so doch ihre Tätigkeit einstellen“; 2 . beide Gremien zu boykottieren, um die Westmächte zum freiwilligen Abzug aus Berlin zu verleiten; 3. „die Kommunikation, den Transport und die Nachschubverbindungen zwischen Berlin und dem Westen [zu] erschweren, um uns herauszudrücken“, während sie weiterhin im Alliierten Kontrollrat mitarbeitete. Die Westmächte waren also nicht unvorbereitet auf die kommende Krise in Berlin, und sie waren entschlossen, sich nicht vertreiben zu lassen ${ }^{232}$. So wie die Anglo-Amerikaner eine Einigung nur noch zu den eigenen Bedingungen akzeptieren würden ${ }^{233}$, erwarteten sie Gleiches von seiten der Sowjets.

Die Erwartung einer sowjetischen Initiative in Deutschland war ein Grund, nach dem Bruch in London nicht sofort die offene Konfrontation zu riskieren. Es galt vielmehr, als Antwort auf die sowjetische Propaganda, zunächst einen letzten Versuch zu starten, um im Kontrollrat ein praktikables Arrangement herbeizuführen, zumindest aber für eine eindeutige Schuldzuweisung zu sorgen. Auf einer Besprechung in London zwischen Marshall, Bevin, Clay und Robertson am 18. Dezember wurde ein letzter Vorstoß in der Währungsreformfrage beschlossen, der mit Marshalls Einverständnis ausdrücklich mehr als eine bloße Geste sein sollte. Beiden Militärgouverneuren wurde erlaubt, das Reparationsprogramm auf der Grundlage des bizonalen Industrieplans fortzuführen, wobei offenblieb, ob die Lieferungen auch an die Sowjetunion wieder aufgenommen, wie es die Briten wünschten, oder nur „zur Aufbewahrung für [spätere] Lieferung“ deklariert würden, wie Clay seit dem Sommer angeregt hatte. Trotz dieser vorsichtigen Zurückhaltung war man sich bewußt, daß aufgrund der in den Westzonen geschaffenen Fakten der Trend zur Teilung unaufhaltsam war, „langsam, aber sicher“, mit oder ohne Kontrollrat: „Es wird sich allmählich eine westdeutsche Regierung herausbilden, ohne dramatische Deklarationen oder Handlungen, außer wenn drastische sowjetische Maßnahmen eine beschleunigte Einrichtung einer westdeutschen Regierung erforderlich machen“; dahinter stand die Hoffnung bzw. Gewißheit, daß Frankreich sich der bizonalen Entwicklung bis Mitte 1948 anschließen werde, durch die „leise“ Übernahme der für sie ad hoc akzeptablen Bizonenregelungen „auf evolutionärem Wege“234.

Aus ähnlichen taktischen und pragmatischen Gründen waren die Briten weiterhin daran interessiert, die „Fassade“ des Kontrollrats aufrechtzuerhalten und entsprechend vorsichtig zu verfahren. Das Interesse der Sowjetunion am Fortbestehen des Kontrollrats sei am ehesten gewährleistet, wenn die Reparationen über diesen abgewickelt würden ${ }^{235}$. Zwar seien die „Nachteile“ der mangelnden Einigungsfähigkeit im Kontrollrat für die Rekonstruktionsbemühungen des Westens erheblich; „auf der anderen Seite wollen wir sicherlich nicht die Abschaffung des Kontrollrats oder das Ende der Vier-Mächte-Verwaltung Berlins“. Die Existenz des Kontrollrats schien, so die Über-

${ }^{232}$ FRUS, 1947/II, S. 905 ff.

${ }^{233}$ NA, RG 59/ASSOA, box 1, folder: Alternative Courses in Berlin (Breakdown of CFM London, 15. 12. 1947, S. 17). PRO, FO 800/466/Ger/47/52 (Marshall-Bevin, 17./18. 12. 1947).

${ }^{234}$ CP, S. 501 f. (fälschlich auf November datiert). NA, RG 59, 740.00119 Control (Germany)/1-748. AMAE, Y 297, Bl. 165 ff. (Bevin-Marshall, 17./18. 12. 1947).

${ }^{235} \mathrm{PRO}, \mathrm{FO} 1046 / 102$ (FO, 18. 1. 1948). In dem Sinn votierte auch Clay, zumal seine Zone kaum berührt war, während Marshall unter dem Druck des Kongresses für ein radikales Ende eintrat. $\mathrm{CP}$, S. $527 \mathrm{f}$., $532 \mathrm{f}$., $541 \mathrm{f}$. „CLAY est décidé à continuer à jouer le jeu quadripartite quoique pensant qu'une rupture aurait beaucoup simplifié les choses." AMAE, Y 297, Bl. 148 ff. (Koenig/Charmasse, 24. 12. 1947). 
legungen über dessen „zukünftige Rolle“, durchaus vorteilhaft: für die gemeinsame Verwaltung Berlins, für Transport, Kommunikation und den „Transfer“ von Kriegsgefangenen und Flüchtlingen. Den Sowjets unterstellten die Briten das Interesse, mit Hilfe des Kontrollrats die Überwachung von Entwaffnung, industrieller Abrüstung und Entnazifizierung aufrechtzuerhalten. Selbst beim Scheitern einer gemeinsamen Währungsreform könnte die „zeitweilige Teilung Deutschlands“ trotz der „vollständigen Trennung der Finanzsysteme“ vermieden oder gemildert werden, falls der Kontrollrat in „konsultativer Eigenschaft“ durch den Austausch von Waren und Ideen zwischen Ost und West „das letzte Loch“ im Eisernen Vorhang blieb ${ }^{236}$.

Auf französischer Seite war es weiterhin Bidault, der den offenen Bruch hinauszuzögern und eine definitive Entscheidung in der Deutschlandfrage zu vermeiden hoffte, jedenfalls solange die französischen Grundforderungen nicht abgesichert waren: „Es handelt sich in gewissem Maße darum zu versuchen, auf einer Drei-MächteEbene das zu verwirklichen, was wir in drei Jahren auf einer Vier-Mächte-Ebene nicht machen konnten." Seine primäre Option blieb die Verbindung von alliierter Einheit in Deutschland und zonaler Zergliederung Deutschlands, also der Kontrollrat. Wenn dieser zerbrach und die Spaltung Deutschlands zur Gründung von Teilstaaten führte, dann mußte Frankreich zuvor der Bizone beitreten, denn nur dieser Beitritt garantierte Einfluß auf die Gründungs- und Entwicklungsbedingungen eines Weststaates. Zugleich zeichnete sich die „Integration Deutschlands in Europa“ immer stärker als alternative Kontrollvariante $\mathrm{ab}^{237}$. Bidaults Deutschlandpolitik in diesen Monaten blieb doppeldeutig: Zwar akzeptierte er nach dem Scheitern der Londoner Konferenz notgedrungen den Vorstoß Marshalls, im Kontrollrat die Sowjets in der Währungsreformfrage zum Offenbarungseid zu zwingen; doch während er grünes Licht für Expertengespräche zur Bildung einer Trizone gab, wurde Koenig angewiesen, darauf hinzuwirken, „soweit wie möglich das Vier-Mächte-Statut zu erhalten“, wofür die Beratungen über die Währungsreform eine „günstige Möglichkeit“ böten ${ }^{238}$. Trotz sich allmählich verändernder Optionen behielt für Bidault und seine Parteigänger der Kontrollrat den Vorrang. Frankreich protestierte daher entsetzt gegen den Beschluß Clays und Robertsons vom 8. Januar 1948 zur „politischen“ Ausgestaltung der Bizone, während parallel die Verhandlungen über den französischen Beitritt zur Bizone in Berlin stattfanden, die dadurch präjudiziert wurden ${ }^{239}$. Vor allem drohte Paris zwischen alle Stühle zu geraten, wenn die Angelsachsen auf der Grundlage eines Bizonenstaates den Bruch im Kontrollrat provozierten. Denn die Einsetzung einer „deutschen De-facto-Regierung“ gebe der Sowjetunion - das gestanden sich intern auch die USA ein - den willkommenen Anlaß, ihrerseits eine Regierung in Berlin einzusetzen und den Kontrollrat zu sprengen ${ }^{240}$. Saint-Hardouin empfahl seiner Regierung eine publizistische Offensive in Deutschland, um aus dieser Zwangslage in eine Vermittler-

236 PRO, FO 1046/102 (Draft, Appendix ,B', ca. Dezember 1947).

${ }^{237}$ AMAE, Y 298, Bl. 5 ff. (Entwurf, 2. 1. 1948), 33 ff. (Bidault an Koenig, 4. 1. 1948).

238 AN, 457 (Bidault) AP 15/Après CMAE London (Bidault-Bevin, 17. 12. 1947); AP 15/Allemagne (Bidault an Koenig, 4. 1. 1948; MAE an London und Washington, 9. 1. 1948). AMAE, Y 297, Bl. 92 ff. (Bidault-Marshall, 17. 12. 1947), 138 ff. (22. 12. 1947). AO, Berlin/3276/5/2019D.

239 AMAE, Y 297, Bl. 187 f. (Saint-Hardouin, 13. 12. 1947). AO, Berlin/3276/5/2019D (Leroy-Beaulieu, 5. 3. 1948).

240 NA, RG 59, 740.00119 Control(Germany)/1-1348. AMAE, Y 298, Bl. 79 ff., 97 ff. CP, S. 534 ff. 
position zurückkehren zu können: durch einen direkten Appell an die Deutschen ${ }^{241}$ ! Koenig erklärte Clay unter vier Augen freimütig, „daß die Franzosen jetzt keine trizonalen Arrangements diskutieren, sondern freie Hand behalten wollten. Er sagte, er glaube, daß dies die Sowjetunion von offenen Aktionen abhalten werde.“" ${ }^{42}$

Obwohl Frankreich sich zwischen beiden Seiten eingeklemmt sah, vermochte es noch einmal von der unsicheren Konstellation in Berlin zu profitieren. Die britische wie die amerikanische Regierung wollten vor der Londoner Sechs-Mächte-Konferenz und vor den entscheidenden Verhandlungen im Kontrollrat über die Währungsreform Frankreich nicht verprellen und bremsten daher ihre Militärgouverneure, die ihren französischen Kollegen rücksichtslos unter Druck zu setzen versuchten. Robertson wurde angewiesen, die letzte Entscheidung über die Vereinbarung liege in London. Daraufhin machte Washington einen gleichartigen Rückzieher ${ }^{243}$. Vergeblich blieben die Proteste Clays, der - in seiner Eitelkeit gekränkt - auf die besatzungspraktische Seite stärker Rücksicht nehmen wollte. „Mein Hauptargument für Eile in der Bizonen-Planung ist, daß die eindeutige Möglichkeit besteht, daß die Sowjetische Militäradministration sofort nach dem für den 10. April erwarteten Vier-Mächte-Bruch eine neue Währung ausgeben könnte." Während die Franzosen sich auf diplomatischem Wege einen Aufschub verschafften, gelang den Sowjets Gleiches, indem sie in der Währungsreformfrage neue Zugeständnisse machten. "Wir mußten diesen Vorschlag annehmen oder wären sonst vor der deutschen Bevölkerung in die Lage gedrängt worden, ohne besonderen Grund den nächsten Schritt zur Teilung zu tun.“ Clay geriet unter Druck, da er ,im Einklang mit der Politik meiner Regierung [...] die Vier-Mächte-Verhandlungen über die Währungsreform bis zum Punkt des offenen Bruchs im Kontrollrat geführt hatte“244.

Auch die Sowjetunion mußte sich nun entscheiden. Nach Molotows Bericht an Stalin über die Londoner Konferenz waren Sokolowski und führende Repräsentanten der SMAD zu Beratungen nach Moskau beordert worden ${ }^{245}$. Nach deren Rückkehr am 10. Januar 1948 verstärkte sich das propagandistische Trommelfeuer, da Stalin inzwischen davon ausging: „Der Westen wird sich Westdeutschland zu eigen machen, und wir werden aus Ostdeutschland unseren eigenen Staat machen." ${ }^{246}$ Jetzt wurden sogar die bislang verschonten Franzosen angegriffen, indem Koenig als „klägliche Marionette" der Angelsachsen in eine Reihe mit diesen gestellt wurde. Hinzu trat der organisierte Druck „von unten“ durch die Deutschen. Der Volkskongreß protestierte gegen seine Nichtzulassung in den Westzonen bei den Zonenkommandeuren und beim Kontrollrat $^{247}$. Am 11. Februar 1948 trug Sokolowski diesen Protest vor den Kon-

241 AMAE, Eu(1944-60)Allemagne/82, Bl. 212 ff. (20. 1. 1948).

${ }^{242}$ CP, S. 537 (12.1. 1948). Krieger, Clay, 314 f. Verärgert registrierte man in Washington, daß die Franzosen wieder einen Rückzieher gemacht hatten, scheinbar „under the influence of de Gaulle's drastic ideas regarding Germany", auch wenn es Hoffnungen gab, daß de Gaulle Bidault keine Schwierigkeiten im Falle einer Einigung bereiten werde. NA, RG 59, 740.00119 Control(Germany)/ $1-1348$.

${ }^{243}$ CP, S. 543 ff. (13. 1. 1948). Vgl. oben S. 302 ff.

${ }^{244}$ CP, S. 561, 578, 589. Die sowjetischen Zugeständnisse kamen so unerwartet (und ungelegen), daß Clay über Draper in Washington durch diskrete Information führender Mitglieder des Kongresses um Verständnis für die Verzögerung der (bi- bzw. trizonalen) Währungsreform werben mußte, um zusätzlichen Druck zu vermeiden.

${ }^{245}$ NA, RG 59, 740.00119 Control(Germany)/1-648.

${ }^{246}$ Diese Einschätzung war für Djilas (Gespräche, S. 195) „neu“.

${ }^{247}$ Die Briten hatten in ihrer Zone sofort ein Verbot ausgesprochen, während die USA am 17./18. 1. 
trollrat und verlangte, erwartungsgemäß vergeblich, die Genehmigung einer „ungehinderten Tätigkeit“ für diesen; Kulturbund, FDJ, SED und KPD appellierten öffentlich an den Kontrollrat und beantragten ebenfalls ihre gesamtdeutsche Zulassung ${ }^{248}$. Wie sehr die Sowjetunion ihre Hoffnungen auf dieses letzte Mittel setzte, wurde aus einer Äußerung Sokolowskis nach der Kontrollratssitzung vom 10. März 1948 erkennbar. Zunächst beklagte er gegenüber Clay und Murphy Umgangsstil und Handlungsunfähigkeit des Kontrollrats und fragte resignierend: „Wie lange kann das weitergehen?" Dann ließ er seiner Verbitterung über die Entwicklung in den Westzonen und den sich in London bzw. Brüssel formierenden „Westblock“ freien Lauf. Bitter fügte er hinzu, „wenn es einen neuen Krieg gibt, werden die arbeitenden Massen dieses Mal die nicht entkommen lassen, die dafür verantwortlich seien. Er deutete zugleich an, daß, soweit er wüßte, keine Initiative für einen Krieg von seiten der Sowjetunion kommen würde, damit andeutend“ - das mochte auf die Blockade vorausdeuten -, „daß wir von der sowjetischen Militärorganisation in Ostdeutschland nichts zu befürchten hätten. “249 In der Berliner Kommandantur häuften sich auch aus nichtigem Anlaß die heftigen, immer persönlicher werdenden Angriffe, so daß sich die Erwartung der Westmächte zu bestätigen schien, daß die Sowjets Berlin zum Hauptschauplatz machen würden ${ }^{250}$ : als Revanche für die endgültige Ausschaltung aus der Ruhr-Kontrolle $^{251}$ und als Hebel im Kampf um Deutschland. Erste Nadelstiche im Berlin-Verkehr hatten bereits Mitte März, also noch vor dem Auszug aus dem Kontrollrat eingesetzt. Demonstrativ verweigerte am 18. März der sowjetische Vertreter im Arbeitsdirektorat den üblichen Dank an den scheidenden französischen Vorsitzenden und die Teilnahme am anschließenden Büffet ${ }^{252}$. In der Sitzung der Kommandantur vom 19. März wurde der Bruch der Vier-Mächte-Verwaltung kaum verhüllt angedroht $^{253}$. Die Erwartung des „show-down“, die Resignation selbst der unmittelbar Betroffenen, die sich bislang gegen das Scheitern gewehrt hatten, entwerteten letzte Kompromißversuche bereits im Ansatz.

Vieles spricht dafür, daß die Sowjetunion selbst nicht wußte, wie es im Kontrollrat weitergehen sollte, ob es überhaupt noch weitergehen konnte ${ }^{254}$. Da die Sechs-

1948 den Volkskongreß für Niedersachsen in ihrer Enklave Bremen zuließen. Danach untersagten auch sie in ihrer Zone weitere Regionalkongresse.

${ }^{248} \mathrm{Um}$ ein antifaschistisch-demokratisches Deutschland, S. 584, 612 f. Der 2. Volkskongreß, der ein Volksbegehren für einen Volksentscheid über die Einheit Deutschlands beschloß, war für den 18. 3 . 1948 terminiert, den Jubiläumstag der Revolution von 1848, zwei Tage vor dem Auszug Sokolowskis aus dem Kontrollrat. Badstübner, Friedenssicherung, S. $315 \mathrm{f}$.

249 NA, RG 59, 740.00119 Control(Germany)/3-1148. Ähnliche Signale gab Molotow dem amerikanischen Botschafter in Moskau, Smith. Demnach erstrebte die Sowjetunion nicht mehr als eine defensive Konsolidierung ihres Machtbereichs in Osteuropa. FRUS, 1948/IV, S. $845 \mathrm{ff}$.

250 Entsprechende Ankündigungen in der Berliner Zeitung in: NA, RG 59, 740.00119 Control(Germany)/1-748. FRUS, 1948/II, S. 885 f. Die SMAD leugnete, "that these press reports reflected Soviet official views". NA, RG 59/Executive Secretariat (Acheson), box 17 (Background material for Secretary's press conference, 23.3. 1948).

251 NA, RG 59/ASSOA, box 1, folder: Alternative Courses in Berlin.

252 AO, Berlin/3276/4/2018 (15.3. 1948). NA, RG 59, 740.00119 Control(Germany)/3-2048. AMAE, Y 333, Bl. 132; Y 457 (No. 2559, 18. 3. 1948).

253 Tägliche Rundschau, 20.3. 1948.

${ }^{254}$ Eine wohl auf die Jahreswende 1947/48 zu datierende Aufzeichnung Piecks mag auf eine frühe Entscheidung zum Bruch hindeuten: „Ob Alliierte weg - ,Tägliche Rundschau - wenn Kontrollrat erhalten, so für Einheit eintreten. Wenn West-Staat, so Funktion Kontrollrat aufhören. Verbot Kongreßsbewegung, weil gegen Einheit.“ SAPMO, ZPA, NI 36/739, Bl. 15 (maschrftl.), 49R (handschrftl.). 
Mächte-Konferenz in London nur das eine Ziel hatte, einen westdeutschen Staat zu gründen, wäre der Kontrollrat funktionslos geworden. Die Londoner Beschlüsse stellten insofern einen „Verstoß gegen die Rechte des Kontrollrats und des Außenministerrats" dar ${ }^{255}$. Offenbar sah man in Moskau keine Chance mehr, die eigenen deutschlandpolitischen Vorstellungen durch Verhandlungen mit den Westmächten zu realisieren. Der Auszug aus dem Kontrollrat war ein hilfloser Versuch, die Westmächte zum Bruch zu veranlassen oder durch eine dramatische Geste zur Kooperation zu zwingen. Es mußte, darin unterschied sich die sowjetische Politik kaum von der westlichen, eine Entscheidung herbeigeführt werden. Da die Westmächte vermeintlich „Angst vor der Einheitsidee Deutschlands“ hatten, blieb als letzter Ausweg der schon seit dem Herbst 1947 vorbereitete Appell an die Deutschen. Mit der Aufwertung des Kontrollrats in der Täglichen Rundschau seit Anfang 1948 wollte die Sowjetunion diesen als Garanten der deutschen Einheit anbieten - stets in der Illusion, die Deutschen würden ihn nicht als Herrschaftsinstrument der Alliierten, sondern als alliierte Klammer des Reiches betrachten, nicht als Einfallstor sowjetischer Machtpolitik, sondern als Sicherung gegen westliche Ausbeutung und Kriegstreiberei.

Nachdem die Tägliche Rundschau am 20. März die Sitzung des Koordinationskomitees vom Vortage in dem Satz zusammengefaßt hatte, „Amerikaner und Engländer machen Viermächteverwaltung zunichte“, war Sokolowskis Schritt kaum spontan ${ }^{256}$, sondern konsequent. Fraglich bleibt, ob die Zugeständnisse in der Währungsreformfrage, die die Sowjetunion nun im Kontrollrat unterbreitete und die vor wenigen Monaten noch den Durchbruch hätten herbeiführen können, mehr waren als ein Versuch, die Verantwortung für den Bruch den Westmächten zuzuschieben, oder ob sie Fanal für die Deutschen zum „nationalen“ Widerstand gegen die Spaltungsabsichten des Westens sein sollten. Daß Sokolowski am 20. März den Kontrollrat sprengte, war ein schwerer taktischer Fehler. Es wäre ein leichtes gewesen, Clay am 10. April diesen Schritt zu überlassen, nachdem dieser sich durch sein Ultimatum in der Währungsreformfrage selbst festgelegt hatte. Und die Sowjets wußten das. Ihre Deutschlandpolitik der nächsten Wochen, Monate und Jahre war ein einziger Versuch, diesen Fehler nachträglich zu korrigieren.

255 Tägliche Rundschau, 10.-12. 3. 1948.

256 Koenig hielt es für erwähnenswert, daß Sokolowski als Vorsitzender das übliche Büffet habe vorbereiten lassen, an dem sich die Kontrollrats-Mitglieder nach dem Ende der Sitzungen zu treffen pflegten. AMAE, Y 301, Bl. $182 \mathrm{ff}$. 